\title{
SAND2000-2097J
}

\section{Strength of Butt and Sharp-Cornered Joints}

E. David Reedy, Jr.

Sandia National Laboratories, Albuquerque, NM

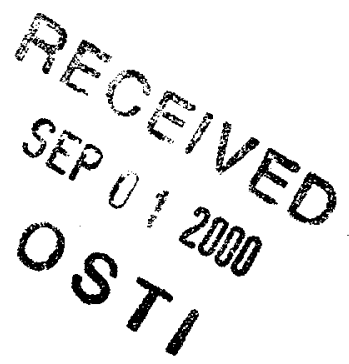

STRENGTH OF BUTT AND SHARP-CORNERED JOINTS ..................................... 1

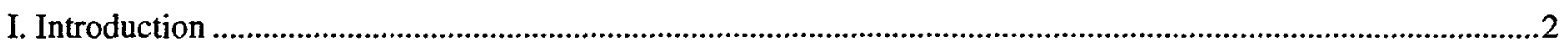

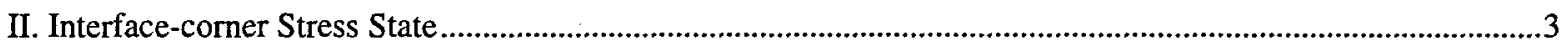

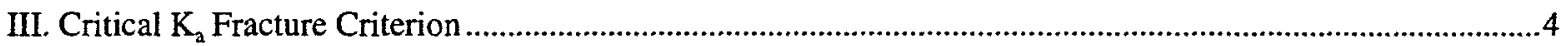

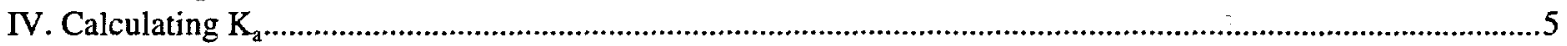

A. Matching Numeric Solution with Asymptotic Form............................................................................

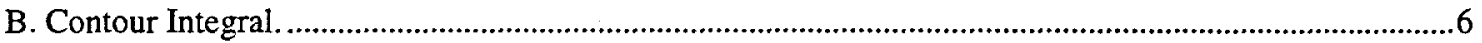

C. Numeric Solutions for Complicated Configurations..................................................................................

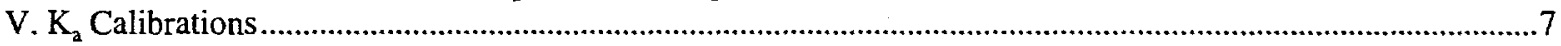

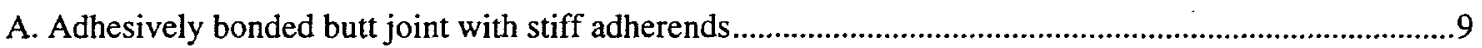

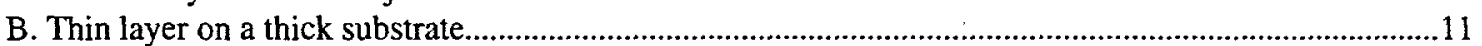

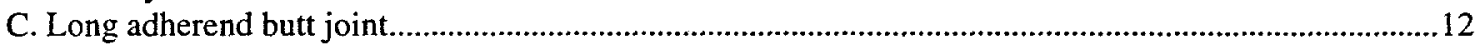

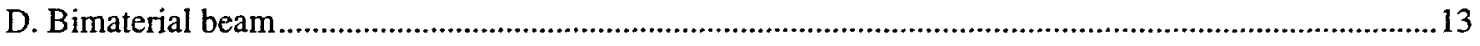

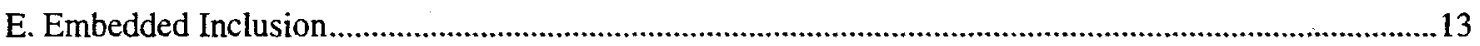

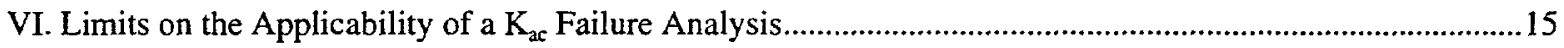

A. Crack Initiation Away From the Interface Corner. ......................................................................15

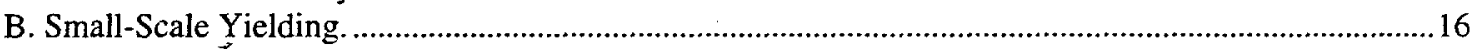

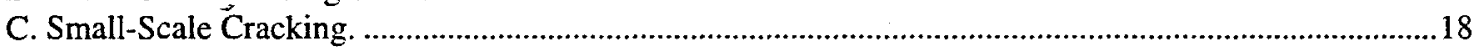

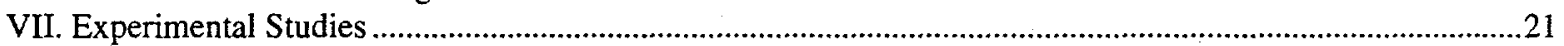

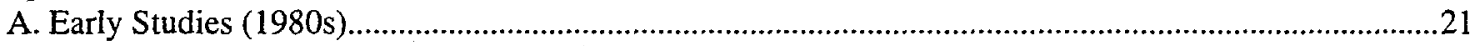

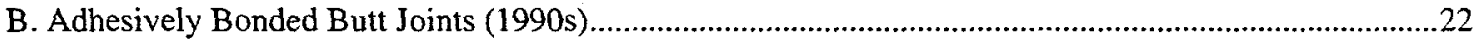

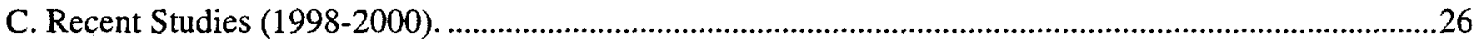

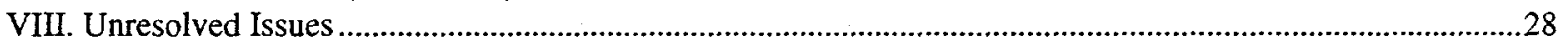

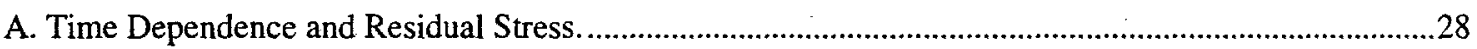

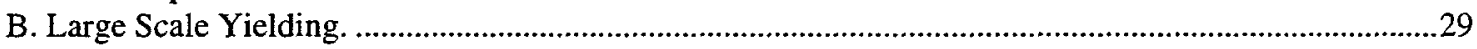

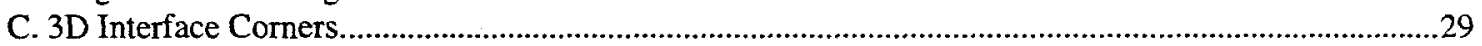

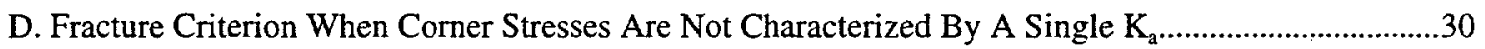

E. Connection between $\mathrm{K}_{\mathrm{ac}}$ and more fundamental properties. ................................................................

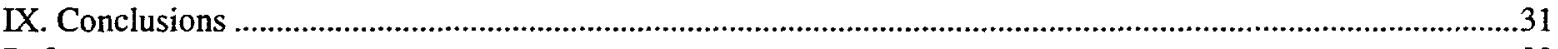

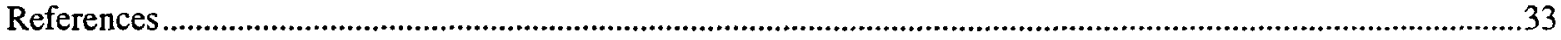

Acknowledgment: This work was performed at Sandia National Laboratories. Sandia is a multiprogram laboratory operated by Sandia Corporation, a Lockheed Martin Company, for the United States Department of Energy under Contract DE-AC04-94AL85000. 


\section{Introduction}

There are three widely accepted methods for predicting the strength of bonded joints. One approach uses shear-lag-based, elastic-plastic stress analyses for bond stress and strain. Joint failure is predicted to occur at a critical adhesive shear strain ${ }^{1}$. In another approach, a detailed finite element analysis of the joint is carried out using an elastic-plastic adhesive material model. Often geometric particulars like spew filets are included, but the joint is considered flaw free (uncracked). It has been suggested that a maximum principal strẻss criterion works best for brittle adhesives, while a maximum principal strain condition should be used for toughened adhesives ${ }^{2}$. The third approach applies linear elastic fracture mechanics concepts to bonded joints. A variety of adhesively bonded fracture specimens has been developed to measure the Mode I, Mode II, and mixed Mode I and II fracture toughness when the crack is within the adhesive layer ${ }^{3}$. Fracture mechanics techniques have also been developed to measure interfacial toughness ${ }^{4}$. One fracture mechanics-based approach uses a critical energy release rate in conjunction with an inherent flaw size to predict joint strength ${ }^{5}$.

In recent years a fourth approach for predicting the strength of bonded joints has shown promise when joints contain sharp corners. For example, a butt joint with sharp-cornered adherends can be thought of as two, edge-bonded, equal-width rectangles (Figure1). Failure in such joints often initiates at the interface corner- the point where the interface intersects the stress-free edge. Asymptotically, the interface-corner region looks like two edge-bonded $90^{\circ}$ wedges (i.e., quarter-planes). It is well known that, within the context of linear elasticity theory, a power law singularity with a real exponent exists at the apex of bonded $90^{\circ}$ wedges for certain material combinations ${ }^{6-8}$. That is,

$$
\sigma \sim K_{a} r^{\lambda-1} \quad(-0.41<\lambda-1<0) \quad \text { Eq. } 1
$$

where the subscript $a$ on $\mathrm{K}$ denotes that this stress intensity factor is associated with the apex of a wedge. The strongest singularity occurs in plane strain when one material is rigid and the other is incompressible. The value of the stress intensity factor $\mathrm{K}_{\mathrm{a}}$ characterizes the magnitude of the stress state in the region of the interface corner. The calibration relation defining $\mathrm{K}_{\mathrm{a}}$ is determined by the full solution and depends on loading, geometry, and elastic properties. It appears reasonable to hypothesize that failure occurs at a critical $\mathrm{K}_{\mathrm{a}}$ value. Such an approach is 


\section{DISCLAIMER}

This report was prepared as an account of work sponsored by an agency of the United States Government. Neither the United States Government nor any agency thereof, nor any of their employees, make any warranty, express or implied, or assumes any legal liability or responsibility for the accuracy, completeness, or usefulness of any information, apparatus, product, or process disciosed, or represents that its use would not infringe privately owned rights. Reference herein to any specific commercial product, process, or service by trade name, trademark, manufacturer, or otherwise does not necessarily constitute or imply its endorsement, recommendation, or favoring by the United States Government or any agency thereof. The views and opinions of authors expressed herein do not necessarily state or reflect those of the United States Government or any agency thereof. 


\section{DISCLAIMER}

Portions of this document may be illegible in electronic image products. Images are produced from the best available original document. 
analogous to linear elastic fracture mechanics except, here the critical $\mathrm{K}_{\mathrm{a}}$ value is associated with a discontinuity other than a crack.

This chapter will focus on methods for performing an interface-corner failure analysis, the limitations to such an approach, supporting experimental studies, and a discussion of unresolved issues in the application of this approach.

\section{Interface-corner Stress State}

The asymptotic stress state near the apex of dissimilar bonded wedges (i.e. interface corner) for plane stress or strain, when the wedge materials are isotropic and linear elastic, has the form

$$
\sigma_{i j}=\sum_{n=1}^{N} K_{a n} r^{\lambda_{n}-1} \bar{\sigma}_{i j n}(\theta)+K_{a 0} \bar{\sigma}_{i j 0}(\theta)+\text { higher order terms } \quad(i, j=r, \theta) \quad \text { Eq. } 2
$$

where $\mathrm{r}, \theta$ refer to a polar coordinate system defined at the interface corner. One or more powerlaw singularities of differing strength can exist, and the exponents can be real or complex ${ }^{6-10}$. The number of stress singularities $N$, the strength of these singularities $\lambda_{n}-1$, and their angular variation $\bar{\sigma}_{i j n}(\theta)$ is determined by the asymptotic analysis and depends on nondimensional elastic properties (e.g., Dundurs' parameters), the local interface-corner geometry (i.e., wedge angle) and edge boundary conditions (stress free, fixed, etc.). The stress intensity factors $\mathrm{K}_{\mathrm{an}}$ determine the contribution of each singular term to the stress state in the region of the interface corner ${ }^{11-16} . \mathrm{K}_{\text {an }}$ depends on global geometry, applied loads and elastic properties. Although not explicitly shown in Eq. 2, there are certain special combinations of elastic properties, wedge angles, and edge loads that can also generate logarithmic singularities $9,17,18$.

In some instances an asymptotic description that includes only the singular terms fails to accurately describe the stress state over a physically significant region about the interface corner. For example, when the r-independent regular term $K_{a 0} \bar{\sigma}_{i j 0}(\theta)$ in Eq. 2 exists, it must often be included in the asymptotic formula ${ }^{19,20}$. For bonded wedges an r-independent regular term always exists for thermally induced strains and locally applied edge tractions but, except for

certain special combinations of elastic properties and wedge angles ${ }^{21}$ usually vanishes for remote applied loads.

The origin of the r-independent asymptotic term can be understood for the simple case of bonded rigid and elastic quarter planes subjected to a uniform temperature change (Figure 2; the 
elastic quarter plane has Young's modulus. E, Poisson's ratio v, and coefficient of thermal expansion $\alpha$ ). If unbonded, a temperature change of $\Delta \mathrm{T}$ would induce expansion relative to the rigid substrate. If plane stress is assumed, a uniaxial stress parallel to the stress-free edge (i.e., normal to the interface) of magnitude

$$
\sigma_{\theta \theta}(0)=\frac{E \Delta \alpha \Delta T}{v}
$$

negates the thermally induced strain that is parallel to the interface and makes the elastic quarter plane compatible with the rigid substrate. This stress is also eonsistent with the stress-free boundary condition. Consequently, $K_{a 0} \bar{\sigma}_{i j 0}(\theta)$ is equal to the uniform stress state defined by Eq. 3 , since this stress state is the solution of the asymptotic problem ${ }^{20}$. Furthermore, it can be shown that Eq. 3 also holds for plane strain. Analyses have been done to determine an explicit form for the r-independent asymptotic term for the general case of two dissimilar bonded wedges subjected to either a uniform temperature change, local edge tractions, or remote tractions ${ }^{21-23}$.

\section{Critical $\mathrm{K}_{\mathrm{a}}$ Fracture Criterion}

The choice of a failure criterion is obvious when interface-corner stresses are described by one real-valued, power-law singularity. In this case, a single interface-corner stress intensity factor $\mathrm{K}_{\mathrm{a}}$ characterizes the magnitude of the stress state in the region of the interface corner.

$$
\sigma_{i j}=K_{a} r^{\lambda-1} \bar{\sigma}_{i j}(\theta) \quad(i, j=r, \theta) \quad \text { Eq. } 4
$$

where $\mathrm{K}_{\alpha}$ is defined so that the stress component normal to the interface $\sigma_{\theta \theta}(\mathrm{r}, 0)=\mathrm{K}_{\mathrm{a}} \mathrm{r}^{\lambda-1}$ (coordinate system defined in Figure 2). Failure is assumed to occur at a critical value of $K_{a}$, referred to as the interface-corner toughness, $\mathrm{K}_{\mathrm{ac}}$. This approach is completely analogous to linear elastic fracture mechanics (LEFM), except here the critical value of the stress intensity factor is associated with a discontinuity other than a crack. It is less apparent how to perform a failure analysis when the asymptotic stress state is described by multiple power-law singular terms (real or complex) or includes a significant $\mathrm{r}$-independent term. When multiple singular terms exist, one cannot simply assume that the highest order singularity dominates. Typically all singular terms must be included to get an accurate representation of the stress state over a reasonably large region ${ }^{11,19,24}$. Approaches for treating multiple singularities have yet to be developed. For this reason, the results presented in this chapter will focus almost exclusively on joints where the asymptotic interface-corner stress state is fully characterized by a single $K_{a}$. 
Fortunately, there are many joints of this type including butt joints, adhesively bonded butt joints, epoxy wedges on a stiff substrate, and encapsulated inclusions subjected to uniform cooling.

One notable feature of the interface-corner failure analysis is that it requires no detailed information about the failure process itself. Failure may be caused by a preexisting interfacial flaw or perhaps by a cavitation instability induced by the high levels of hydrostatic tension found at the interface. If a small interfacial crack is present, it could be sharp, bridged, or have a yield zone comparable to its length. To be applicable, it is only necessary that the failure process zone is deeply embedded within the region dominated by the interface-corner singularity at failure.

\section{Calculating $K_{a}$}

Several approaches have been developed for determining $\mathrm{K}_{\mathrm{a}}$ for a specified joint geometry, material combination, and applied loading. Two commonly applied approaches post process finite element results for the joint of interest. In addition, broadly applicable numeric methods are being developed to solve complicated joint geometries that involve, for instance, multiple anisotropic materials.

\section{A. Matching Numeric Solution with Asymptotic Form.}

One commonly used approach for determining $\mathrm{K}_{\mathrm{a}}$ is to match detailed finite element results with the known form of the asymptotic solution ${ }^{12,15,16}$. For example, displacements normal to the stress-free edge, in the region dominated by the stress singularity, were used to determine $\mathrm{K}_{\mathrm{a}}$ values for an adhesively bonded butt joint with rigid adherends ${ }^{16}$. The asymptotic problem for this idealized joint is simply bonded rigid and elastic quarter planes, and the asymptotic solution is described by one real-valued, power-law singularity. The asymptotic solution for $\mathrm{U}_{\theta}(-\pi / 2)$, the normal displacement along the stress-free edge, requires that

$$
U_{\theta}(-\pi / 2)=\frac{K_{a} r^{\lambda} g_{\theta}(-\pi / 2)}{E} \quad \text { Eq. } 5
$$

in the region dominated by the stress singularity. Note that the function $\mathrm{g}_{\theta}(\theta)$ and the parameter $\lambda$ $(\lambda-1$ is the strength of the stress singularity) are fully determined by the asymptotic analysis. The value of $\mathrm{K}_{\mathrm{a}}$ can be determined from the computed free-edge displacements by a linear leastsquares fit 


$$
\frac{U_{\theta}(-\pi / 2)}{r^{2} g_{\theta}(-\pi / 2) / E}=C_{1}+C_{2} r \text { where } C_{1}=K_{a} \quad \text { Eq. } 6
$$

The finite element mesh used when determining $K_{a}$ must be sufficiently refined in the region dominated by interface-comer singularity to accurately calculate the $U_{\theta}(-\pi / 2)$ values used in the Eq. 6 . The adequacy of the mesh can be assessed by plotting $\log \mathrm{U}_{\theta}(-\pi / 2)$ vs. $\log (\mathrm{r})$. In the region dominated by the stress singularity, the log of the calculated edge displacement should vary linearly with the log of distance from the interface corner over a distance of several decades, and the line should have a slope $\lambda$ that agrees with the asymptotic solution. Note that this approach is not limited to matching edge displacements; others often match interfacial stresses instead.

The main advantage of using the matching approach to determine $\mathrm{K}_{\mathrm{a}}$ values is that it can be easily applied. All that is needed to post process the linear-elastic, finite element results is a plotting program with a least-squares fit capability. The main disadvantage of matching approach is the need to construct a finite element mesh that is highly refined in the region of the interface corner. Otherwise, the extracted $\mathrm{K}_{\mathrm{a}}$ values may lack accuracy. With due diligence in meshing, however, one can obtain highly accurate $\mathrm{K}_{\mathrm{a}}$ results ${ }^{25}$. Finally note that, although the matching approach is most readily applied when the asymptotic solution is described by one real-valued, power-law singularity, it has been successfully adapted to cases where multiple power-law singularities exist ${ }^{19,26}$.

\section{B. Contour Integral.}

Another widely used method for calculating interface-corner stress intensity factors uses a path-independent integral. This integral is derived via an application of Betti's reciprocal work theorem ${ }^{27-29}$. The reciprocal work contour integral (RWCI) method was first used to determine stress intensities for crack and notch geometries in homogeneous bodies, but was later extended to notched bimaterials ${ }^{30}$. More recent enhancements include conversion of the line integral to an area integral for improved accuracy ${ }^{25,31}$.

The path-independent RWCI used to calculate $\mathrm{K}_{\mathrm{a}}$ is defined as follows:

$$
K_{a}=\int_{C}\left(\sigma_{i j}^{*} u_{i}-\sigma_{i j} u_{i}^{*}\right) n_{j} d s
$$

where $\sigma_{i j}$ and $u_{i}$ are the numerically calculated stresses and displacements for the problem of interest, $n_{j}$ is the unit outward normal to a counter-clockwise contour $C$ that encircles the 
interface corner, and $\mathrm{ds}$ is an infinitesimal line segment of $\mathrm{C}$. The auxiliary fields $\sigma_{i j}^{*}$ and $u_{i}^{*}$ are the asymptotic solution corresponding to $\lambda^{*}=-\lambda$, where $\lambda$ is the strength of the singularity associated with $\mathrm{K}_{\mathrm{a}}$. The stress intensity of the auxiliary fields $K_{a}^{*}$ is chosen so that Eq. 7 holds. The path independent RCWI offers a convenient way for calculating accurate $\mathrm{K}_{\mathrm{a}}$ values without constructing a highly refined finite element mesh.

\section{Numeric Solutions for Complicated Configurations.}

There are many corner configurations of practical importance for which the analytic solution of the asymptotic problem is not readily available. For example, an interface corner may be at the apex of three or more bonded wedges, and some if not all of the wedge materials may be anisotropic. In addition to complicated two-dimensional problems, there is a growing interest in fully three-dimensional, multimaterial geometries where singularities occur along edges and at three-dimensional corners. In complicated configurations such as these, it may be difficult to apply methods for calculating stress intensity factors that require knowledge of the analytic form of singular stress fields (when using matching methods or contour integrals, for instance). Fortunately, broadly applicable numerical methods are being developed to solve such complicated asymptotic problems ${ }^{32-35}$. These methods typically determine the order of the stress singularities and the angular variation of the displacement fields numerically and then use the numerically determined fields in a solution scheme that calculates stress intensity factors. For example, one approach extracts the stress intensity factors in a post-processing step by using the wedge-tip displacements calculated from a full finite element solution together with the asymptotic displacement fields determined by a modified Steklov method ${ }^{34}$. Another approach uses a finite element eigenanalysis to obtain asymptotic displacements fields. These fields are then used to construct enriched finite elements that directly calculate stress intensity factors ${ }^{33}$.

\section{V. $K_{a}$ Calibrations}

The interface-corner stress intensity factor, $\mathrm{K}_{\mathrm{a}}$, depends on the applied load, elastic properties, and the overall joint geometry. In recent years $\mathrm{K}_{\mathrm{a}}$ calibrations have been published for a number of geometries of practical interest. These calibrations provide convenient formulas that can be used in a failure analysis without recourse to a detailed numerical analysis. They also provide insights regarding the dependencies of $\mathrm{K}_{\mathrm{a}}$ on geometry and material properties. Note that 
all calibrations presented below are for joints whose asymptotic interface-corner solution is described by one real-valued, power-law singularity, and a single $\mathrm{K}_{\mathrm{a}}$, characterizes the magnitude of the stress state in the region of the corner.

Based upon dimensional considerations and linearity with applied load, $\mathrm{K}_{\mathrm{a}}$ must have the form

$$
K_{a}=\sigma^{*} h^{1-\lambda} A(\alpha, \beta, L / h, \ldots) \quad \text { Eq. } 8
$$

where $\sigma^{*}$ is a characteristic stress, $\mathrm{h}$ is a characteristic length scale, and $\mathrm{A}$ is a function of nondimensional material and geometric parameters. As noted above, the strength of the stress singularity, $\lambda-1$, is known from the asymptotic analysis and depends on nondimensional elastic properties in addition to the local interface-corner geometry (e.g., wedge angle). Consequently, the $\mathrm{K}_{\mathrm{a}}$ calibration is defined by specifying the choice of characteristic stress and length scale and prescribing the functional dependence of $\mathrm{A}$ on all relevant nondimensional geometric and elastic parameters.

Material property dependence for traction-loaded, bi material plane elasticity problems can be completely described in terms of two dimensionless parameters ${ }^{36}$. Consequently, Dundurs' elastic mismatch parameters, $\alpha$ and $\beta$, are commonly used to define material property dependence in $\mathrm{K}_{\mathrm{a}}$ calibrations. For a bimaterial with material 1 above the interface and material 2 below,

$$
\alpha=\frac{\bar{E}_{1}-\bar{E}_{2}}{\bar{E}_{1}+\bar{E}_{2}}, \quad \beta=\frac{\mu_{1}\left(\kappa_{2}-1\right)-\mu_{2}\left(\kappa_{1}-1\right)}{\mu_{1}\left(\kappa_{2}+1\right)+\mu_{2}\left(\kappa_{1}+1\right)}
$$

with, $\bar{E}_{i}=E_{i}$ for plane stress and $\bar{E}_{i}=E /\left(1-v_{i}^{2}\right)$ for plane strain, and where $E_{\mathrm{i}} \mu_{\mathrm{i}}$, and $\mathrm{v}_{\mathrm{i}}$ (for $\mathrm{i}=1,2)$ are the Young's modulus, shear modulus, and Poisson's ratio of material 1 and 2. Furthermore, $\kappa_{\mathrm{i}}=\left(3-v_{\mathrm{i}}\right) /\left(1+v_{\mathrm{i}}\right)$ for plane stress and $\kappa_{\mathrm{i}}=\left(3-4 v_{\mathrm{i}}\right)$ for plane strain. Note that interchanging material 1 and 2 simply changes the sign of $\alpha$ and $\beta$, and when material 1 is rigid,

$$
\alpha=1, \beta= \begin{cases}\frac{1-v_{2}}{2} & \text { in plane stress } \\ \frac{1-2 v_{2}}{2\left(1-v_{2}\right)} & \text { in plane strain }\end{cases}
$$

In the following, $\mathrm{K}_{\mathrm{a}}$ calibrations are presented for two classes of problems, butt joints and encapsulated inclusions. Note that one must be careful when comparing the $\mathrm{K}_{\mathrm{a}}$ calibrations published by various researchers. Characteristic stress and length are often chosen differently, and even the definition of $\mathrm{K}_{\mathrm{a}}$ can change (the convention used here is to include the characteristic 
length scale in the $\mathrm{K}_{\mathrm{a}}$ definition as shown in Eq. 8). Also note that the characteristic stress for plane stress and plane strain conditions will in general differ.

\section{A. Adhesively bonded butt joint with stiff adherends}

A butt joint that bonds rigid adherends together with a thin adhesive layer is one of the simplest idealized joint geometries of practical importance (Figure 3). The asymptotic problem is just a quarter plane with one edge fixed and the other edge stress-free (Figure 2). This idealized joint is a reasonable representation when the adherends are muçh stiffer than the adhesive, such as the case of steel adherends and epoxy adhesive, and when the adhesive layer is thin relative to other joint dimensions. When the layer is relatively thin, it behaves as if it is semi-infinite and the stress in the adhesive layer is uniform and unaffected by the stress-free edge in regions sufficiently far from the stress-free edge. For typical epoxy properties (Young's modulus of 2.5 GPa, Poisson's ratio of 0.4), a bond-length to bond-thickness ratio of greater than four is sufficient for an elastic layer to be considered thin ${ }^{20}$. Restricting consideration to joints with rigid adherends and with a thin adhesive layer greatly simplifies the $\mathrm{K}_{\mathrm{a}}$ calibration since layer thickness is the only length scale. As a result, the function A (Eq. 8) does not depend on geometric parameters but only on $\beta$ or equivalently the adhesive layer's Poisson's ratio (Eq. 10).

The $\mathrm{K}_{\mathrm{a}}$ calibration for the idealized, rigid-adherend, thin-bond butt joint has been determined for tension, uniform temperature change, and shear ${ }^{16,37}$.

Tension. In this calibration, the characteristic length scale is one-half the bond thickness ( $h$ in Figure 3), and the characteristic stress $\sigma^{*}$ is the in-plane stress found at the center of the layer in a region remote from the stress-free edge. This characteristic stress is related to the nominal, applied transverse (butt tensile) stress $\bar{\sigma}$ for an adhesive layer with Poisson's ratio $\mathrm{v}$ by

$$
\sigma^{*}=\left\{\begin{array}{cl}
v \bar{\sigma} & \text { plane stress } \\
\frac{v}{(1-v)} \bar{\sigma} & \text { plane strain }
\end{array}\right.
$$

Table 1 lists the corresponding $A(1, \beta)$ values. These values are in good agreement with those reported by others ${ }^{38,39}$. Since the adherends are rigid and the adhesive layer is thin, the interfacecorner stress field will be essentially the same for plane strain and axisymmetric geometries. Consequently, this $\mathrm{K}_{\mathrm{a}}$ calibration also applies to a butt joint formed by bonding cylindrical rods 
together with a thin adhesive layer. The same $\mathrm{K}_{\mathrm{a}}$ relation is also applicable to a transversely cracked elastic layer that is sandwiched between rigid layers (assuming a single, isolated crack). The stress-free edge can be considered a symmetry plane when the bounding layers are rigid.

Uniform Temperature Change. The same $\mathrm{K}_{\mathrm{a}}$ calibration defined for tensile loading also applies when the adhesive undergoes a uniform temperature change, $\Delta \mathrm{T}$, if the characteristic stress is defined as

$$
\sigma^{*}= \begin{cases}-E \alpha \Delta T & \text { plane stress } \\ -\frac{E \alpha \Delta T}{(1-v)} & \text { plane strain }\end{cases}
$$

where $\alpha$ is the coefficient of thermal expansion. This is true because tensile and uniform adhesive-shrinkage load types are actually related ${ }^{16}$. The superposition of an appropriate uniform stress state with the solution for a uniform pressure applied to the layer's exterior edge yields solutions for transverse tension and also for uniform adhesive shrinkage. The solution for the uniform edge pressure can be thought of as providing the fundamental singular solution, and the characteristic stress defined in Eqs. 11 and 12 is the stress superimposed with the edge pressure to obtain a stress-free edge.

Shear. The joint's thin adhesive layer is sheared by tangentially displacing one rigid adherend relative to the other. The same asymptotic problem shown in Figure 2 applies to both the tensile-loaded and shear-loaded rigid-adherend butt joint; the strength of the stress singularity is independent of the type of loading. In this calibration, the characteristic length scale is again taken to be one-half the bond thickness ( $h$ in Figure 3), and the characteristic stress $\sigma^{*}$ is the nominal shear stress $\bar{\tau}$ found at the center of the layer in a region remote from the stress-free edge. Values of $A(1, \beta)$ for shear are listed in Table 1 . These values are in good agreement with those reported by others ${ }^{39}$. Note that, for this antisymmetric loading, the magnitude of $K_{d}$ is the same at the joint's four interface corners (A, B, C, and D in Figure 4), but when the joint is subjected to positive shear, $K_{a}$ is positive at $B$ and $C$, and negative at $A$ and $D$. This $K_{a}$ calibration can be applied to an adhesively bonded, thick-adherend lap joint, either flat or tubular, when the adherends are much stiffer than the adhesive, provided that there is negligible bending induced by the loading. 
Affect of adherend stiffness. Even though the rigid adherend idealization is reasonable for steel adherends joined by an epoxy adhesive, a noticeable deviation occurs when steel is replaced by aluminum ${ }^{40}$. Table 2 shows that the strength of the stress singularity decreases from -0.32 for rigid adherends to -0.30 for steel adherends to -0.27 for aluminum adherends (for an epoxy with $E=3.5 \mathrm{GPa}, v=0.35)$. Table 2 also lists $A(\alpha, \beta)$ values for a $\mathrm{K}_{a}$ calibration for these three adherend materials. Once again the characteristic length scale is the half-bond thickness (h in Figure 3) and the characteristic stress $\sigma^{*}$ is the in-plane stress found at the center of the layer in a region remote from the stress-free edge. The relationship between $\sigma^{*}$ and the nominal, applied tensile stress $\bar{\sigma}$ is

$$
\begin{array}{cc}
v_{2}\left[1-\left(\frac{E_{2}}{E_{1}} \frac{v_{1}}{v_{2}}\right)\right] \bar{\sigma} & \text { plane stress } \\
\sigma^{*}=\left(\frac{v_{2}}{1-v_{2}}\right)\left[1-\left(\frac{E_{2}}{E_{1}} \frac{v_{1}\left(1+v_{1}\right)}{v_{2}\left(1+v_{2}\right)}\right)\right] \bar{\sigma} & \text { plane strain }
\end{array}
$$

where $E_{i}, v_{i}$ are Young's modulus and Poisson's ratio of the adherend (material 1) and the adhesive layer (material 2), respectively. Note that Eq.13 reduces to Eq. 11 when the adherends are rigid $\left(E_{1}->\infty\right)$. Additional values of $A(\alpha, \beta)$ for $-1<\alpha<1$ for $\beta=0, \alpha / 4$ can be found in ${ }^{41}$.

\section{B. Thin layer on a thick substrate}

Rigid substrate. A thin adhesive layer on a rigid substrate is another idealized geometry of practical importance. An example is a thin polymer film deposited on a silicon substrate. For convenience material 1 is taken to be rigid $(\alpha=1)$. The only length scale is layer thickness $h_{2}$ ( $\mathrm{L} \gg>\mathrm{h}_{2}$ in Figure 1). The same asymptotic problem for an adhesively bonded butt joint with rigid adherends (Figure 2) applies to a thin layer on a rigid substrate. Furthermore, $\mathrm{a} \mathrm{K}_{\mathrm{a}}$ calibration for a uniformly cooled layer can be defined using the same thermally induced in-plane stress (Eq. 12 ), but now the characteristic length scale is layer thickness $h_{2}$ (Figure 1). Values of $A(1, \beta)$ are listed in Table 1 for a wide range of $\beta$.

Finite stiffness substrate. A $\mathrm{K}_{\mathrm{a}}$ calibration for the case of a thin layer on a relatively

thick, finite stiffness substrate $\left(h_{2} / h_{1} \leq 0.1, h_{2} / L \leq 0.1\right.$ in Figure 1$)$ has been published ${ }^{42}$. This calibration is presented as a polynomial expression that is a function of two variables: the strength of the singularity ( $\lambda-1$ in Eq. 4 , where $\lambda-1$ depends on Dundurs' parameters $\alpha, \beta)$ and 
the Poisson's ratio of the thin layer. When specialized to the case of a rigid substrate, this calibration yields values that are within a couple of per cent of those listed in Table 1.

\section{Long adherend butt joint}

The only length scale in a butt joint with $h_{1} / L$ and $h_{2} / L$, both $>1$ (Figure 1 ), is joint-width $2 \mathrm{~L}$. A K $\mathrm{K}_{\mathrm{a}}$ calibration for the long adherend idealization is available and is said to apply whenever $h_{1} / L$ and $h_{2} / L$ are greater than two ${ }^{15}$. For tensile loading, the nominal the characteristic stress $\sigma^{*}$ is the nominal applied stress, and characteristic length is the half-joint width ( $L$ in Figure 1 ). The calibration also applies to a uniform temperature change if the characteristic stress is defined by

$$
\sigma^{*}=\frac{-E_{1} E_{2}}{v_{1}\left(1+v_{1}\right) E_{2}-v_{2}\left(1+v_{2}\right) E_{1}}\left[\left(1+v_{1}\right) \alpha_{1}-\left(1+v_{2}\right) \alpha_{2}\right] \Delta T \quad \text { plane strain } \quad \text { Eq. } 14
$$

The function $\mathrm{A}$ is given as a polynomial fit

$$
A(\omega)=1-2.89 \omega+11.4 \omega^{2}-51.9 \omega^{3}+135.7 \omega^{4}-135.8 \omega^{5}
$$

where $\omega=1-\lambda$ is the negative of the strength of the stress singularity (Eq. 4).

Interestingly, for this particular geometry the nondimensional function can be seemingly correlated with a single parameter-the strength of the stress singularity rather than on both of Dundurs' parameters. Although the strength of the singularity does itself depend on Dundurs' parameters, an unlimited number of $\alpha, \beta$ pairs can generate the same strength singularity. Graphs showing curves of constant $1-\lambda$ for the range of all possible $\alpha$ and $\beta$ pairs can be found in several references ${ }^{7,15}$. Furthermore the long-adherend butt joint exhibits a special symmetry that allows one to interchange the materials without changing the strength of the singularity (i.e., $\lambda(\alpha, \beta)=\lambda(-\alpha,-\beta))$ or the stress intensity factor (i.e., $A(\alpha, \beta)=A(-\alpha,-\beta))$. It must be emphasized, however, that the dependence of function $A$ on only $1-\lambda$ is a special case, and, in general, this type of reduced dependence does not occur. More recently reported values of $A(\alpha, \beta)$ for $\alpha=0.2$, $0.5,0.8,0.99$ and $\beta=0$ or $\alpha / 4^{41}$ for the same joint geometry are within a few per cent of those determined by Eq. 15. The accuracy of Eq. 15 is thought to be good for Poisson's ratios from 0.2 to 0.4 , but there may be some divergence for Poisson's ratios outside of this range ${ }^{42,43}$. For this reason, another form for the function $A$ has been proposed to improve the accuracy of the relationship for a wider range of Poisson's ratios ${ }^{43}$. Specifically, 


$$
A(\alpha, \omega)=e^{[-2.45 \omega(1.1-\omega)]}-0.0235 \alpha^{6}
$$

Eq. 16

where once again $\omega=1-\lambda$.

Long-adherend scarf joints. The long-adherend butt joint can be generalized to a scarf joint by allowing the interface to intersect the stress-free edge at a nonnormal inclination. $\mathrm{A} \mathrm{K}_{\mathrm{a}}$ calibration for the long adherend scarf joint is available for both remote tension and bending ${ }^{44}$. Results are presented in tabular form for $\alpha= \pm 0.2, \pm 0.5, \pm 0.8, \pm 0.99$ with $\beta=0$ or $\alpha / 4$ for scarf angles of $15,30,45,60,75$, and 90 degrees.

\section{Bimaterial beam}

$K_{a}$ calibrations covering the full range of possible variations in butt-joint geometry $\left(h_{1}, h_{2}\right.$, and $\mathrm{L}$ in Figure 1) are available ${ }^{42}$. These polynomial fits can be specialized to the important case of a bimaterial beam formed by two long strips $\left(h_{1} / L\right.$ and $\left.h_{2} / L \gg 1\right)$, where $h_{1}$ and $h_{2}$ are not necessarily equal. A $\mathrm{K}_{\mathrm{a}}$ calibration derived specifically for bimaterials beams is also available ${ }^{45}$. Calibration results are presented for $\alpha= \pm 0.23, \pm 0.5, \pm 0.7, \pm 0.90$ with $\beta=0$ or $\alpha / 4$ and $h_{1} / h_{2}$ varying from $1 / 32$ to 32 . The two calibrations are in good agreement.

\section{E. Embedded Inclusion}

Rigid square inclusion in an epoxy disk. A simple, two dimensional idealization of an encapsulated, sharp-cornered component or particle is a rigid, square inclusion embedded within a thin, isotropic material (Figure 5). When viewed asymptotically, the inclusion tip is the apex of a wedge (Figure 6). The solution of this asymptotic problem contains two singular terms with generally differing strengths. However, for a symmetric loading-such as that generated by uniform cooling -only one of these singularities is excited, and the magnitude of the asymptotic stress state is fully characterized by a single stress intensity factor. The $\mathrm{K}_{\mathrm{a}}$ calibration for a rigid, square inclusion embedded within a thin disk and subjected to uniform cooling for both fully bonded and unbonded (frictionless sliding) conditions has been determined for plane stress ${ }^{46}$. The $K_{a}$ calibration uses inclusion edge-length as the characteristic length (h in Figure 5), and the characteristic stress is

$$
\sigma^{*}=\frac{-E \alpha \Delta T}{1-v}
$$


The function $A$ depends on $\beta(\alpha=1)$ and the nondimensional geometric parameter $D / h$. Values of A for various $\beta$ and $D / h$ are listed in Table 3 for both bonded and unbonded inclusions.

The singular stress state generated by the bonded inclusion is very different from that generated by the unbonded inclusion. For an encapsulant with a Poisson's ratio of 0.35 , the strength of stress singularity for the bonded inclusion is -0.25 , whereas the strength of the singularity for the unbonded inclusion is -0.67 (Figure 7). The angular variation of the stress field also differs. When the inclusion is fully bonded, the magnitude of the radial stress in front of the inclusion tip $\left(\theta=0^{\circ}\right.$, Figure 8$)$ is much larger than the hoop stress. When the inclusion is unbonded, hoop and radial stress have the same magnitude but are of opposite sign (Figure 9). This suggests that an epoxy disk containing an unbonded inclusion is more likely to crack when cooled than a disk containing a fully bonded inclusion. When unbonded, the inclusion tip stress field is fully characterized by a single, interface-corner stress intensity factor, and the associated singular field dominates a relatively large region (roughly 15 percent of the inclusion edge length for an epoxy with $E=3.5 \mathrm{GPa}$ and $v=0.35$, Figure 10). Elastic-plastic calculations for a thermally induced strain of -0.0004 show that, when the inclusion is unbonded, encapsulant yielding has a significant effect on the inclusion-tip stress state $\left(\sigma_{y}=74 \mathrm{MPa}\right.$, Figure 11). Yielding relieves stress parallel to the interface and greatly reduces the radial compressive stress in front of the inclusion. As a result, the encapsulant is subjected to a nearly uniaxial tensile stress at the inclusion tip, and the calculated yield zone is embedded within the region dominated by the elastic hoop-stress singularity.

Inclusion in an infinite media. Chen and Nisitani ${ }^{11}$ noted that for the case of bonded, dissimilar elastic wedges that together form a full plane, when $\beta(\alpha-\beta)>0$, there are at most two power-law singular terms in the asymptotic expansion of the stress field with $-1<\lambda-1<0$. The exponent defining the strength of each of the singular terms is real, and the two exponents are generally different. They also found that one of the singular terms is associated with symmetric loading about the line bisecting the apex of the wedge, whereas the other is associated with an asymmetric loading about the bisecting line (i.e., $\mathrm{x}$ axis in Figure 6). In another study Chen ${ }^{47}$ reports $K_{a}$ calibrations for a bonded inclusion embedded within an infinite plate subjected to uniaxial tension, biaxial tension, or shear at infinity. Results are presented for a variety of inclusion shapes, including rectangles, diamonds, and hexagons, and broad range of bimaterial 
combinations. Note that the $\mathrm{K}_{\mathrm{a}}$ for a symmetric (asymmetric) loading will be associated with the stress singularity term corresponding to that mode of loading.

\section{Limits on the Applicability of a $\mathbf{K}_{\mathrm{ac}}$ Failure Analysis}

Two basic requirements must be met before the $\mathrm{K}_{\mathrm{ac}}$ criterion can be applied. One obvious requirement is that failure must initiate at the interface corner. The other requirement is that the interface-corner singularity field (Eq. 4) must be a good approximation to the actual field in an annular region surrounding the corner. Consequently, the corner must appear sharp on a length scale commensurate with that defining the region dominated by the interface-corner stress singularity, and unstable crack growth must initiate from a fracture process zone that is deeply embedded within the region dominated by the interface-corner singularity. When these conditions are met, $\mathrm{K}_{\mathrm{a}}$ is a unique measure of the intensity of the stress field at the corner, independent of geometry and details of the applied loading. This restriction is analogous to the familiar small-scale yielding requirement of LEFM ${ }^{48,49}$.

\section{A. Crack Initiation Away From the Interface Corner.}

Cracking in bonded or encapsulated bodies will often initiate at a sharp interface corner whenever such cornerss are present. For example, crack growth in epoxy-bonded, metaladherend, cylindrical butt joints initiates adhesively (on the interface) along a small segment of the specimen periphery. ${ }^{5,50,51}$. However, failure sometimes initiates away from the interface corner. This is particularly true for thin, highly constrained, elastomeric adhesive bonds. For example, adhesively bonded butt joints with PMMA (polymethylmethacrylate) adherends and a nearly incompressible, elastomeric adhesive (Solithane 113) fail away from the edge when the bond is sufficiently thin ${ }^{5}$. The stress state in a thin elastomeric bond is quite different from that in a thin, glassy polymer bond, and this provides an explanation for the tendency for elastomeric bonds to sometimes fail away from a sharp interface corner.

Consider the case of a cylindrical butt joint with rigid adherends and a thin, elastic bond. In the center of the adhesive layer, far from the stress-free edge,

$$
\sigma_{r r}=\sigma_{\theta \theta}=\frac{v}{1-v} \sigma_{z z} \quad \text { Eq. } 18
$$

A typical glassy epoxy adhesive has a Poisson's ratio of about 0.35 ; consequently, in-plane stresses are equal to roughly half the axial stress. Furthermore, a plane strain finite element 
analysis of a rigid-adherend butt joint shows that stress within a thin bond is nearly uniform when more than four bond thicknesses from the edge, and $\sigma_{z} \approx \bar{\sigma}$, the nominal applied stress ${ }^{20}$. In contrast, Eq. 18 indicates that pure hydrostatic tension is generated in elastomeric bonds since elastomers are nearly incompressible and have a Poisson's ratio approaching 0.5. Furthermore, stress varies continuously with radial distance in a rigid-adherend butt joint with a thin, nearly incompressible bond ${ }^{52}$. The solution for a thin bond with $v=0.5$ is

$$
\sigma_{H T}=\sigma_{z z}=\sigma_{r r}=\sigma_{\theta \theta}=2 \bar{\sigma}\left[1-\left(\frac{2 r}{D}\right)^{2}\right] \text {, }
$$

where $\mathrm{r}$ is radial distance, $\mathrm{D}$ is the bond diameter, and $\bar{\sigma}$ is the nominal applied stress. The bond is subjected to a pure hydrostatic tension, $\sigma_{\mathrm{HT}}$, and at the center of the bond $\sigma_{\mathrm{H} T}=2 \bar{\sigma}$. Furthermore, a large region of the bond is subjected to elevated levels of hydrostatic tension $\left(\sigma_{\mathrm{HT}}>\bar{\sigma}\right.$ for $\left.2 \mathrm{r} / \mathrm{D}<0.71\right)$. These results suggest that, if interfacial flaws of sufficient size exist away from the bond edge, the relatively high hydrostatic stress state generated within a thin elastomeric bond may be sufficient to cause these flaws to propagate. A linear elastic fracture mechanics analysis is generally applicable in those instances when failure initiates away from an interface corner. Note, however, that such an analysis should include compressibility effects, and model the actual bond-thickness to bond-diameter ratio. Calculations for a tensile-loaded, cylindrical butt joint with rigid adherends have shown that $\sigma_{\mathrm{HT}}$ is extremely sensitive to Poisson's ratio values and the bond-thickness to bond-diameter ratio ${ }^{53,54}$. For example, published results for an adhesively bonded cylindrical butt joint with rigid adherends indicate that for a bond diameter-to-thickness ratio of $50, \sigma_{H T} / \bar{\sigma} \approx 2.00,1.15$, and 1.00 for $v=0.50,0.49$, and 0.34 , respectively, while for $\mathrm{v}=0.5, \sigma_{H T} / \bar{\sigma} \approx 1.9,1.7$, and 1.1 for $\mathrm{D} / \mathrm{h}=10,5$, and 2 , respectively ${ }^{53}$.

\section{B. Small-Scale Yielding.}

For $\mathrm{K}_{\mathrm{ac}}$ to characterize the failure process, the fracture process zone must be deeply embedded within the region dominated by the interface-corner singularity. To check if this condition is met, one must determine the size of the region dominated by the interface-corner singularity and also estimate the size of the fracture process zone. An example of such a calculation is presented to illustrate the nature of the small-scale yielding requirement. This particular calculation is for an adhesively bonded butt joint with rigid adherends ${ }^{55}$. The failure load and epoxy properties used in the calculation are based on a previously reported series of 
steel/epoxy butt-joint tests ${ }^{50}$. The epoxy adhesive layer is $1.0 \mathrm{~mm}$ thick and has a Young's modulus E of $3.5 \mathrm{GPa}$, Poisson's ratio $v$ of 0.35 , a room temperature tensile yield strength of 70 $\mathrm{MPa}$ and a compressive yield strength of $100 \mathrm{MPa}$ (at a strain rate of $0.0002 / \mathrm{s}$ ). If a linear dependence on pressure $\mathrm{P}$ is assumed, $\sigma_{\mathrm{y}}=82+0.53 \mathrm{P}(\mathrm{MPa})$. Failure of a joint with a 1-mmthick bond occurs at a nominal applied stress $\bar{\sigma}$ of $30.7 \mathrm{MPa}$, a value consistent with an interface toughness of $\mathrm{K}_{\mathrm{ac}}=12.7 \mathrm{MPa} \mathrm{mm}^{0.32}$.

The size of the region dominated by the stress singularity can be estimated by comparing finite element results for the full joint model with the singularity solution (Eq. 4). For a tensileloaded butt joint with rigid adherends and a thin (essentially semi-infinite), epoxy bond, the calculated interfacial normal stress is in good agreement with the singular asymptotic solution for a distance of 15 percent of the bond thickness (Figure 12). Consequently, not only must the corner appear sharp when viewed at this length scale, but also material yielding and subcritical crack growth must be limited to a few percent of the total bond thickness.

The size of the interface-corner fracture process zone is not known, but one can estimate the extent of yielding. Figure 13 shows three different predictions for the interface-corner yield zone at joint failure. Epoxy yielding is rate and temperature dependent and is thought to be a manifestation of stress-dependent, nonlinear viscoelastic material response. A precise estimate of the size of the interface-corner yield zone is, of course, totally dependent on the accuracy of the epoxy constitutive model. This constitutive model must be valid at the extremely high strain and hydrostatic tension levels generated in the region of an interface corner. Unfortunately, accurate epoxy models of this type are not readily available. Nevertheless, simpler material models can be used to provide some insights. The crudest yield zone prediction shown in Figure 13 uses a linear-elastic adhesive model to determine when the calculated effective stress exceeds the epoxy's yield strength. Also shown are results using a standard, elastic-perfectly-plastic J2-flow theory and an elastic-perfectly-plastic, Drucker-Prager model that incorporates a pressuredependent yield strength. A realistic adhesive model should include pressure-dependent yielding. Figure 13 shows that the size and shape of the calculated yield zone is a strong function of which adhesive constitutive model is used. The calculated yield zone determined when using elasticity and $\mathrm{J} 2$-flow theory is in poor agreement with that determined when pressure-dependent yielding is included. The Drucker-Prager solution shows the largest yield zone, and the zone is shifted towards the interface. This is because of the presence of high levels of hydrostatic tension at the 
interface. Note that the slip-line theory solution (Figure 14) for a rigid-perfectly-plastic adhesive predicts a hydrostatic interfacial tension of $1.5 \sigma_{\mathrm{y}}{ }^{56}$.

Figure 12 plots the calculated interfacial normal stress for the J2-flow and DruckerPrager adhesive models along with interface-corner singularity and rigid-perfectly-plastic slipline solutions. As observed previously, the interfacial normal stress is in good agreement with the singularity solution over a distance equal to 15 percent of the 1 -mm-thick bond. At this bond thickness, the yield zone is deeply embedded within the region dominated by the singularity. Tests have been performed on joints as thin as $0.25 \mathrm{~mm}$ with good agreement with an interfacecorner failure analysis ${ }^{50}$. An interface-corner failure analysis cannot, however, be applied to arbitrarily thin bonds. The region dominated by the singularity solution scales with bond thickness and shrinks as bond thickness is reduced. Ultimately it reaches a size comparable to that of the yield zone at joint failure.

\section{Small-Scale Cracking.}

In the case of joints composed of bonded brittle materials, the small-scale cracking problem provides insight into how much subcritical cracking can occur without invalidating the use of a $\mathrm{K}_{\mathrm{ac}}$ criterion. The small-scale interfacial cracking problem for a crack originating at an interface corner is completely analogous to the small-scale yielding problem of traditional fracture mechanics ${ }^{31,57}$. Illustrative results for small-scale interfacial cracking will be presented below; however, first some commonly used interfacial fracture mechanics concepts will be defined. These definitions are specialized to plane strain and where the upper adherend is rigid (Figure 15, Material 1).

The singular stress state at the tip of a crack lying on the interface between two dissimilar, linear-elastic, isotropic materials is well known ${ }^{4,58}$. The interfacial tractions directly ahead of the crack tip (Figure 15) are given by

$$
\left(\sigma_{y y}+i \sigma_{x y}\right)_{\theta=0}=\frac{K r^{i \varepsilon}}{\sqrt{2 \pi r}}
$$

where 


$$
K=K_{1}+i K_{2} \quad, \quad i \equiv \sqrt{-1} \text {, and } \quad \varepsilon=\frac{-\ln (3-4 v)}{2 \pi}
$$

Furthermore, the energy release rate $G$ for crack advance along the interface is related to the complex interfacial stress intensity factor by

$$
G=\frac{\left(1-\beta^{2}\right)}{E^{*}}|K|^{2}
$$

where

$$
E^{*}=\frac{2 E}{\left(1-v^{2}\right)} \text { and }|K|^{2}=K_{1}^{2}+K_{2}^{2}
$$

A generalized interpretation of mode measure has been suggested by Rice ${ }^{58}$, and this definition is now widely used. Mode mixity $\hat{\psi}$ is defined as the ratio of interfacial shear stress to normal stress at a fixed distance $\hat{l}$ in front of the crack tip.

$$
\hat{\psi}_{r=\hat{l}}=\tan ^{-1}\left[\left(\frac{\sigma_{x y}}{\sigma_{y y}}\right)_{\theta=0, r=\hat{l}}\right]=\tan ^{-1}\left[\frac{\operatorname{Im}\left(K \hat{l}^{i \varepsilon}\right)}{\operatorname{Re}\left(K \hat{l}^{i \varepsilon}\right)}\right]
$$

The choice of reference length $\hat{l}$ is arbitrary and is sometimes based on a characteristic in-plane length of the body analyzed or on an intrinsic material length scale. In any case, $\hat{\psi}$ values corresponding to two different length scales, $\hat{l}_{1}$ and $\hat{l}_{2}$, are related by

$$
\hat{\psi}_{r=\hat{l}_{2}}=\hat{\psi}_{r=\hat{l}_{1}}+\varepsilon \ln \left(\hat{l}_{2} / \hat{l}_{1}\right)
$$

The solution of the small-scale cracking problem for a tensile-loaded, adhesively bonded butt joint with rigid adherends illustrates how much subcritical cracking can occur without invalidating the use of a $\mathrm{K}_{\mathrm{ac}}$ criterion ${ }^{55}$. A short, interfacial crack is considered to be fully embedded within the region dominated by the interface-corner stress singularity (Figure 16). The angular variation of displacements along the outer boundary ( $r>>a)$ is known from the interface-corner solution, and $\mathrm{K}_{\mathrm{a}}$ determines the magnitude of the loading. In accordance with linear elasticity, $|\mathrm{K}|$, for the interfacial crack, must depend linearly on $\mathrm{K}_{\mathrm{a}}$. The only length scale in this asymptotic problem is the crack length a, and for the rigid-adherend case, the only nondimensional parameter that exists or can be formed is Dundurs' parameter $\beta(\alpha=1)$. Consequently, to be dimensionally correct, the energy release rate must depend on crack length and $\mathrm{K}_{\mathrm{a}}$ as 


$$
G=\frac{\left(1-\beta^{2}\right)}{E^{*}}|K|^{2}=\frac{\left(1-\beta^{2}\right)}{E^{*}} K_{a}^{2} a^{2 \lambda-1} D(1, \beta)
$$

Dimensional considerations require that mode mixity $\hat{\psi}_{r=a}$ is also only a function of $\beta$. The functions $D(1, \beta)$ and $\hat{\psi}_{r=a}$ are determined by solving the asymptotic problem for a range of $\beta$ values. The $\mathrm{G}$ relation defined by Eq. 26 can be specialized to the case of a tensile-loaded, adhesively bonded butt joint with rigid adherends by substituting the $\mathrm{K}_{\mathrm{a}}$ relationship for that geometry and loading (Eq. 8 in conjunction with 11 for plane strain and Table 1).

$$
G=\frac{\left(1-\beta^{2}\right)}{E^{*}}\left(\frac{v}{1-v}\right)^{2} A(1, \beta)^{2} D(1, \beta)\left(\frac{h}{a}\right)^{1-2 \lambda} \bar{\sigma}^{2} h
$$

When $v=0.35, \lambda \sim 2 / 3$. Equation 27 indicates that when small-scale cracking conditions exist, $G$, for an adhesively-bonded butt joint with rigid adherends, varies as $h^{2 / 3}$ and as $a^{1 / 3}$. Table 4 lists $D(1, \beta)$ and mode mixity $\hat{\psi}_{r=a}$ values for a broad range of $\beta$. Note that the reported $D(1, \beta)$ apply not only to the adhesively-bonded butt joint but also to any problem where the asymptotic problem is a quarter plane with one edge fixed and the other edge stress-free (e.g., debonding at the tip of a transverse crack in a thin layer on a rigid substrate). Equation 26 relates $G$ to any existing $\mathrm{K}_{\mathrm{a}}$ relation.

Another useful result is the energy release rate for a long, interfacial crack that is so far from the interface corner that it is no longer influenced by its presence. The steady-state asymptotic problem for plane strain is readily determined by a J-integral evaluation ${ }^{59}$

$$
G_{s s}=\frac{(1+v)(1-2 v)}{(1-v) E} \bar{\sigma}^{2} h
$$

A finite element solution for a geometry approximating the long crack limit indicates that $\hat{\psi}_{r=2 h}=-16.4^{\circ}$.

A full, finite element analysis of an adhesively-bonded butt joint with rigid adherends has been performed to investigate the range of applicability of the asymptotic solutions. The failure load and epoxy properties used in these calculations are the same as those used in the scale yielding calculations for steel/epoxy adhesively bonded butt joints presented above (i.e., $E=3.5$ $\mathrm{GPa}, v=0.35, \mathrm{~K}_{\mathrm{ac}}=12.7 \mathrm{MPa} \mathrm{mm}{ }^{0.32}, \bar{\sigma}=30.7 \mathrm{MPa}, 2 \mathrm{~h}=1.0 \mathrm{~mm}$ ). Finite element calculations were carried out for a crack length that ranges from 0.001 to 10 times the bond thickness.

Figure 17 illustrates the nature of the small-scale cracking problem when $a=0.01 \mathrm{~mm}$ and $2 \mathrm{~h}=1.0 \mathrm{~mm}$. Asymptotic interface-corner and small-scale cracking solutions for interfacial 
normal stress are compared to finite element results for the full joint model. The interface-corner stress solution is defined by Eqs. 4 ( $\mathrm{K}_{\mathrm{a}}$ is defined by Eq. 8 in conjunction with Eq. 11, for plane strain, and Table 1). Note that the reason the plotted curve on this log-log plot is not a straight line is that stress is plotted as a function of distance from the crack tip, not distance from the interface corner. The small-scale cracking result is obtained by using Eq. 27 and the phase angle listed in Table 4 to determine the complex interfacial stress intensity factor using Eqs. 22-25. The interfacial normal stress is then calculated using Eq. 20. The small-scale cracking solution merges with the full joint solution at a distance of $<.01 \mathrm{~mm}$. At a distance of $0.01 \mathrm{~mm}$ in front of the crack-tip (a distance equal to the crack length), the small-scale cracking solution is within 10 percent of the full-joint model solution. The stress field associated with the interface crack is embedded within the field governed by the interface-corner singularity. Once beyond the region perturbed by the interface crack, the interface-corner singularity and the full-joint model solutions are within 10 percent out to a distance of $0.15 \mathrm{~mm}$ (15 percent of the total bond thickness).

Figure 18 compares the calculated energy release rate using the full joint model $\left(\mathrm{G}_{\mathrm{FEA}}\right)$ with the asymptotic solutions for small-scale cracking $\left(\mathrm{G}_{\text {asym }}\right)$ and steady-state cracking $\left(\mathrm{G}_{\mathrm{ss}}\right)$ over a broad range of crack lengths. Together the asymptotic solutions form a fairly tight envelope of $\mathrm{G}_{\mathrm{FEA}}$ over the full range of crack lengths. The small-scale cracking solution is within a few percent of $\mathrm{G}_{\mathrm{FEA}}$ for $\mathrm{a} / \mathrm{h}<.02$ and differs by 20 percent $\mathrm{at} \mathrm{a} / \mathrm{h}=1$. The steady-state cracking solution is within a few percent of $\mathrm{G}_{\mathrm{FEA}}$ for $\mathrm{a} / \mathrm{h}>2$ and differs by 16 percent $\mathrm{at} \mathrm{a} / \mathrm{h}=1$. Figure 19 plots a similar comparison for mode mixity. Here the phase angle is defined at a characteristic length scale of $0.01 \mathrm{~mm}$. Again, the asymptotic solutions form a fairly tight envelope of the phase angle calculated using the full joint model. These results suggest that the $\mathrm{K}_{\mathrm{ac}}$ criterion can be applied even if a subcritical crack extends a distance equal to several per cent of the bond thickness.

\section{Experimental Studies}

\section{A. Early Studies (1980s)}

It appears that the first study investigating the applicability of the $\mathrm{K}_{\mathrm{ac}}$ criterion was published in $1982^{12}$. Three different types of three-layer, steel/epoxy/steel model laminates were subjected to various loading conditions. The epoxy layer joining the steel adherends in these model laminates was a relatively thick $25 \mathrm{~mm}$ and only eight samples were tested. The measured 
$\mathrm{K}_{\mathrm{ac}}$ values are reasonably consistent, with the exception of one outlying data point. In another study, single-lap joints with varying overlap lengths were tested ${ }^{13}$. These joints have a large spew fillet, and the asymptotic stress state at the sharp embedded corner, where failure presumably initiates, is described by two, real-valued power-law singularities. Neither of the two singularities dominated, so an "equivalent-strength singularity" was used in the analysis. The agreement between measured strength and that predicted using a $\mathrm{K}_{\mathrm{ac}}$ criterion is good for large overlap lengths, but is rather poor for smaller overlaps. The author indicates that adhesive used in the tests is ductile, and that may be a factor affecting the accuracy of his predictions. Another study is notable for endeavoring to apply the $\mathrm{K}_{\mathrm{ac}}$ failure criterion to a microelectronics packaging problem ${ }^{14}$. Three different epoxy/Fe-Ni alloy bimaterial configurations---each with a different asymptotic geometry (flush, or with either the epoxy or Fe-Ni alloy protruding)-- were cooled from the cure temperature to induce delamination. The strength of the stress singularity $\lambda-1$ differed in each case, and a $K_{a c}$ vs. $\lambda-1$ relation was constructed. This relationship was treated as a material property and used to predict the tendency of epoxy encapsulated Fe-Ni inserts and LSI packages to delaminate. Test results are consistent with the predictions. Some of the configurations tested in this study have more than one singular term, and all have an $r$-independent term generated by cooling. The existence of a unique $\mathrm{K}_{\mathrm{ac}}$ vs. $\lambda-1$ relationship assumes that, even when the number of singularities and constant terms change with changes in the configuration, the highest order term dominates. In general this is not true.

\section{B. Adhesively Bonded Butt Joints (1990s).}

The need for a rigorous test of the applicability of the $\mathrm{K}_{\mathrm{ac}}$ criterion motivated an extended experimental study that is reported in a series of five papers ${ }^{40,50,51,60,61}$. In this work a large number of adhesively bonded butt joints were tested. The adherends were solid metal cylinders (28.6 $\mathrm{mm}$ diameter by $38.1 \mathrm{~mm}$ long) that had been precision machined to guarantee the ends were flat and perpendicular to the cylinder axis and that the edges were left sharp. The epoxy bond was relatively thin. Joints with bonds as thin as $0.25 \mathrm{~mm}$ and as thick as $2.0 \mathrm{~mm}$ were tested. This test geometry was chosen because: (1) it is widely used in the adhesives' community (e.g., ASTM D897 and D2095); (2) it is a relatively simple joint geometry to fabricate and test (7-10 joints were tested at each nominally identical condition); and (3) joint strength should vary 
with adhesive bond thickness in a definite and easily measurable way when the $\mathrm{K}_{\mathrm{ac}}$ criterion applies.

Effect of bond thickness. The effect of bond thickness on joint strength was the focus of two test series ${ }^{40,50}$. One test series used steel adherends, while the other used aluminum adherends. Fabrication and test conditions for the two test series are summarized in Table 5. Thirty-seven joints with 303 stainless steel adherends were tested, while 27 joints with 6061-T6 aluminum adherends were tested. The same triamine-cured DGEBA epoxy (Shell's Epon 828 epoxy resin crosslinked with a Huntsman's Jeffamine T403 hardener using a 100/36 weight ratio) was used in both test series. This adhesive has a Young's modulus of $3.5 \mathrm{GPa}$, a Poisson's ratio of 0.35 , and a compressive yield strength of $100 \mathrm{MPa}$ (measured at room temperature and when loaded at a strain rate of $0.0002 \mathrm{~s}^{-1}$ ). The adhesive bond thickness was varied, and had target bond thicknesses of $0.25,0.50,1.00$, and $2.00 \mathrm{~mm}$ (actual thickness was determined after fabrication). The joints were cured near or at room temperature and tested at room temperature to minimize residual stress effects. The joints were tested in a conventional, screw-driven load frame. All specimens were loaded at a crosshead displacement rate of $0.2 \mathrm{~mm} / \mathrm{s}$ using a load train that utilized a chain linkage to minimize misalignment effects. Time to failure ranged between 10 and 25s, depending on joint strength. The calibration for an adhesively bonded butt joint with stiff adherends was used to calculate $\mathrm{K}_{\mathrm{ac}}$ from measured joint strength and bond thickness (Eq. 8, in conjunction with plane strain $\sigma^{*}$ from Eq. 13 and $A(\alpha, \beta)$ from Table 2). An examination of the failed joints showed that failure always initiated adhesively (on the interface) along a small segment of the specimen periphery.

Figure 20 plots the $\mathrm{K}_{\mathrm{ac}}$ data for the steel adherend joints ${ }^{50}$. The average value of $\mathrm{K}_{\mathrm{ac}}$ is 13.3 $\mathrm{MPa} \mathrm{mm}{ }^{0.30}$. Although there is moderate variability for each target bond thickness, $\mathrm{K}_{\mathrm{ac}}$ values do not vary in any systematic way with bond thickness (standard deviation/average $=13$ percent). This suggests that $\mathrm{K}_{\mathrm{ac}}$ is indeed a material property. Figure 21 plots the predicted variation in butt-joint strength with bond thickness when $\mathrm{K}_{\mathrm{ac}}=13.3 \mathrm{MPa} \mathrm{mm}{ }^{0.30}$ along with the underlying test data. The predicted relation is an excellent fit to the data.

Figure 22 plots the $\mathrm{K}_{\mathrm{ac}}$ data for the joints with aluminum adherends ${ }^{40}$. It is again apparent that the measured $\mathrm{K}_{\mathrm{ac}}$ values do not depend on bond thickness and can be considered a material property. The average value of $\mathrm{K}_{\mathrm{ac}}$ is $18.1 \mathrm{MPa} \mathrm{mm}{ }^{0.27}$, with a standard deviation/average ratio of 
8 percent. Figure 23 shows that the predicted variation in joint strength with bond thickness for a $\mathrm{K}_{\mathrm{ac}}$ value of $18.1 \mathrm{MPa} \mathrm{mm} \mathrm{mm}^{0.27}$ is a good fit to the underlying test data.

The applicability of the $\mathrm{K}_{\mathrm{ac}}$ criterion to a bond thickness as small as $0.25 \mathrm{~mm}$ implies that the fracture process zone must be rather small. As discussed earlier, the interface-corner stress singularity dominates a region along the interface that equals 15 per cent of the bond thickness in adhesively bonded butt joints. Consequently, when a bond is $0.25 \mathrm{~mm}$ thick, the interface singularity dominates a region extending about $40 \mu \mathrm{m}$ along the interface. This suggests that the yield zone and fracture process zone probably extend more than $10 \mu \mathrm{m}$ along the interface before rapid crack propagation initiates. Subcritical cracking must be small with respect to this distance, and corner sharp must appear sharp on this scale.

Effect of adherend stiffness. If an adhesively bonded butt joint fails at a fixed $K_{a c}$ value, then Eq. 8 (in conjunction with Eq. 13 for plane strain and Table 2) indicates that $\log (j o i n t$ strength) vs. $\log$ (bond thickness) is a straight line with a slope equal to the order of the stress singularity for that joint. Because of the difference in Young's modulus, the order of the stress singularity for steel adherends is -0.30 and is -0.27 for aluminum adherends (Table 2). Figure 24 compares test data plotted in Figures 21 and 23, except $\log$ (joint strength) is plotted versus $\log$ (bond thickness) ${ }^{40}$. A least-squares fit of the data for the joints with steel adherends has a slope of -0.33 , while the fit of the data for joints with aluminum adherends has a slope of -0.25 . Although variability in the strength data introduces some uncertainty in the measured strengthbond thickness relation, the difference in the measured joint strength-bond thickness relation for joints with aluminum and steel adherends seems to correlate with the difference in the order of the interface-corner stress singularity.

Variability in measured $K_{a c}$ and the effect of surface preparation. Data drawn from five separate test series were used to assess the reproducibility of $K_{a c}$ measurements and to examine the effect of surface preparation on $\mathrm{K}_{\mathrm{ac}}$ values ${ }^{51}$. Table 6 lists fabrication parameters for the five sets of adhesively bonded butt joints. All had 6061-T6 aluminum adherends, and they were fabricated and tested over a period of 15 months. The aluminum bonding surfaces of most joints were lightly sandblasted (60 grit alumina oxide at $40 \mathrm{psi}$ ), although the surfaces of some joints in Sets 1 and 2 were left in the as-machined condition to assess the effect of surface roughness. The roughness of the as-machined and sandblasted surfaces was measured with a noncontact, optical probe. Table 6 lists root mean square roughness, $R_{q}$, as defined in Surface 
Texture (ASME B46.1-1995). A long wavelength cutoff of $0.8 \mathrm{~mm}$ was used for as-machined surfaces, whereas a cutoff of $2.5 \mathrm{~mm}$ was used for sandblasted surfaces. The adherends were cleaned just prior to bonding. An aqueous alkaline solution (Brulin $815 \mathrm{GD}$ ) was used in most cases, although some plugs in Set 5 were solvent cleaned (trichloroethylene) to assess the effect of the method of cleaning. The same Epon 828/Jeffamine T-403 epoxy adhesive was used as in the studies discussed above, but here the adhesive was cured above room temperature, and the weight mix ratio of Epon 828 to Jeffamine T-403 was changed to 100:43. Set 1 was cured for 24 hours at $50^{\circ} \mathrm{C}$ followed by an additional 24 hours at $40^{\circ} \mathrm{C}$. This cure schedule was chosen to minimize residual stress. The epoxy's glass transition temperature is $68{ }^{\circ} \mathrm{C}$ (dielectric measurement technique). Note that Sets $2-5$ added an initial 24 hours at $28^{\circ} \mathrm{C}$ step to the cure schedule to simplify handling. This modification of the cure schedule has minimal effect on the epoxy's properties. Compression tests of molded epoxy plugs cured with and without the $28^{\circ} \mathrm{C}$ step yielded nearly identical stress-strain relations. All except one set of joints included joints of several different bond thicknesses (e.g., 0.25, 0.5, and $1.0 \mathrm{~mm}$ ).

Some variability in a toughness parameter like $\mathrm{K}_{\mathrm{ac}}$ is expected when measured using nominally identical specimens and test procedures. Variability can be caused by variations in the flaw population and by variations in material and interface properties. Variations in fabrication and test procedures could also contribute. Many steps are required to make a butt-joint specimen. For example, the alkaline aqueous cleaning procedure involves ten separate steps, and many of these steps are carefully timed. Furthermore, some processes, such as sandblasting, are not fully controlled. The operator of the sandblaster manually directs the grit stream across the adherend surface, and the grit can degrade or become contaminated with use. Table 7 shows $K_{a c}$ data for four sets of nominally identical joints fabricated over a period of eight months (all with sandblasted surfaces, cleaned using the alkaline aqueous method, and cured with the $28 / 50 / 40^{\circ} \mathrm{C}$ cure cycle). The coefficient of variation (standard deviation/average) of $\mathrm{K}_{\mathrm{ac}}$ for the joints in Sets 2, 3, 4 and 5 is $6,9,6$, and 8 percent, respectively. The variability of $K_{a c}$ in the sets with multiple bond thickness is no greater than sets with a single bond thickness. Table 7 shows that, in spite of possible variations in processing during the nine-month period when Sets 2-5 were fabricated, the measured $\mathrm{K}_{\mathrm{ac}}$ value for these sets is reasonably consistent. The average $\mathrm{K}_{\mathrm{ac}}$ value is $15.4 \mathrm{MPa}$ $\mathrm{mm}^{0.27}$, with Set 5 showing the largest deviation from the mean (10 percent). 
The time interval between the fabrication and testing of joints in Sets $2-5$ varied from 1 to 17 days. Since physical aging can cause polymer properties to change with time, differences in the fabrication-to-test time interval are a potential contributor to the measured variability in $\mathrm{K}_{\mathrm{ac}}$. This issue was addressed in Set 4 tests. Forty-one joints were fabricated at one time. One-half of the joints was tested the day following fabrication, whereas the other half was tested 14 days later. Table 8 shows that there is no discernable difference in the measured $\mathrm{K}_{\mathrm{ac}}$ for the two groups of joints. Physical aging of this epoxy adhesion does not appear to be a consideration for the cure cycle and time interval investigated.

The dependence of $\mathrm{K}_{\mathrm{ac}}$ on surface preparation was also studied. Both Set 1 and Set 2 contained joints with sandblasted $\left(\mathrm{R}_{q}=5 \mu \mathrm{m}\right)$ and as-machined $\left(\mathrm{R}_{q}=1 \mu \mathrm{m}\right)$ surfaces. Table 9 shows that $K_{a c}$ is strongly dependent on surface roughness. The measured $K_{a c}$ of Set 1 joints increased 36 percent when the as-machined surface was sandblasted. Set 2 joints showed an even greater increase in $K_{a c}$ ( 86 percent). It should be noted that, although the as-machined surfaces of the Set 1 and Set 2 adherends have similar $R_{q}$ values, the nature of the roughness is quite different. Set 1 plugs contain several sets of straight, parallel grooves. Each set of grooves covers the entire surface, but each set is rotated with respect to the others. The machining marks on Set 2 are concentric circles overlaid with short, arc-like scratches. Table 9 shows that the method of cleaning had only a modest effect on $\mathrm{K}_{\mathrm{ac}}$. Joints cleaned with the aqueous alkaline procedure have a 10 percent higher $\mathrm{K}_{\mathrm{ac}}$ than the joints cleaned with a solvent.

\section{Recent Studies (1998-2000).}

Epoxy wedge on aluminum substrate. An epoxy wedge cast onto an aluminum beam has been used to study the effect of wedge angle in two recent investigations. One study casts a 30 -mm-long by 10 -mm-high epoxy block at the clamped end of a 220 -mm-long, 3.2-mm-thick

cantilevered aluminum beam ${ }^{62,63}$. The side of the epoxy block opposite the clamped edge was wedge shaped. The wedge tip singularity for the three wedge angles tested---55 (an acute epoxy angle), $70^{\circ}$, and $90^{\circ}$---is characterized by a single $\mathrm{K}_{\mathrm{a}}$. Tests were carried out to measure the number of cycles required to initiate an interfacial fatigue crack for a range of applied $\mathrm{K}_{\mathrm{a}}$. These data were used to define a $\mathrm{K}_{\mathrm{a}}$-based fatigue initiation envelope. It is also noted that since plastic zone size is a strong function of the applied $\mathrm{K}_{\mathrm{a}}$, a $\mathrm{K}_{\mathrm{a}}$-based fatigue criterion may be applicable in cases where static joint strength is so high that $\mathrm{K}_{\mathrm{ac}}$ cannot be properly defined. 
The aim of another study was to formulate a crack nucleation criterion that is independent of wedge angle ${ }^{64}$. In these tests a $76-\mathrm{mm}$-long by 12.7 -mm-thick block of epoxy was cast on a 12.7-mm-thick aluminum beam. The aluminum beam was loaded in four-point bending. One side of the epoxy block was wedge shaped, and the following four epoxy wedge angles were considered: $0^{\circ}$ (interface crack), $45^{\circ}, 90^{\circ}$, and $135^{\circ}$. Note that this range of epoxy wedge angles include cases with complex singularities and multiple $\mathrm{K}_{\mathrm{a}}$. Moiré interferometry was used to make high-resolution displacement measurements near the wedge tip. These measurements indicated that the interface was compliant and suggested the use of a cohesive zone model. Parameters for the cohesive zone model were determined by matching the measured interface crack-tip displacements $\left(0^{\circ}\right.$ wedge). This fit reveals that the interface has a low toughness and a peak separation traction of only $3 \mathrm{MPa}$. Calculated results using this cohesive zone model reproduced the observed dependence of failure load on wedge angle.

Scarf joint. The $\mathrm{K}_{\mathrm{ac}}$ criterion has been applied to adhesively bonded scarf joints with three different scarf angles ${ }^{65}$. Joints with scarf angles of $0^{\circ}$ (i.e. adhesively bonded butt joint), $15^{\circ}$, and $30^{\circ}$ and with bond thickness that ranged from 0.4 to $2 \mathrm{~mm}$ were tested. The adherends were $2014 \mathrm{~A}-\mathrm{T} 4$ aluminum with a $10-\mathrm{mm}$ by $30-\mathrm{mm}$ rectangular cross section. Two types of adhesive were used. One adhesive was a brittle, high-temperature-cured epoxy (Ciba Geigy F922), while the other was a more ductile, room temperature cured epoxy (Ciba Geigy Araldite). Specimens bonded with the $\mathrm{F} 922$ epoxy were cured at either $160^{\circ} \mathrm{C}$ or $120^{\circ} \mathrm{C}$ to induce different levels of residual stress. It is assumed that the residual stress is associated with the temperature change from the cure temperature to room temperature $\left(\mathrm{T}_{\mathrm{g}}\right.$ data are not given). The $-100^{\circ} \mathrm{C}$ and $-140^{\circ} \mathrm{C}$ temperature changes generate a large fraction of the applied $\mathrm{K}_{\mathrm{a}}$. Indeed, it appears that the inferred residual stress contributes to 90 percent or more of the applied $\mathrm{K}_{\mathrm{a}}$ for the $160^{\circ} \mathrm{C}$ cured butt joints, and the contribution associated with the applied tensile load is on the same order as the reported standard deviation in the measured $\mathrm{K}_{\mathrm{ac}}$.

Glass/silicon anodic bonds. The $\mathrm{K}_{\mathrm{a}}$ criterion has been applied to anodic bonding, a common process in the wafer-level packaging of microelectromechanical systems ${ }^{66}$. Anodicbonded, glass/silicon test specimens with varying bond area were tested in bending. Fracture initiated at the silicon/glass interface corner on the tensile side of the specimen, and there was a significant variation in fracture stress with the bond area. The asymptotic interface-corner stress field for the sample geometry tested is characterized by two real power-law singularities: one has 
a strength of -0.497 (nearly as strong as that for a crack), and the other has a strength of -0.364 . The test results suggest that the observed variation in failure stress with bond area could be correlated using just the $\mathrm{K}_{\mathrm{a}}$ associated with the stronger singularity. As an aside, Dunn and his colleagues have also used a $\mathrm{K}_{\mathrm{a}}$-based approach to successfully predict the fracture of homogeneous materials containing a sharp notch when the material is isotropic ${ }^{67,68}$ and when the material is anisotropic ${ }^{69,70}$.

\section{Unresolved Issues}

Although the $\mathrm{K}_{\mathrm{ac}}$ criterion has been applied with some notable successes, there are still numerous unresolved issues. These include the development of methods for treating timedependent response, three-dimensional corners, and large-scale yielding, and the development of a criterion that can be applied when the corner stress state is not characterized by a single $K_{a}$. Furthermore, a clearly desirable goal is the development of an approach for calculating $\mathrm{K}_{\mathrm{ac}}$ from more fundamental quantities.

\section{A. Time Dependence and Residual Stress.}

Interface-corner stress intensity factors are defined within the context rate-independent, linear elasticity theory. It is tacitly assumed that multiple loads can be superimposed, regardless of their duration, and stress does not change with time. For example, residual stress in an adhesively bonded butt joint is assumed to persist indefinitely, even when residual stress is developed and sustained over a much longer time scale than that associated with applied loading. There are some test data that suggest that this assumption may not always be correct, especially when polymeric materials are involved ${ }^{61}$. Figure 25 plots characteristic stress (Eq. 8) vs. bond thickness data for three series of butt-joint tests. The characteristic stress includes contributions from both the applied load at failure and the estimated residual stress (assuming linear-elastic response). Test-Series-1 specimens were cured and tested at room temperature to minimize residual stress. Test-Series-2 and Series-3 specimens were tested at temperatures well below their cure temperatures to introduce residual stress during cooling. The joint specimens were then loaded in roughly 10 seconds. If the $\mathrm{K}_{\mathrm{ac}}$ criterion holds, the slope of each of the three lines in Figure 25 should be roughly $-1 / 3$, the strength of the stress singularity for a steel/epoxy butt joint. This is clearly not so. Interestingly, the anticipated behavior holds when the residual stress term is neglected (Figure 26). The reason why residual stress does not appear to contribute in the 
expected way is particularly puzzling for Series-3 test conditions since the magnitude of characteristic residual stress is comparable to the measured characteristic failure stress for a 1$\mathrm{mm}$-thick bond. These results seem to suggest that the residual stress generated during cooling from the cure temperature has little effect on joint strength.

Stress relaxation tests were carried out for the adhesive used in those butt joint tests ${ }^{61}$. This adhesive was found to display a highly nonlinear, stress-level-dependent viscoelasticity at stress levels approaching the adhesive's yield strength (Figure 27). Furthermore, significant stress relaxation was observed even at temperatures of more than $100^{\circ} \mathrm{C}$ below the adhesive's glass transition temperature Figure 28. These results indicate that the peak stress in an adhesive joint, in the yield zone at the interface corner where failure initiates, can decay significantly when given sufficient time. Note that it is not necessary that all residual stress in a bond relaxes out to affect bond strength; only the stress in the failure region is of importance. Consequently, it is possible that the first step (residual stress sustained over a long period of time) in this two-step loading process has little effect on the second loading step (mechanical load applied within 10s). The influence of residual stress on joint strength might be much less than would be predicted by a linear analysis.

\section{B. Large Scale Yieldińn.}

Many modern adhesives are toughened, and yield zones can be large compared to the region dominated by an interface-corner singularity. Attempts to extend an interface-corner-type analysis to ductile materials are still in their initial phase. Several recent studies have investigated the nature of the asymptotic, interface-corner stress field in a power-law-hardening material. Most of this work has concentrated on determining the strength of the stress singularity ${ }^{71-76}$, although there have been several studies where the associated stress intensity factor has also been determined for a limited range of loadings ${ }^{56,77.78}$. This type of analysis has yet to lead to an experimentally verified fracture criterion for bonded materials undergoing large-scale yielding.

\section{3D Interface Corners.}

Work to develop an interface-corner-based failure analysis has for the most part focused on planar or axisymmetric geometries. However, many configurations have three-dimensional corners (e.g., points on the interface between bonded rectangular parallelepipeds where two edges intersect), and failure can initiate at three-dimensional corners. The strength of the 
singular stress field surrounding a three-dimensional interface corner differs from that along an edge where often two-dimensional analysis can be applied ${ }^{32,79,80}$. Only recently has a failure analysis based upon the stress intensity associated with three-dimensional corner singularity been subjected to experimental validation ${ }^{80}$. Aluminum/epoxy butt joints with a square cross section and with edge lengths of $4,6.2,8.9,12.5$, and $17.8 \mathrm{~mm}$ were tested in four-point bending. The beam's square cross section was aligned to either subject a three-dimensional corner to the highest bending stress, or when rotated $45^{\circ}$, to subject an interface edge to the highest bending stress. The theoretical values for the strength of the stress singularity $(-0.35$ for threedimensional, and -0.28 for two-dimensional) are in good agreement with those inferred from the tests $(-0.33$ for three-dimensional, and -0.27 for two-dimensional).

\section{Fracture Criterion When Corner Stresses Are Not Characterized By A Single $\mathrm{K}_{\mathrm{a}}$.}

Although there are many instances where the interface-corner stress state is fully characterized by a single $\mathrm{K}_{\mathrm{a}}$, there are others where it is not. For example, consider the case of a thin, elastic layer on a rigid substrate (Figure 1 , with adherend 1 rigid and $2 L>>h_{2}$ ). There is one power-law stress singularity with a real exponent in this case, and $\mathrm{K}_{\mathrm{a}}$ is defined by Eq. 8, in conjunction with $\sigma^{*}$ from Eq. 12 and $A(1, \beta)$ from Table 1. There is also an r-independent stress term for uniform cooling (Eq. 3). Figure 29 compares plane-stress, finite element results for interfacial normal stress with asymptotic results where either the $r$-independent term is or is not included $\left(h_{2}=1 \mathrm{~mm}, E=4.0 \mathrm{GPa}, v=0.25, E \alpha \Delta \mathrm{T}=-6.5 \mathrm{MPa}, \sigma_{y}=70 \mathrm{MPa}\right)$. There is a marked difference in the two asymptotic solutions at a physically significant distance of a micron or greater. Only when the r-independent term is included in the asymptotic solution is the interfacial normal stress in good agreement with the full, finite element solution over any appreciable distance ( $\sim 5$ percent of the layer thickness). This clearly suggests that for such cases, an interface-corner fracture criterion must involve both $K_{a}$ and the stress intensity $K_{a 0}$ associated with the $\mathrm{r}$-independent term. One could envision an experimentally measured failure criterion that depends on both $\mathrm{K}_{\mathrm{a}}$ and $\mathrm{K}_{\mathrm{a} 0}$, but that would add substantial complexity to the theory and greatly increase the number of tests required to define the failure criterion. It would be preferable if the failure criterion were a physically meaningful scalar quantity that could be easily computed from $\mathrm{K}_{\mathrm{a}}$ and $\mathrm{K}_{\mathrm{a} 0}$ values. For example, Figure 29 shows that a nearly constant cleavage stress with a magnitude of $\sim \sigma_{y}$ is generated over the portion of the interface where yielding occurs ( $1.5 \sigma_{y}$ in 
plane strain). If failure occurs whenever a certain length of interface is subjected to this cleavage stress, then a critical length of the interfacial yield zone is a potential failure criterion. For specified values of $\mathrm{K}_{\mathrm{a}}$ and $\mathrm{K}_{\mathrm{a} 0}$, the length of the interfacial yield zone can be estimated using the known form of the asymptotic stress distribution.

\section{E. Connection between $\mathbf{K}_{\mathrm{ac}}$ and more fundamental properties.}

$\mathrm{K}_{\mathrm{ac}}$ is a measured quantity. Its value will depend on the type of interface corner (e.g., butt joint vs. embedded inclusion), wedge angles, properties of the bonded materials, surface preparation (e.g., smooth or rough), loading rate, temperature, environment, and so on. Similar dependencies occur for other types of fracture toughness parameters. A clearly desirable goal would be the development of an approach for calculating $\mathrm{K}_{\mathrm{ac}}$ from more fundamental quantities. In this way some of the stated dependencies could be determined without recourse to measurement. It is unlikely that such a goal will be fully achieved in the near future. An approach that uses a cohesive zone model does appear to hold some promise ${ }^{64}$. Nevertheless, to be successful, one must know much more about failure mechanisms and constitutive behavior at large strains than is currently known. In fact, one of the advantages of the $\mathrm{K}_{\mathrm{ac}}$ criterion, when applicable, is that it can be applied without detailed information about the failure process itself.

\section{Conclusions}

There has been considerable progress in recent years towards developing a stress intensity factor-based method for predicting crack initiation at a sharp, bimaterial corner. There is now a comprehensive understanding of the nature of multi-material, two-dimensional, linearelastic, wedge-tip stress fields. In general, the asymptotic stress state at the apex of dissimilar bonded elastic wedges (i.e. at an interface corner) can have one or more power-law singularities of differing strength and with exponents that can be real or complex. There are, however, many configurations of practical importance, (e.g. adhesively bonded butt joints, bi-material beams, etc.) where interface-corner stresses are described by one, real-valued power-law singularity. In such cases, one can reasonably hypothesize that failure occurs at a critical value of the stress intensity factor: when $K_{a}=K_{a c}$. This approach is completely analogous to LEFM except that the critical stress intensity factor is associated with a discontinuity other than a crack. To apply the $\mathrm{K}_{\mathrm{ac}}$ criterion, one must be able to accurately calculate $\mathrm{K}_{\mathrm{a}}$ for arbitrary geometries. There are several well-established methods for calculating $K_{a}$. These include matching asymptotic and 
detailed finite element results, evaluation of a path-independent contour integral, and general finite element methods for calculating $\mathrm{K}_{\mathrm{a}}$ for complex geometries. A rapidly expanding catalog of $K_{a}$ calibrations is now available for a number of geometries of practical interest. These calibrations provide convenient formulas that can be used in a failure analysis without recourse to a detailed numerical analysis.

The $\mathrm{K}_{\mathrm{ac}}$ criterion has been applied with some notable successes. For example, the variation in strength of adhesively bonded butt joints with bond thickness and the dependence of this relationship on adherend stiffness is readily explained. No other one-parameter fracture criterion is able to make this sort of prediction. Nevertheless, the interface-corner fracture toughness approach is just in its initial states of development, and its strengths and limitations must be more clearly defined. There are still numerous issues yet to be resolved, including the development of methods for treating time-dependent response, three-dimensional corners, largescale yielding, and the development of a criterion that can be applied when the corner stress state is not characterized by a single $\mathrm{K}_{\mathrm{a}}$. 


\section{References}

(1) Hart-Smith, L. J. In Joining of Composite Materials, ASTM STP 749; Kedward, K. T., Ed.; American Society for Testing and Materials: Philadelphia, 1981; pp 3-31.

(2) Adams, R. D.; Wake, W. C. Structural Adhesive Joints in Engineering; Elsevier Applied Science Publishers: London and New York, 1984.

(3) Liechti, K. M. In Adhesives and Sealanats; Dostal, C. A., Ed.; ASM International, 1990; Vol. 3, pp 335-348.

(4) Hutchinson, J. W.; Suo, Z. In;, 1992; Vol. 29, pp 63-191.

(5) Anderson, G. P.; DeVries, K. L. International Journal of Fracture 1989, 39, 191200.

(6) Bogy, D. B. Journal of Applied Mechanics 1968, 35, 460-466.

(7) Bogy, D. B. International Journal of Solids and Structures 1970, 6, 1287-1313.

(8) Williams, M. L. Journal of Applied Mechanics 1952, 19, 526-528.

(9) Bogy, D. B. Journal of Applied Mechanics 1971, 38, 377-386.

(10) Hein, V. L.; Erdogan, F. International Journal of Fracture 1971, 7, 317-330.

(11) Chen, D. H.; Nisitani, H. Journal of Applied Mechanics 1993, 60, 607-613.

(12) Gradin, P. A. Journal of Composite Materials 1982, 16, 448-456.

(13) Groth, H. L. International Journal of Adhesion and Adhesives 1988, 8, 107-113.

(14) Hattori, T.; Sakata, S.; Murakami, G. Journal of Electronic Packaging 1989, 111, 243-248.

(15) Munz, D.; Yang, Y. Y. Journal of Applied Mechanics 1992, 59, 857-861.

(16) Reedy, E. D., Jr. Engineering Fracture Mechanics 1990, 36, 575-583:

(17) Chen, D.-H. International Journal of Fracture 1996, 75, 357-378.

(18) Dempsey, J. P. Journal of Adhesion Science and Technology 1995, 9, 253-265.

(19) Munz, D.; Yang, Y. Y. International Journal of Fracture 1993, 60, 169-177.

(20) Reedy, E. D., Jr. International Journal of Solids and Structures 1993, 30, 767777.

(21) Yang, Y. Y. Archive of Applied Mechanics 1999, 69, 364-378.

(22) Munz, D.; Fett, T.; Yang, Y. Y. Engineering Fracture Mechanics 1993, 44, 185194. 
(23) Yang, Y. Y.; Munz, D. International Journal of Solids and Structures 1997, 34, 1199-1216.

(24) Liu, X. H.; Suo, Z.; Ma, Q. Acta Materialia 1999, 47, 67-76.

(25) Banks-Sills, L. International Journal of Fracture 1997, 86, 385-398.

(26) Yang, Y. Y.; Munz, D. Computers \& Structures 1995, 57, 467-476.

(27) Carpenter, W. C. International Journal of Fracture 1984, 24, 45-58.

(28) Sinclair, G. B.; Okajima, M.; Griffin, J. H. International Journal for Numerical Methods in Engineering 1984, 20, 999-1008.

(29) Stern, M.; Becker, E. B.; Dunham, R. S. International Joumal of Fracture 1976, $12,359-368$.

(30) Carpenter, W. C.; Byers, C. International Journal of Fracture 1987, 35, 245-268.

(31) Akisanya, A. R.; Fleck, N. A. International Journal of Solids and Structures $1997,34,1645-1665$.

(32) Pageau, S. S.; Biggers, S. B., Jr. International Journal for Numerical Methods in Engineering 1995, 38, 2225-2239.

(33) Pageau, S. S.; Biggers, S. B., Jr. International Journal for Numerical Methods in Engineering 1997, 40, 2693-2713.

(34) Szabó, B. A.; Yosibash, Z. International Journal for Numerical Methods in Engineering 1996, 39, 409-434.

(35) Yosibash, Z.; Szabó, B. A. International Journal for Numerical Methods in Engineering 1995, 38, 2055-2082.

(36) Dundurs, J. Journal of Applied Mechanics 1969, 36, 650-652.

(37) Reedy, E. D., Jr. Engineering Fracture Mechanics 1991, 38, 273-281.

(38) Ding, S.; Meekisho, L.; Kumosa, M. Engineering Fracture Mechanics 1994, 49, 569-585.

(39) Wang, C. H.; Rose, L. R. F. International Journal of Adhesion and Adhesives 2000, 20, 145-154.

(40) Reedy, E. D., Jr.; Guess, T. R. International Journal of Fracture 1997, 88, 305314.

(41) Akisanya, A. R. Journal of Strain Analysis for Engineering Design 1997, 32.

(42) Tilscher, M.; Munz, D.; Yang, Y. Y. Journal of Adhesion 1995, 49, 1-21. 
(43) Fett, T. Engineering Fracture Mechanics 1998, 59, 29-45.

(44) Liu, D.; Fleck, N. A. International Journal of Fracture 1999, 95, 67-88.

(45) Klingbeil, N. W.; Beuth, J. L. Engineering Fracture Mechanics 2000, 66, 93-110.

(46) Reedy, E. D., Jr.; Guess, T. R. International Journal of Solids and Structures in press.

(47) Chen, D. H. Engineering Fracture Mechanics 1994, 49, 533-546.

(48) Kanninen, M. F.; Popelar, C. H. Advanced Fracture Mechanics; Oxford University Press: New York, 1985.

(49) Kinloch, A. J.; Young, R. J. Fracture Behavior of Polymers; Applied Science Publishers: New York, 1983.

(50) Reedy, E. D., Jr.; Guess, T. R. International Journal of Solids and Structures 1993, 30, 2929-2936.

(51) Reedy, E. D., Jr.; Guess, T. R. International Journal of Fracture 1999, 98, L3-L8.

(52) Lindsay, G. H. Journal of Applied Physics 1967, 38, 4843-4852.

(53) Anderson, G. P.; DeVries, K. L.; Sharon, G. In Delamination and Debonding of Materials, ASTM STP 876; Johnson, W. S., Ed.; American Society for Testing and Materials: Philadelphia, 1985; pp 115-134.

(54) Lai, Y.-H.; Dillard, D. A.; Thornton, J. S. Journal of Applied Mechanics 1992, 59.

(55) Reedy, E. D., Jr. International Journal of Solids and Structures 2000, 37, 2429 2442

(56) Reedy, E. D., Jr.; Guess, T. R. International Journal of Fracture 1996, 81, 269282.

(57) Grenestedt, J. L.; Hallstrom, S. Journal of Applied Mechanics 1997, 64, 811-818.

(58) Rice, J. R. Journal of Applied Mechanics 1988, 55, 98-103.

(59) Rice, J. R. Journal of Applied Mechanics 1968, 35, 379-386.

(60) Reedy, E. D., Jr.; Guess, T. R. Journal of Adhesion Science and Technology 1995, 9, 237-251.

(61) Reedy, E. D., Jr.; Guess, T. R. Journal of Adhesion Science and Technology 1996, $10,33-45$.

(62) Lefebvre, D. R.; Dillard, D. A. Journal of Adhesion 1999, 70, 119-138.

(63) Lefebvre, D. R.; Dillard, D. A. Journal of Adhesion 1999, 70, 139-154. 
(64) Mohammed, I.; Liechti, K. M. Journal of the Mechanics and Physics of Solids $2000,48,735-764$.

(65) Qian, Z.; Akisanya, A. R. Acta Materialia 1998, 46, 4895-4904.

(66) Dunn, M. L.; Cunningham, S. J.; Labossiere, P. E. W. Acta Materialia 2000, 48, 735-744.

(67) Dunn, M. L.; Suwito, W.; Cunningham, S. International Joumal of Solids and Structures 1997, 34, 3873-3883.

(68) Dunn, M. L.; Suwito, W.; Cunningham, S.; May, C. W. International Joumal of Fracture 1997, 84, 367-381.

(69) Suwito, W.; Dunn, M. L.; Cunningham, S. Journal of Applied Physics 1998, 83, 3574-3582.

(70) Suwito, W.; Dunn, M. L.; Cunningham, S.; Read, D. T. Journal of Applied Physics 1999, 85, 3519-3534.

(71) Duva, J. M. Journal of Applied Mechanics 1988, 55, 361-364.

(72) Duva, J. M. Journal of Applied Mechanics 1989, 56.

(73) Lau, C. W.; Delale, F. Journal of Engineering Materials and Technology 1988, II0, 41-47.

(74) Rudge, M. R. H. International Joumal of Fracture 1993, 63, 21-26.

(75) Zhang, N. S.; Joseph, P. F. International Journal of Fracture 1998, 94, 299-319.

(76) Zhang, N. S.; Joseph, P. F. International Journal of Fracture 1998, 90, 175-207.

(77) Reedy, E. D., Jr. Journal of Applied Mechanics 1993, 60, 715-720.

(78) Sckuhr, M. A.; Brueckner-Foit, A.; Munz, D.; Yang, Y. Y. International Journal of Fracture 1996, 77, 263-279.

(79) Koguchi, H. International Journal of Solids and Structures 1997, 34, 461-480.

(80) Labossiere, P. E. W.; Dunn, M. L. Journal of the Mechanics and Physics of Solids in press. 
Table 1. Nondimensional functions $A(1, \beta)$ used in the $K_{a}$ calibration for a butt joint with a thin adhesive layer and rigid adherends, and also for a thin layer on a rigid substrate.

\begin{tabular}{cccccc}
\hline$v^{1}$ & $\beta$ & $1-\lambda$ & $\begin{array}{c}\text { Butt joint loaded in } \\
\text { transverse tension } \\
\text { or by uniform } \Delta \mathrm{T} \\
\mathrm{A}(1, \beta)\end{array}$ & $\begin{array}{c}\text { Butt joint loaded in } \\
\text { shear }\end{array}$ & $\begin{array}{c}\text { Layer on substrate } \\
\text { loaded by uniform } \\
\Delta \mathrm{T}\end{array}$ \\
\hline 0.05 & 0.474 & 0.077 & 14.7 & $\mathrm{~A}(1, \beta)$ & $\mathrm{A}(1, \beta)$ \\
0.10 & 0.444 & 0.133 & 6.63 & 2.57 & 15.7 \\
0.15 & 0.412 & 0.179 & 3.96 & 2.05 & 6.89 \\
0.20 & 0.375 & 0.219 & 2.63 & 1.73 & 4.13 \\
0.25 & 0.333 & 0.255 & 1.84 & 1.51 & 2.82 \\
0.30 & 0.286 & 0.289 & 1.32 & 1.34 & 2.06 \\
0.35 & 0.231 & 0.320 & 0.958 & 1.21 & 1.57 \\
0.40 & 0.167 & 0.350 & 0.654 & 1.10 & 1.23 \\
0.45 & 0.091 & 0.378 & 0.391 & 1.01 & 0.99 \\
\hline
\end{tabular}

${ }^{1}$ Plane strain 
. Table 2. Nondimensional function $A(\alpha, \beta)$ used in the $K_{a}$ calibration for a butt joint with a thin adhesive layer and finite stiffness adherends.

\begin{tabular}{lcccc}
\hline & $\alpha$ & $\beta$ & $1-\lambda$ & $\mathrm{A}(\alpha, \beta)$ \\
\hline Rigid/Epoxy & 1.000 & 0.231 & 0.320 & 0.958 \\
Steel/Epoxy & 0.966 & 0.222 & 0.302 & 0.989 \\
Aluminum/Epoxy & 0.902 & 0.207 & 0.268 & 1.061 \\
\hline
\end{tabular}


Table 3 . Nondimensional $A(1, \beta)$ function used in the $K_{a}$ calibration for a rigid square inclusion embedded in a thin, epoxy disk.

\begin{tabular}{lccrcccc}
\hline Interface & $v^{1}$ & $\beta$ & \multicolumn{1}{c}{$\mathrm{D} / \mathrm{h}$} & \multicolumn{1}{c}{$\lambda-1$} & $\bar{\sigma}_{\mathrm{rr}}\left(0^{\mathrm{O}}\right)$ & $\bar{\sigma}_{\theta \theta}\left(0^{\mathrm{O}}\right)$ & $\mathrm{A}(1, \beta)$ \\
\hline Bonded & 0.35 & 0.231 & 7.07 & -0.250 & -63.25 & 1.00 & 0.0135 \\
Unbonded & 0.05 & 0.475 & 14.14 & -0.667 & -1.00 & 1.00 & 0.1779 \\
Unbonded & 0.15 & 0.425 & 14.14 & -0.667 & -1.00 & 1.00 & 0.1455 \\
Unbonded & 0.25 & 0.375 & 14.14 & -0.667 & -1.00 & 1.00 & 0.1182 \\
Unbonded & 0.35 & 0.325 & 14.14 & -0.667 & -1.00 & 1.00 & 0.0949 \\
Unbonded & 0.45 & 0.275 & 14.14 & -0.667 & -1.00 & 1.00 & 0.0748 \\
Unbonded & 0.35 & 0.325 & 7.07 & -0.667 & -1.00 & 1.00 & 0.0940 \\
Unbonded & 0.35 & 0.325 & 5.66 & -0.667 & -1.00 & 1.00 & 0.0935 \\
Unbonded & 0.35 & 0.325 & 4.71 & -0.667 & -1.00 & 1.00 & 0.0927 \\
Unbonded & 0.35 & 0.325 & 3.54 & -0.667 & -1.00 & 1.00 & 0.0910 \\
Unbonded & 0.35 & 0.325 & 2.83 & -0.667 & -1.00 & 1.00 & 0.0886 \\
Unbonded & 0.35 & 0.325 & 2.18 & -0.667 & -1.00 & 1.00 & 0.0831 \\
\hline
\end{tabular}

${ }^{1}$ Plane stress 
Table 4. Parameters defining the small-scale cracking solution when the asymptotic solution is a quarter plane with one edge fixed and the other edge stress free (Figure 2).

\begin{tabular}{cccc}
\hline$v$ & $\beta$ & $\mathrm{D}(1, \beta)$ & $\begin{array}{c}\hat{\psi}_{r=a} \\
\text { (degrees) }\end{array}$ \\
\hline 0.05 & 0.474 & 4.26 & -12.3 \\
0.10 & 0.444 & 4.51 & -13.5 \\
0.15 & 0.412 & 4.75 & -14.4 \\
0.20 & 0.375 & 5.00 & $-15: 1$ \\
0.25 & 0.333 & 5.26 & -15.7 \\
0.30 & 0.286 & 5.55 & -16.2 \\
0.35 & 0.231 & 5.89 & -16.5 \\
0.40 & 0.167 & 6.30 & -16.7 \\
0.45 & 0.091 & 6.81 & -16.7 \\
\hline
\end{tabular}


Table 5. Fabrication parameters for two sets of adhesively boned butt joint, one with stainless steel adherends and one with aluminum adherends.

\begin{tabular}{|c|c|c|}
\hline & SS Test Series & AL Test Series \\
\hline $\begin{array}{l}\text { Adherends } \\
\text { Surface } \\
\text { Preparation }\end{array}$ & $\begin{array}{l}303 \text { Stainless Steel } \\
\text { Sandblasted } \\
\text { Cleaned } \\
\text { Passivated at RT using } \\
\text { sodium dichromate/nitric acid }\end{array}$ & $\begin{array}{l}6061 \text { T6 Aluminum } \\
\text { Sandblasted } \\
\text { Cleaned }\end{array}$ \\
\hline Adhesive & $\begin{array}{l}\text { Shell Epon } 828 \text { epoxy resin } \\
\text { Huntsman T } 403 \text { hardener } \\
\text { 100/36 weight ratio }\end{array}$ & $\begin{array}{l}\text { Shell Epon } 828 \text { epoxy resin } \\
\text { Huntsman T } 403 \text { hardener } \\
\text { 100/36 weight ratio }\end{array}$ \\
\hline Cure Schedule & $\mathrm{RT}>7$ days & $\begin{array}{l}28^{\circ} \mathrm{C} \text { for minimum of } 1 \text { day } \\
\text { then stored at } \mathrm{RT} \\
>7 \text { days before test }\end{array}$ \\
\hline
\end{tabular}


Table 6. Fabrication parameters for five different sets of adhesively bonded butt joints.

\begin{tabular}{cccccc}
\hline Set & $\begin{array}{c}\text { Surface } \\
\text { Roughness } \\
\mathrm{R}_{\mathrm{q}}(\mu \mathrm{m})\end{array}$ & Cleaning Method & $\begin{array}{c}\text { Cure } \\
\mathrm{Cycle}^{1} \\
\left({ }^{\circ} \mathrm{C}\right)\end{array}$ & $\begin{array}{c}\text { Bond } \\
\text { Thickness } \\
(\mathrm{mm})\end{array}$ & $\begin{array}{c}\text { Number } \\
\text { Joints }\end{array}$ \\
\hline 1 & 1 & Aqueous Alkaline & $50 / 40$ & $0.2 / 0.5 / 1.0$ & 27 \\
\hline 2 & 5 & & & 0.5 & 9 \\
\hline 3 & 5 & Aqueous Alkaline & $28 / 50 / 40$ & $0.3 / 0.5 / 1.0$ & 20 \\
\hline 4 & 5 & Aqueous Alkaline & $28 / 50 / 40$ & 0.5 & 7 \\
\hline 5 & 5 & Aqueous Alkaline & $28 / 50 / 40$ & $0.3 / 0.5 / 1.0$ & 41 \\
\hline \multirow{5}{*}{ Aqueous Alkaline } & $28 / 50 / 40$ & $0.3 / 0.5 / 1.0$ & 12 \\
\hline
\end{tabular}

${ }^{1}$ Held 24 hours at each temperature. 
Table 7. Variability in $\mathrm{K}_{\mathrm{ac}}$ when measured using nominally identical specimens and test procedures.

\begin{tabular}{cccccc}
\hline Set & $\begin{array}{c}\text { Date } \\
\text { Fabricated }\end{array}$ & $\begin{array}{c}\text { Nominal Bond } \\
\text { Thickness } \\
(\mathrm{mm})\end{array}$ & $\begin{array}{c}\text { Joints } \\
\text { Tested }\end{array}$ & $\begin{array}{c}\mathrm{K}_{\mathrm{ac}} \\
\left(\mathrm{MPa} \mathrm{mm}{ }^{0.27}\right)\end{array}$ & $\begin{array}{c}\text { Standard } \\
\text { Deviation } \\
\left(\mathrm{MPa} \mathrm{mm}^{0.27}\right)\end{array}$ \\
\hline 2 & $4 / 98$ & 0.5 & 7 & 14.9 & 0.9 \\
3 & $6 / 98$ & 0.6 & 10 & 15.5 & 1.4 \\
4 & $10 / 98$ & $0.3 / 0.5 / 1.0^{1}$ & 41 & 14.4 & 0.9 \\
5 & $12 / 98$ & $0.3 / 0.5 / 1.0^{1}$ & 12 & 16.9 & 1.3 \\
\hline
\end{tabular}

${ }^{1}$ Approximately equal number of samples of each thickness tested. 
Table 8. Variability in $\mathrm{K}_{\mathrm{ac}}$ with time interval between fabrication and test (Set 4).

\begin{tabular}{ccccc}
\hline $\begin{array}{c}\text { Days Between } \\
\text { Fabrication } \\
\text { and Test }\end{array}$ & $\begin{array}{c}\text { Nominal Bond } \\
\text { Thickness } \\
(\mathrm{mm})\end{array}$ & $\begin{array}{c}\text { Joints } \\
\text { Tested }\end{array}$ & $\begin{array}{c}\mathrm{K}_{\mathrm{ac}} \\
\left(\mathrm{MPa} \mathrm{mm}^{0.27}\right)\end{array}$ & $\begin{array}{c}\text { Standard } \\
\text { Deviation } \\
\left(\mathrm{MPa} \mathrm{mm}^{0.27}\right)\end{array}$ \\
\hline 1 & $0.3 / 0.5 / 1.0^{1}$ & 20 & 14.4 & 1.0 \\
14 & $0.3 / 0.5 / 1.0^{1}$ & 21 & 14.5 & 0.9 \\
\hline
\end{tabular}


Table 9. Sensitivity of $\mathrm{K}_{\mathrm{ac}}$ to surface preparation.

\begin{tabular}{cccccc}
\hline Set & Cleaning Method & $\begin{array}{c}\text { Surface } \\
\text { Roughness } \\
\mathrm{R}_{\mathrm{q}}(\mu \mathrm{m})\end{array}$ & $\begin{array}{c}\text { Joints } \\
\text { Tested }\end{array}$ & $\begin{array}{c}\mathrm{K}_{\mathrm{ac}} \\
\left(\mathrm{MPa} \mathrm{mm}^{0.27}\right)\end{array}$ & $\begin{array}{c}\text { Standard } \\
\text { Deviation } \\
\left(\mathrm{MPa} \mathrm{mm}^{0.27}\right)\end{array}$ \\
\hline \multirow{2}{*}{1} & Aqueous Alkaline & 1 & 27 & 12.9 & 1.1 \\
\hline \multirow{2}{*}{2} & Aqueous Alkaline & 5 & 9 & 17.6 & 1.7 \\
\hline \multirow{2}{*}{5} & Aqueous Alkaline & 1 & 20 & 8.0 & 0.7 \\
& Aqueous Alkaline & 5 & 7 & 14.9 & 0.9 \\
\hline
\end{tabular}




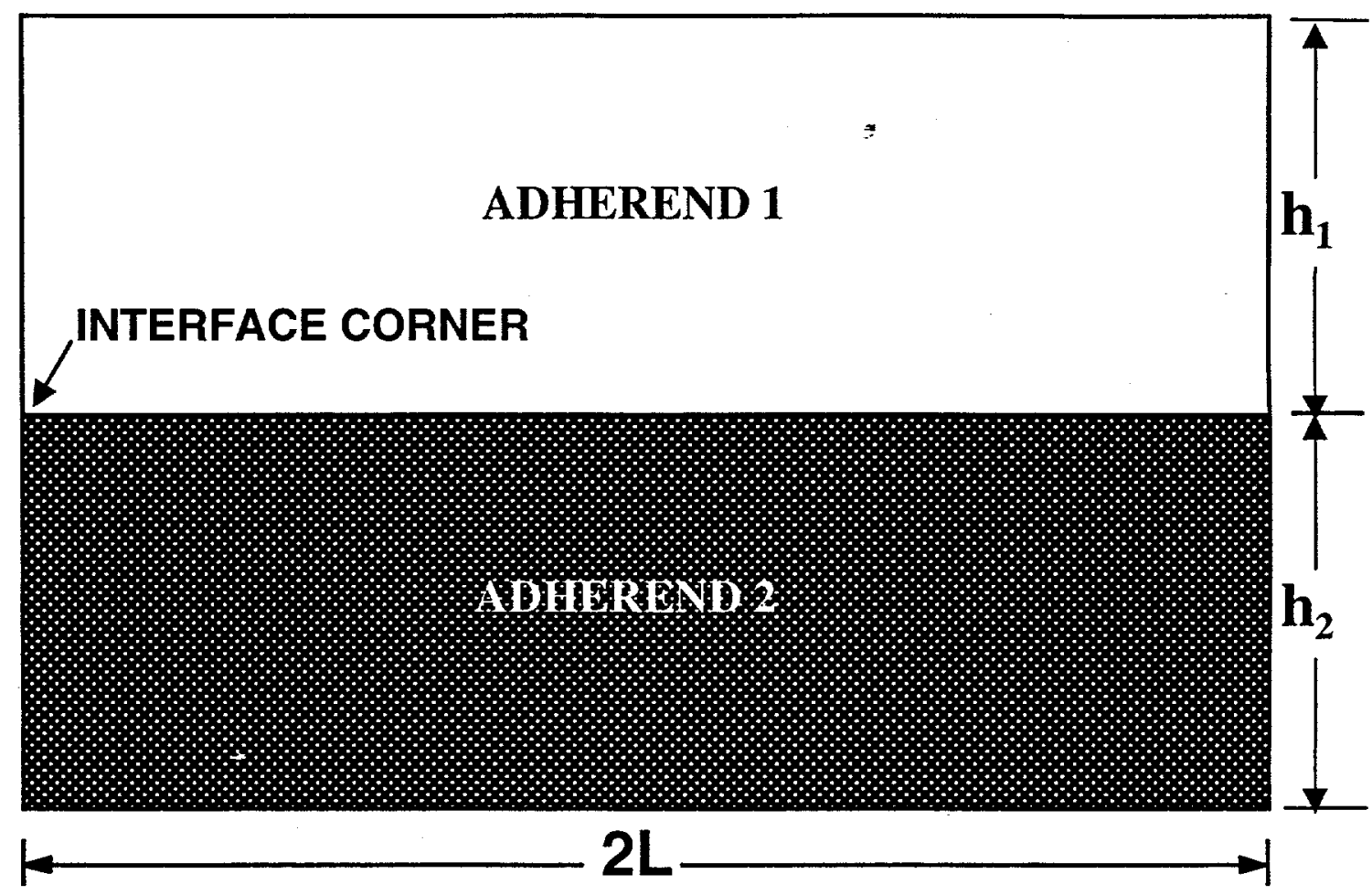

Figure 1. Conventions used to define the butt-joint geometry. 


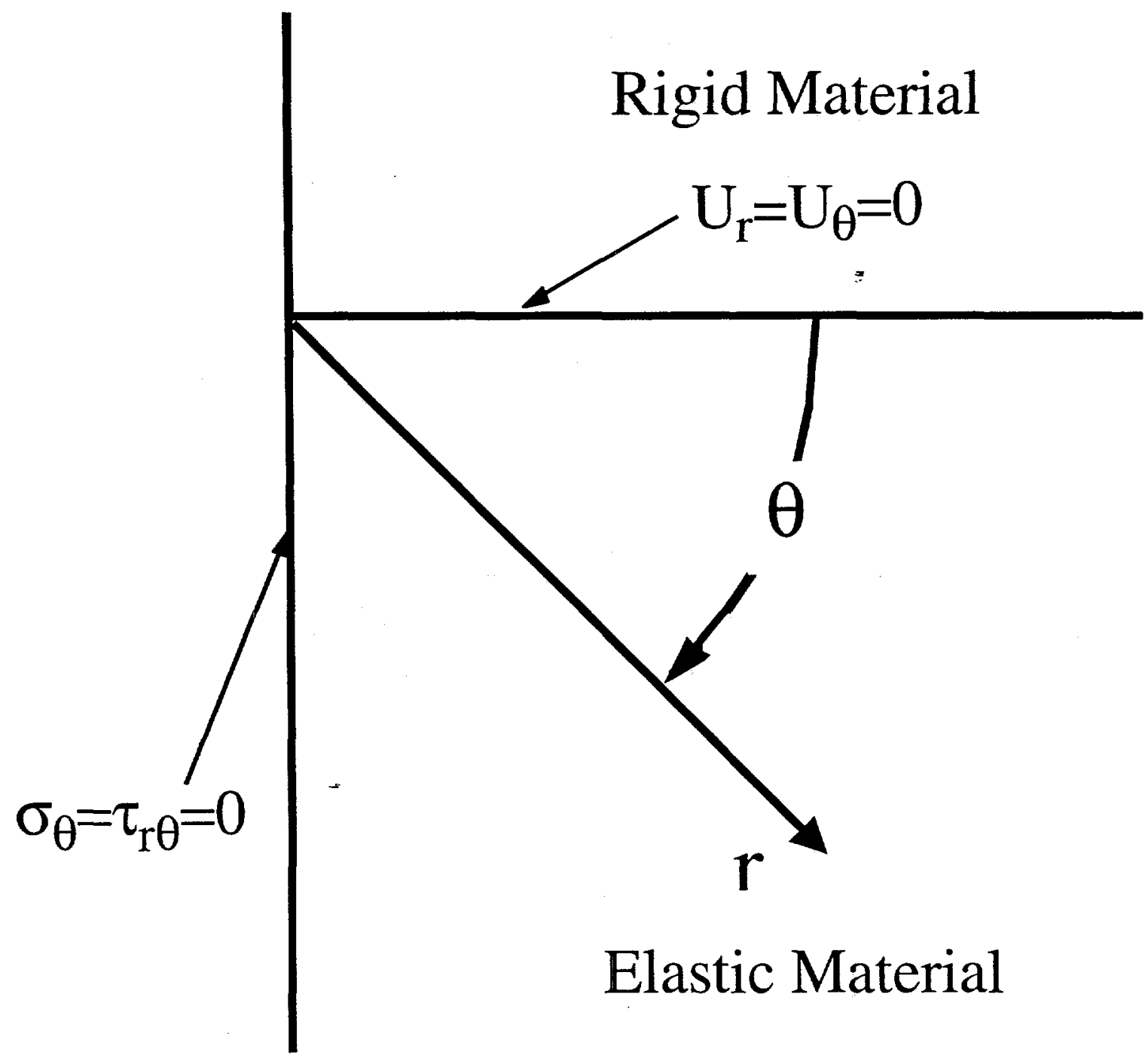

Figure 2. Asymptotic problem for a butt joint with a rigid adherend. Note: the elastic material's stress-free edge is at $\theta=-\pi / 2$. 


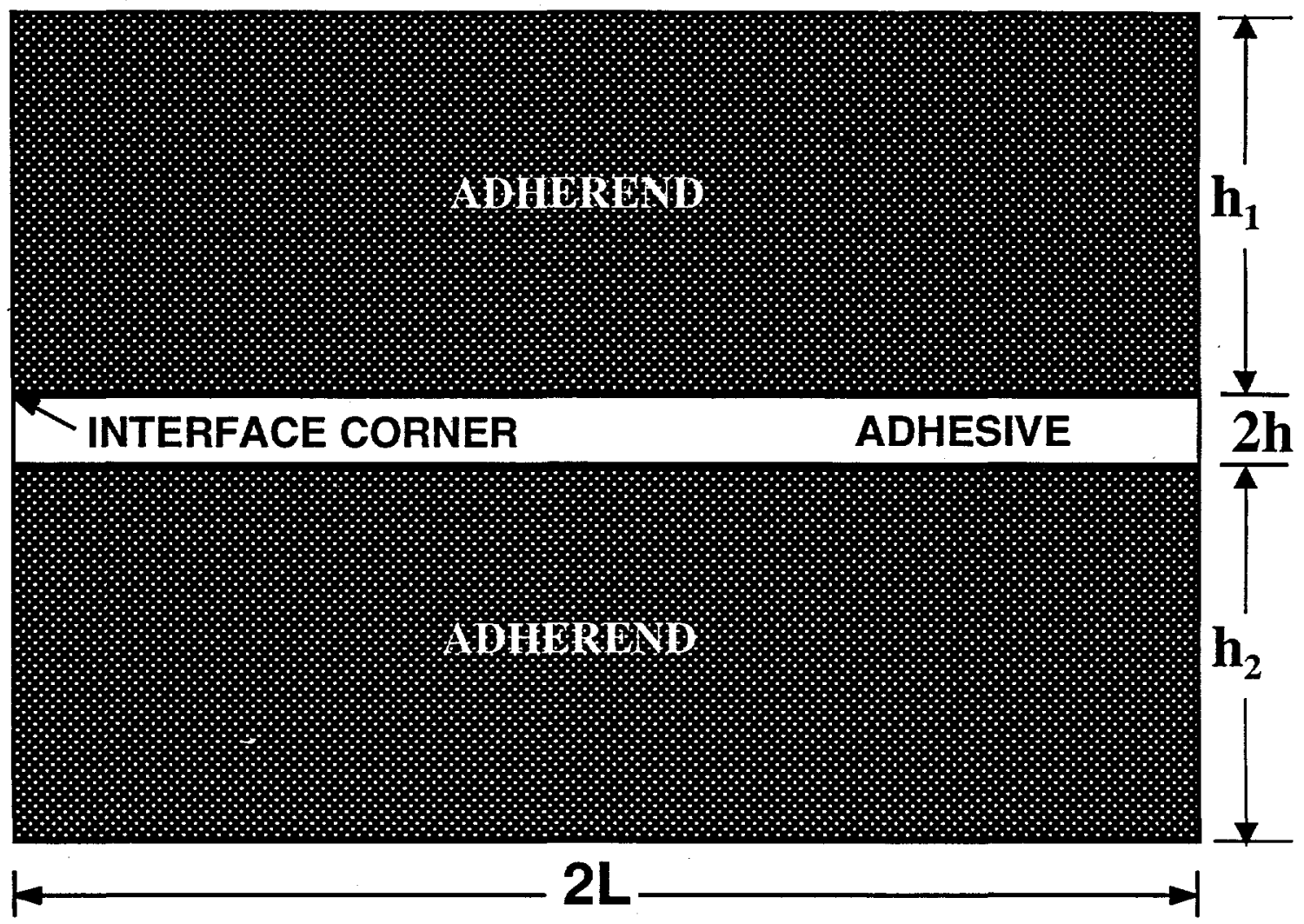

Figure 3. Conventions used to define the adhesively bonded butt joint geometry. 


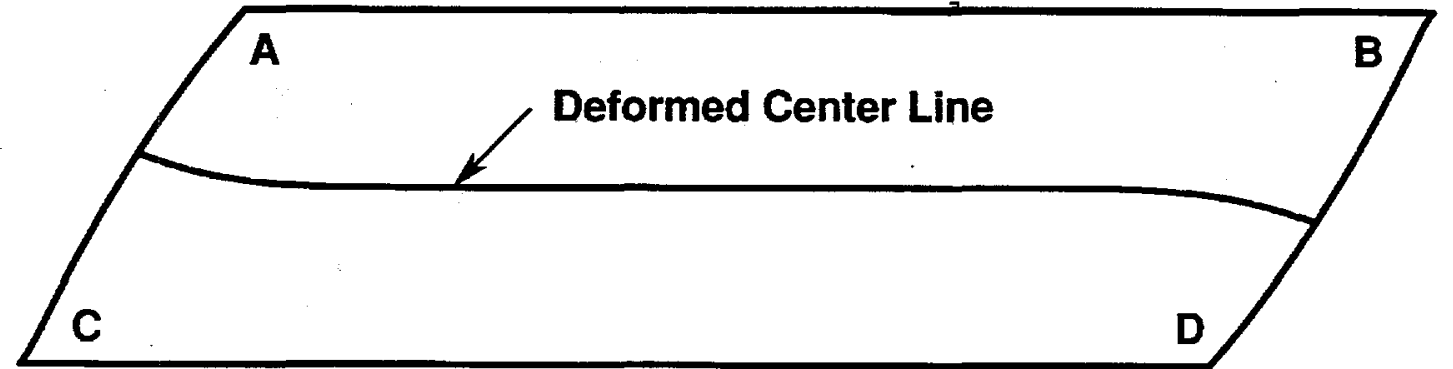

Figure 4. Deformed shape of the elastic layer in an adhesively bonded butt joint with rigid adherends when subjected to a positive-shear loading. 


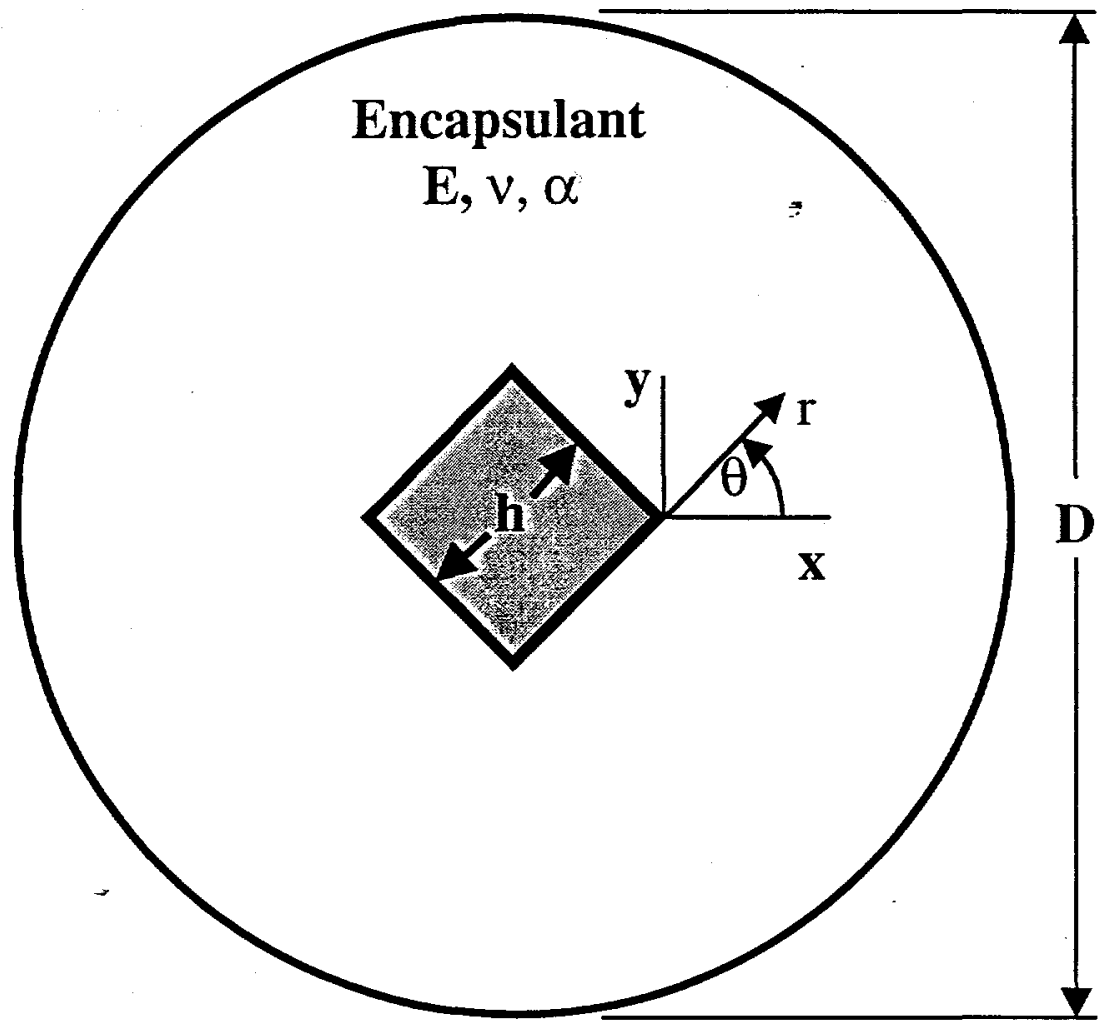

Figure 5. Rigid, square inclusion encapsulated within a linear-elastic disk. 


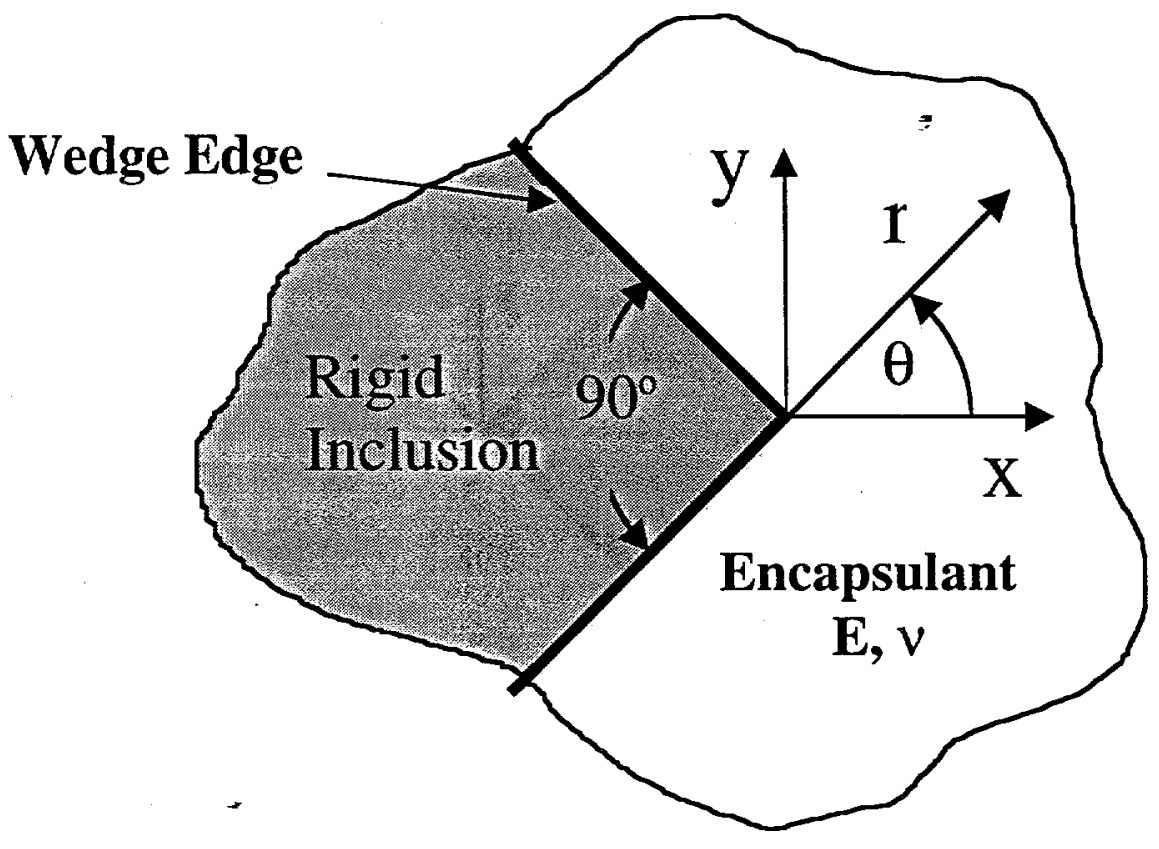

Figure 6. Asymptotic problem for encapsulated, rigid wedge. Symmetry about $\mathbf{x}$ axis. 


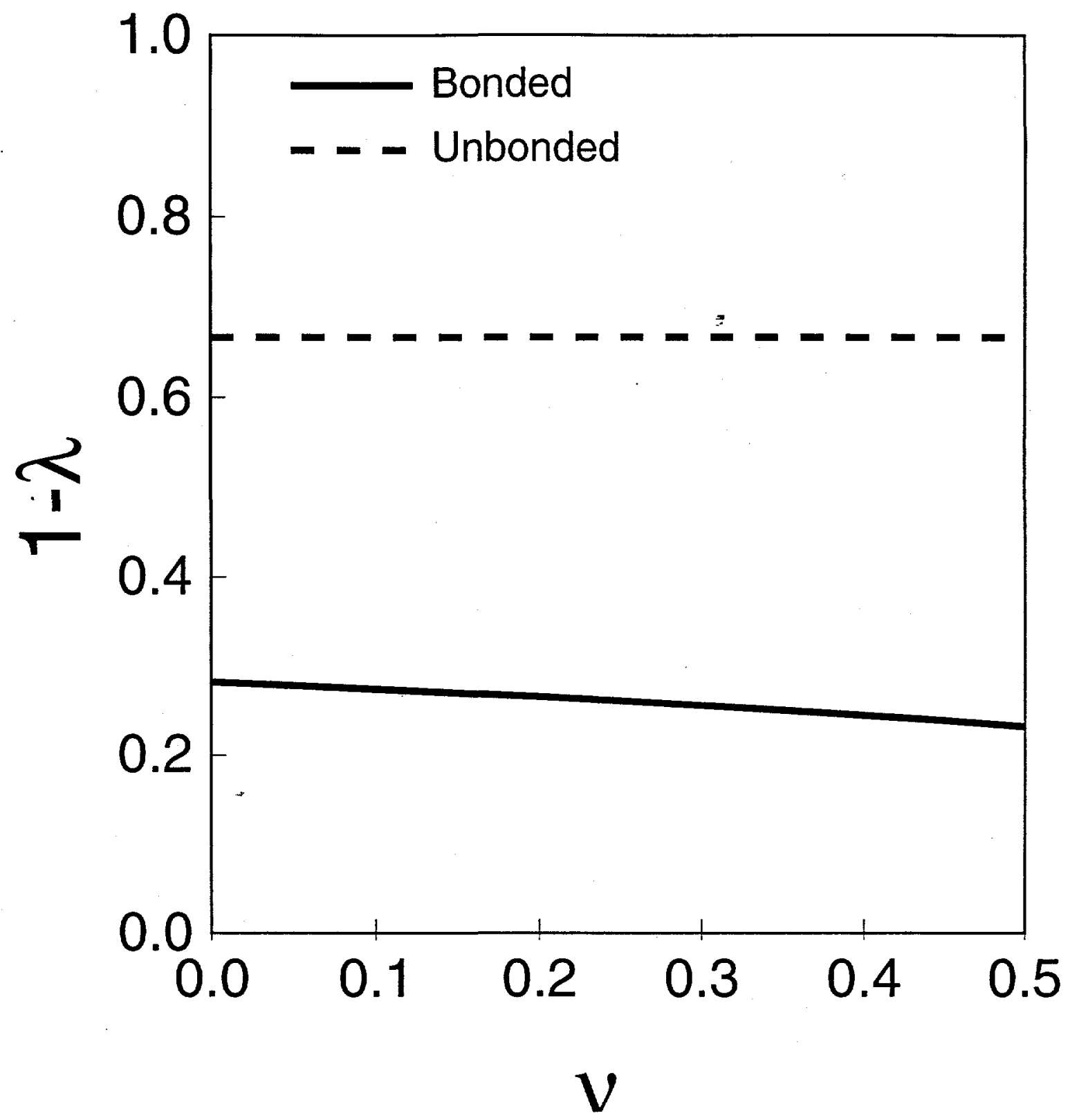

Figure 7. Variation of the strength of the stress singularity, $-(1-\lambda)$, with Poisson's ratio $v$ for either a bonded or an unbonded rigid square inclusion. 


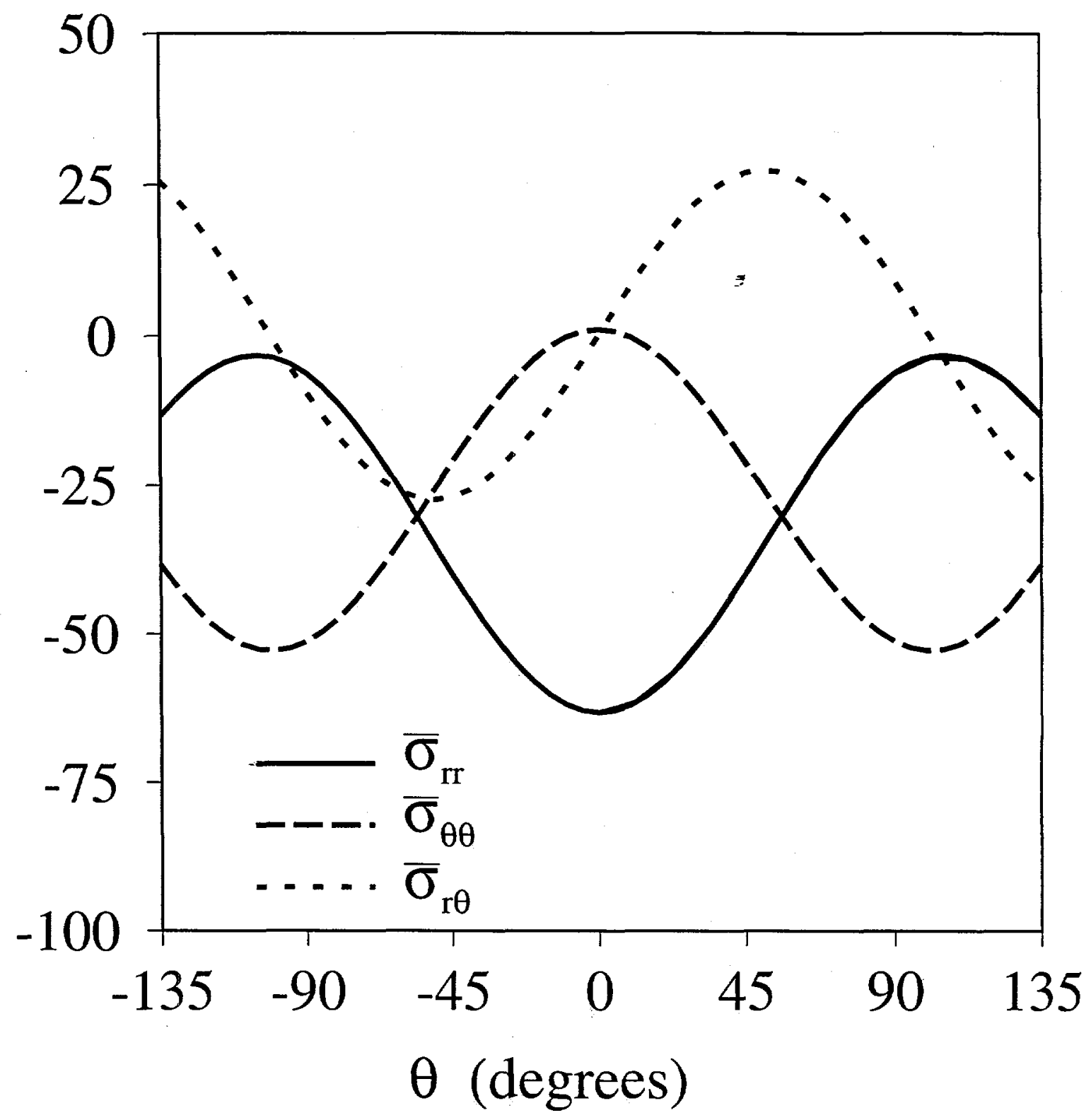

Figure 8. Angular variation of $\sigma_{\mathrm{rr}}, \sigma_{\theta \theta}$, and $\sigma_{\mathrm{r} \theta}$ about the tip of a fully bonded, rigid square inclusion (encapsulant $v=0.35$ ). 


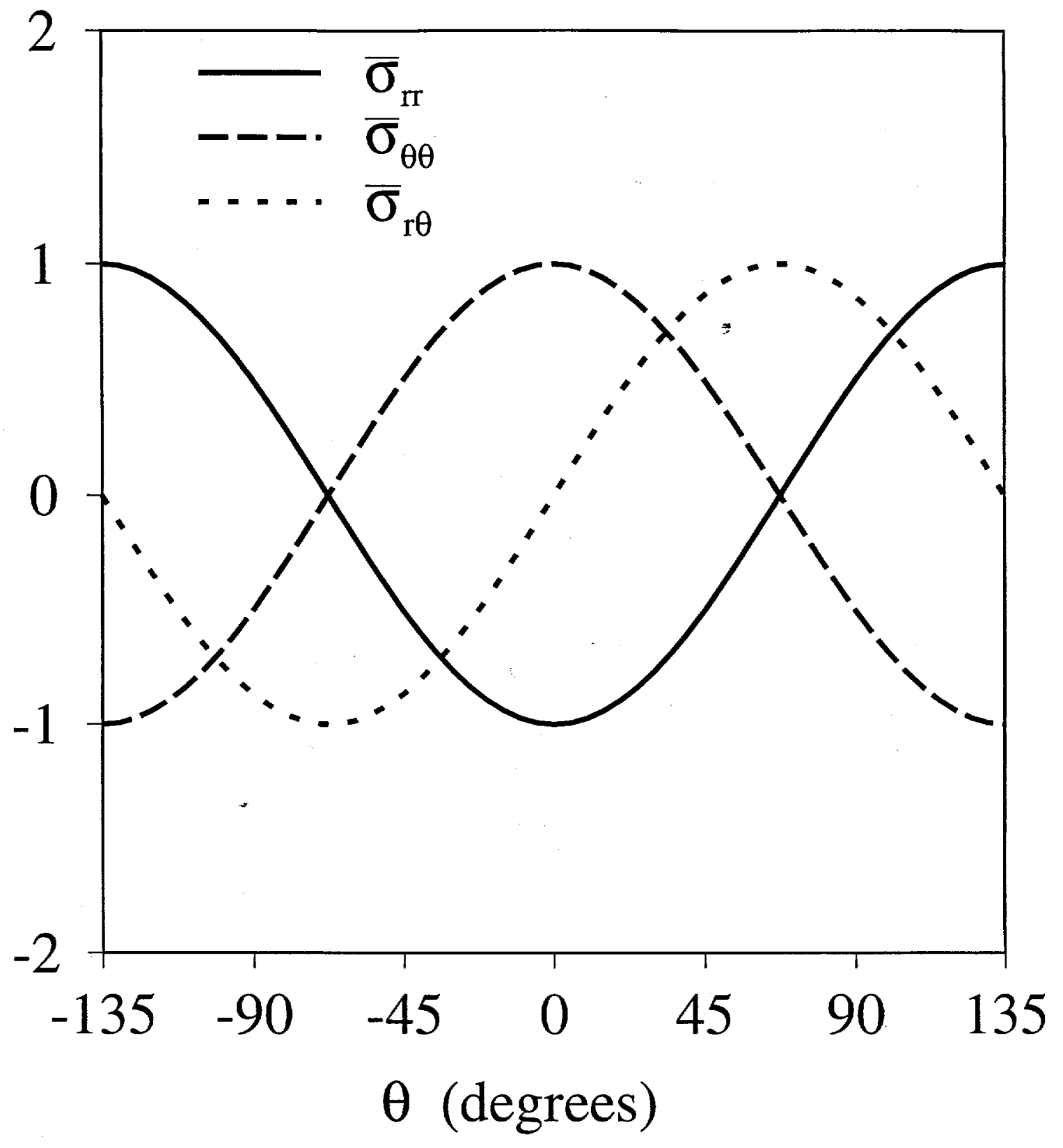

Figure 9. Angular variation of $\sigma_{\mathrm{rr}}, \sigma_{\theta \theta}$, and $\sigma_{\mathrm{r} \theta}$ about the tip of an unbonded, rigid square inclusion (frictionless sliding). 


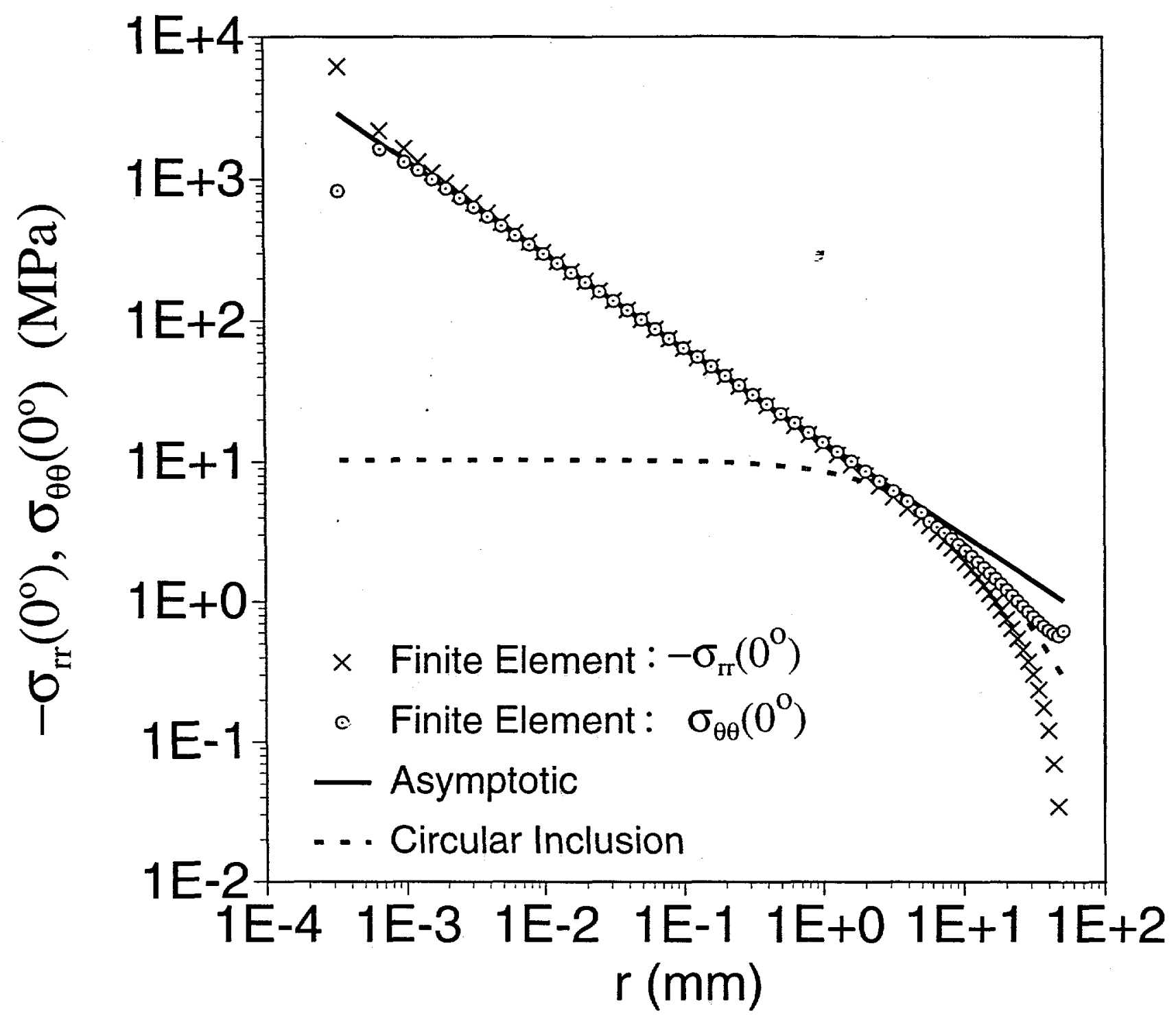

Figure 10. Comparison of linear-elastic finite element and asymptotic solutions for stress in front of an unbonded inclusion, embedded within an epoxy disk, with $h=18 \mathrm{~mm}$ and $\Delta \mathrm{T}=-100^{\circ} \mathrm{C}$. 


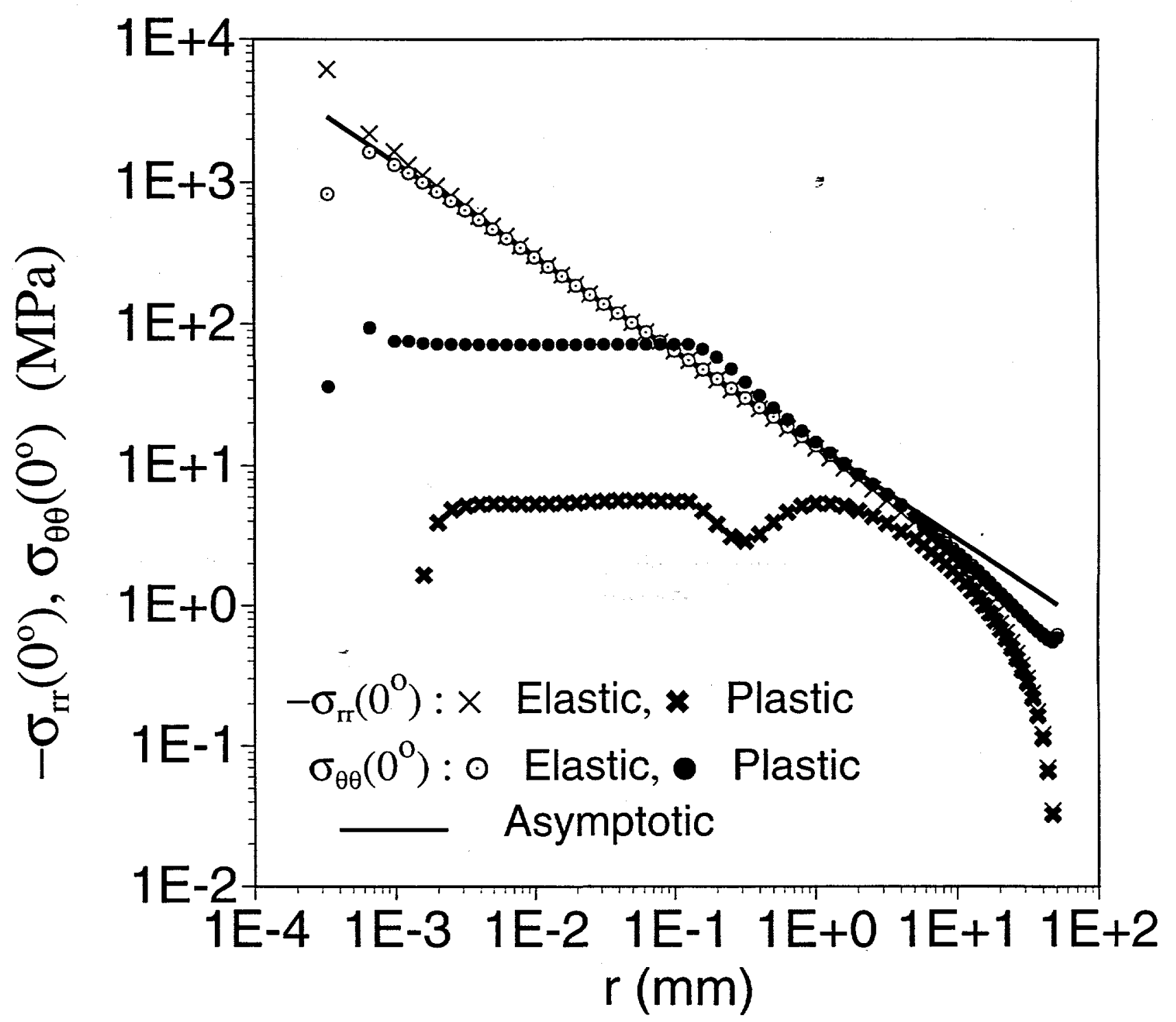

Figure 11. Comparison of linear-elastic and elastic-perfectly-plastic finite element solutions with asymptotic solution for stress in front of an unbonded inclusion, embedded within an epoxy disk, with $h=18 \mathrm{~mm}$ and $\Delta \mathrm{T}=-100^{\circ} \mathrm{C}$. 


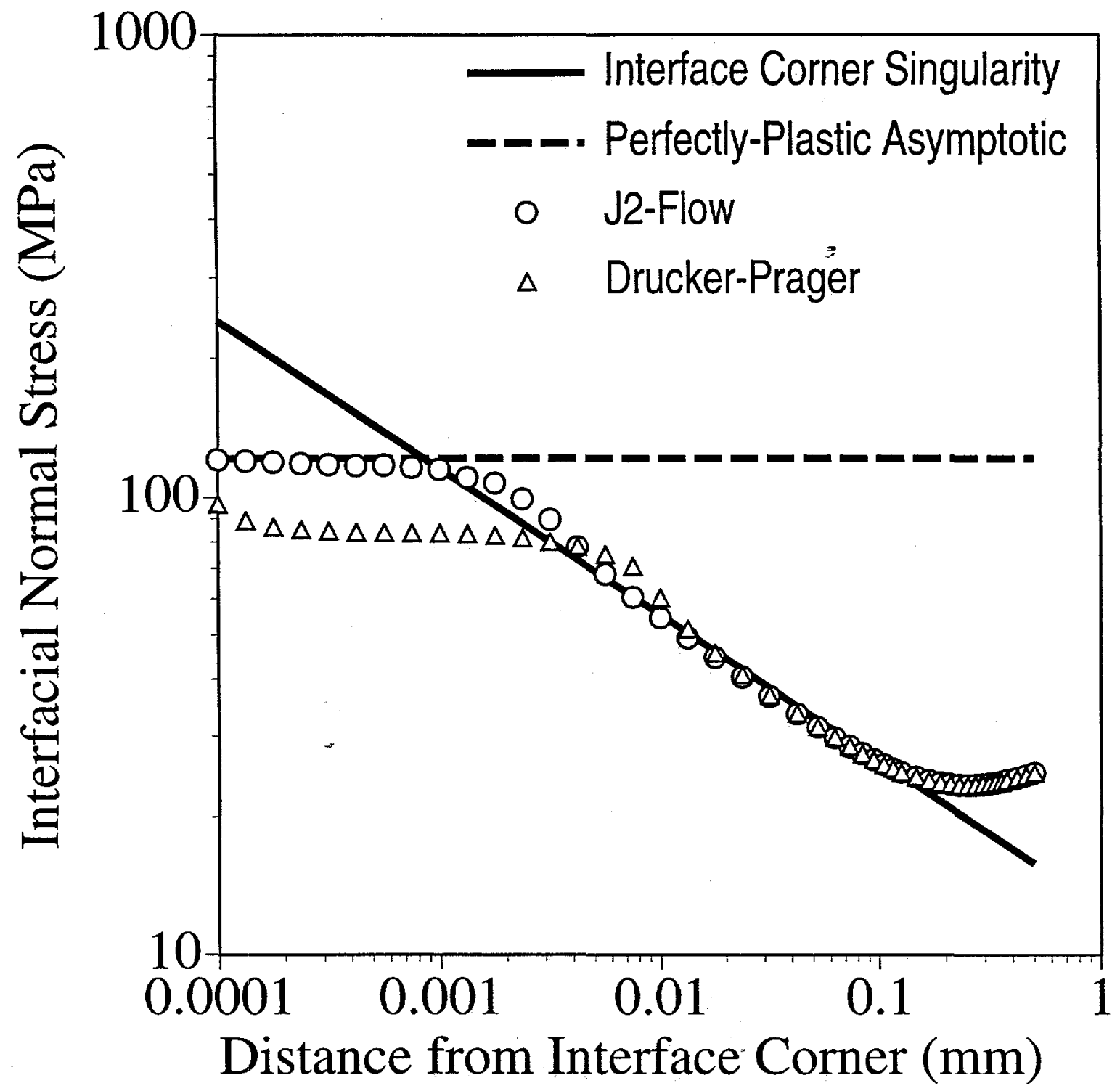

Figure 12. Comparison of calculated interfacial normal stress when the adhesive layer yields with interface-corner singularity and perfectly plastic asymptotic solutions. 


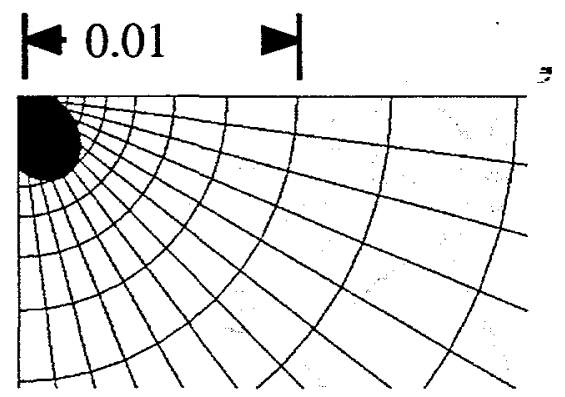

Elastic $\left(\sigma_{\mathrm{e}}>82 \mathrm{MPa}\right)$
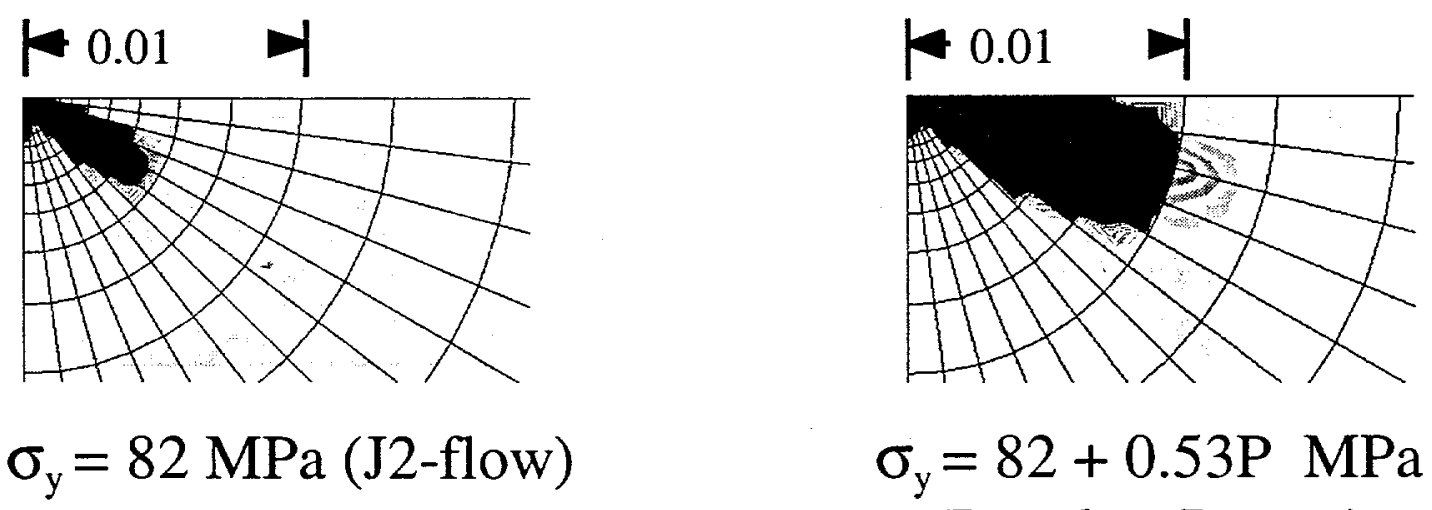

$\sigma_{\mathrm{y}}=82+0.53 \mathrm{P} \mathrm{MPa}$

(Drucker-Prager)

Figure 13. Calculated interface-corner yield zones. Dark gray in the plasticity calculations corresponds to an equivalent plastic strain $>0.0001$. 


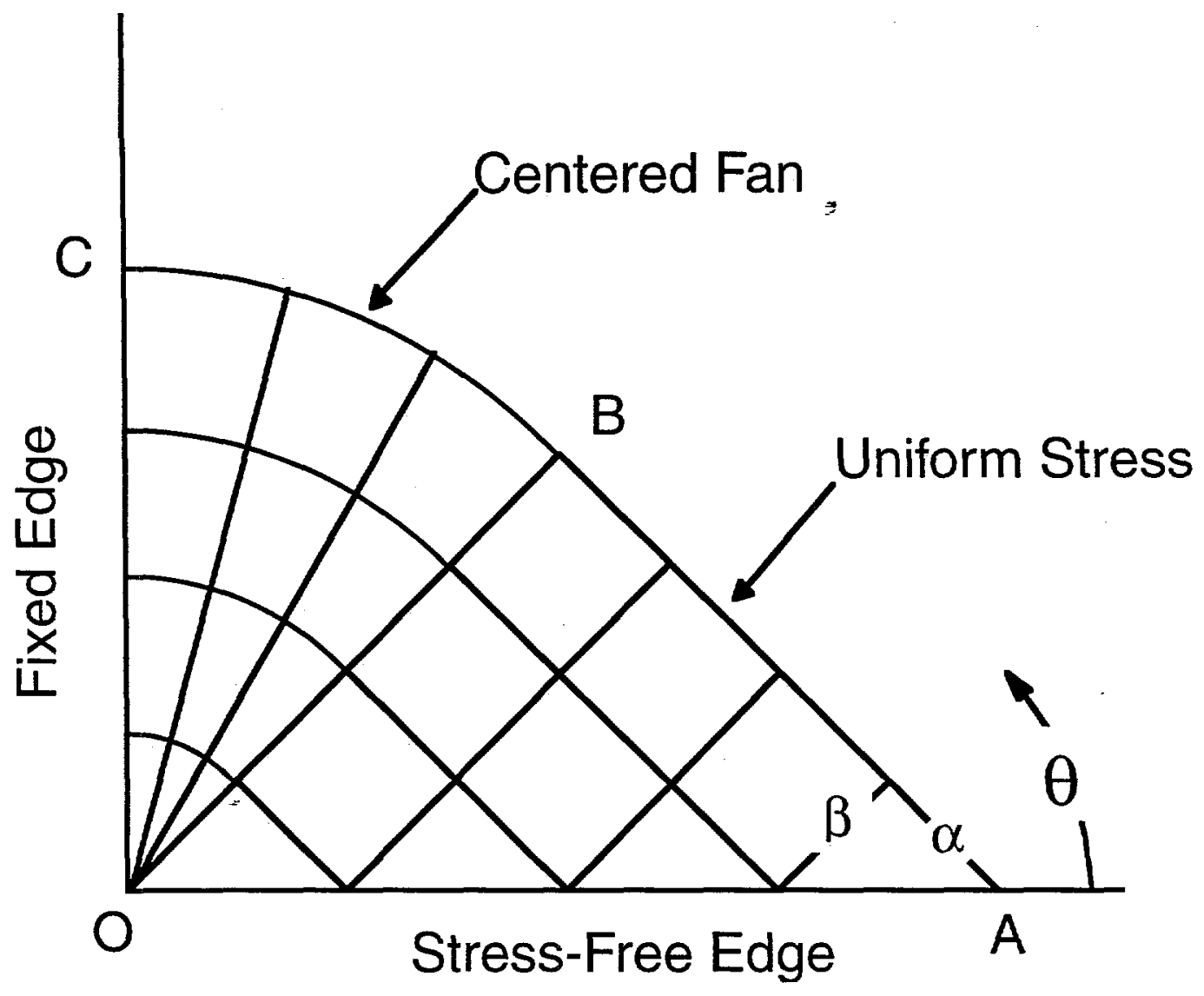

Figure 14. Asymptotic, interface-corner slip-line solution for a perfectly plastic quarter plane bonded to a rigid substrate. 


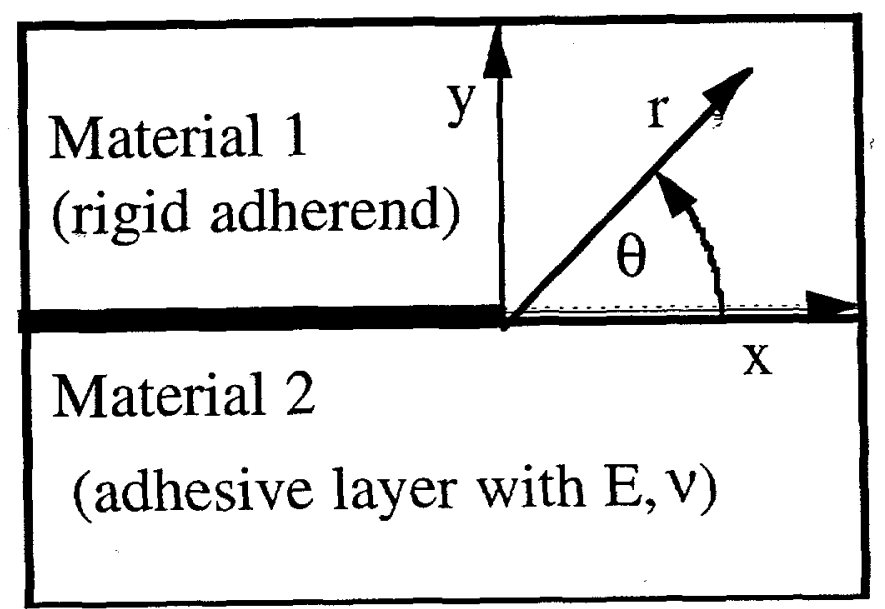

Figure 15. Conventions used to define interfacial crack configuration. 


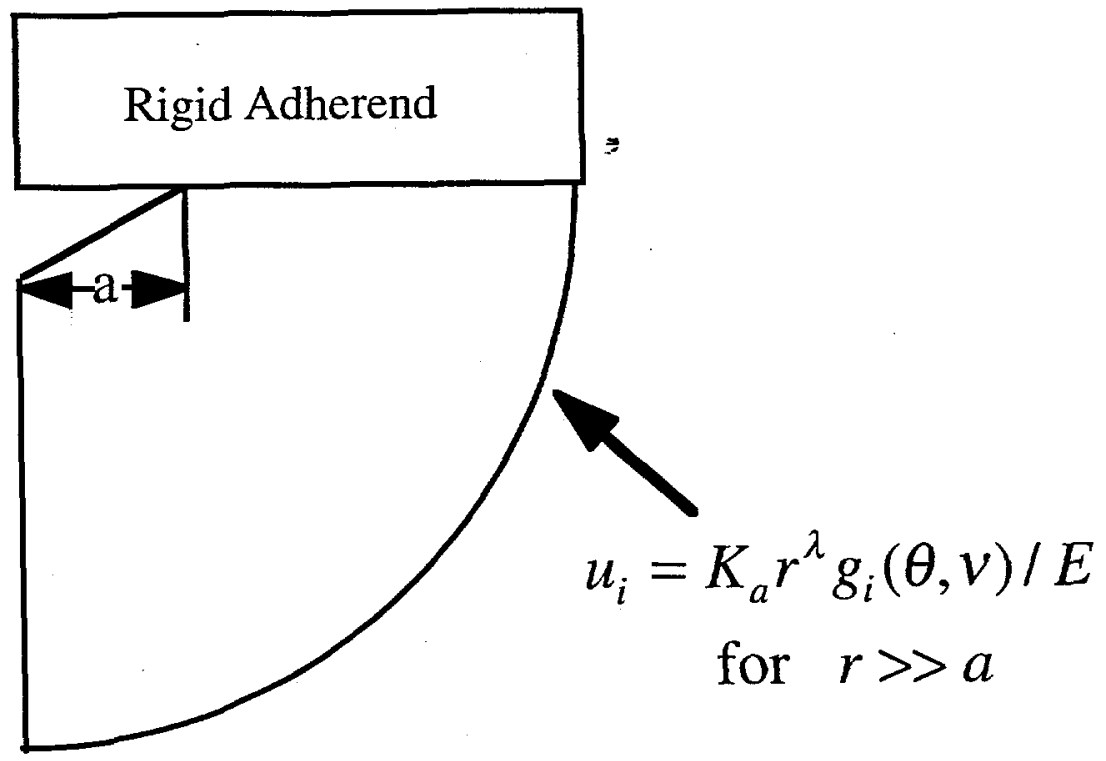

Figure 16. Small-scale cracking problem. 


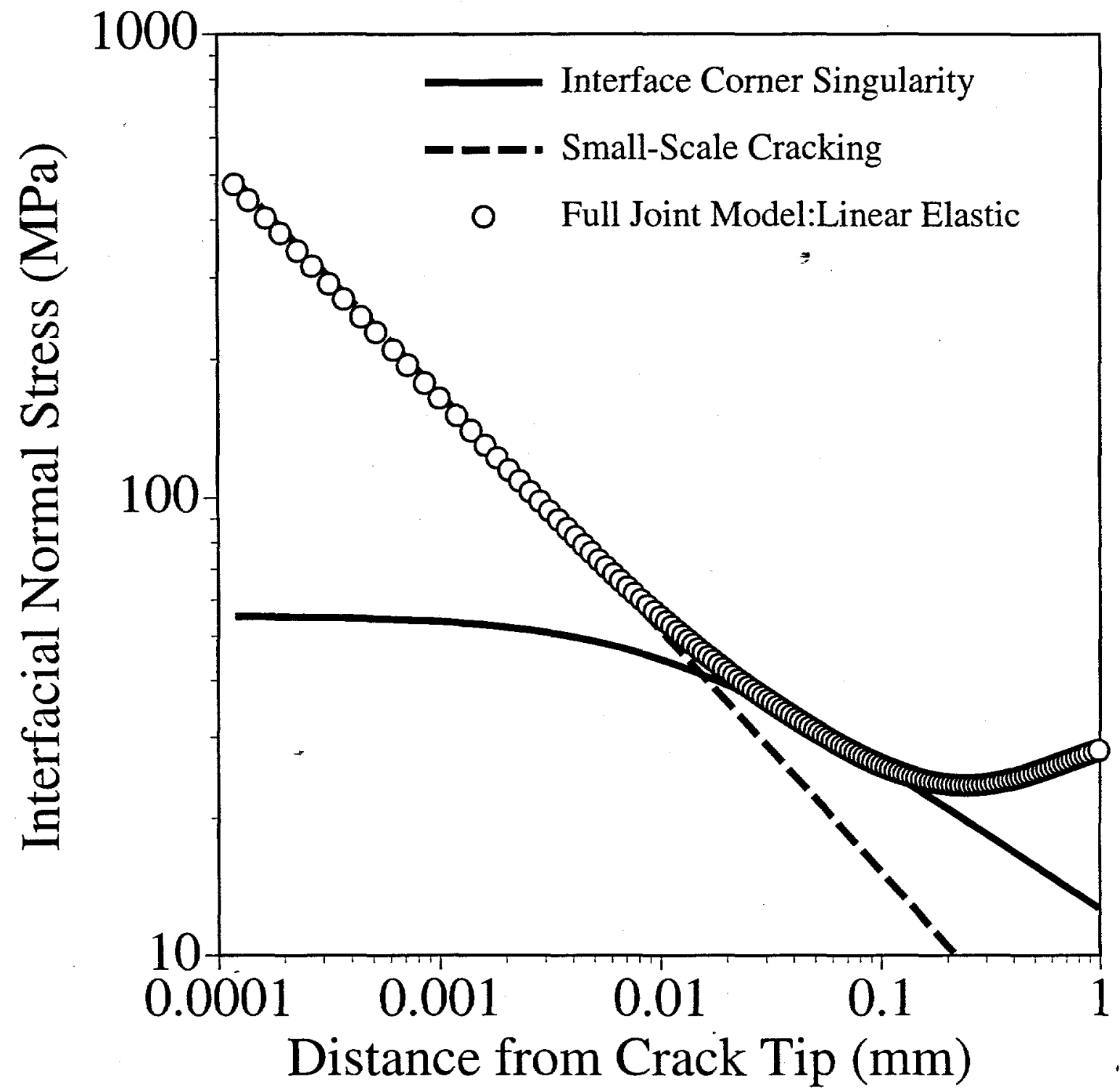

Figure 17. Comparison of asymptotic interface-corner and small-scale cracking solutions for interfacial normal stress with finite element results for the full joint model $(\mathrm{a}=0.01 \mathrm{~mm}, \bar{\sigma}=30.7 \mathrm{MPa})$. 


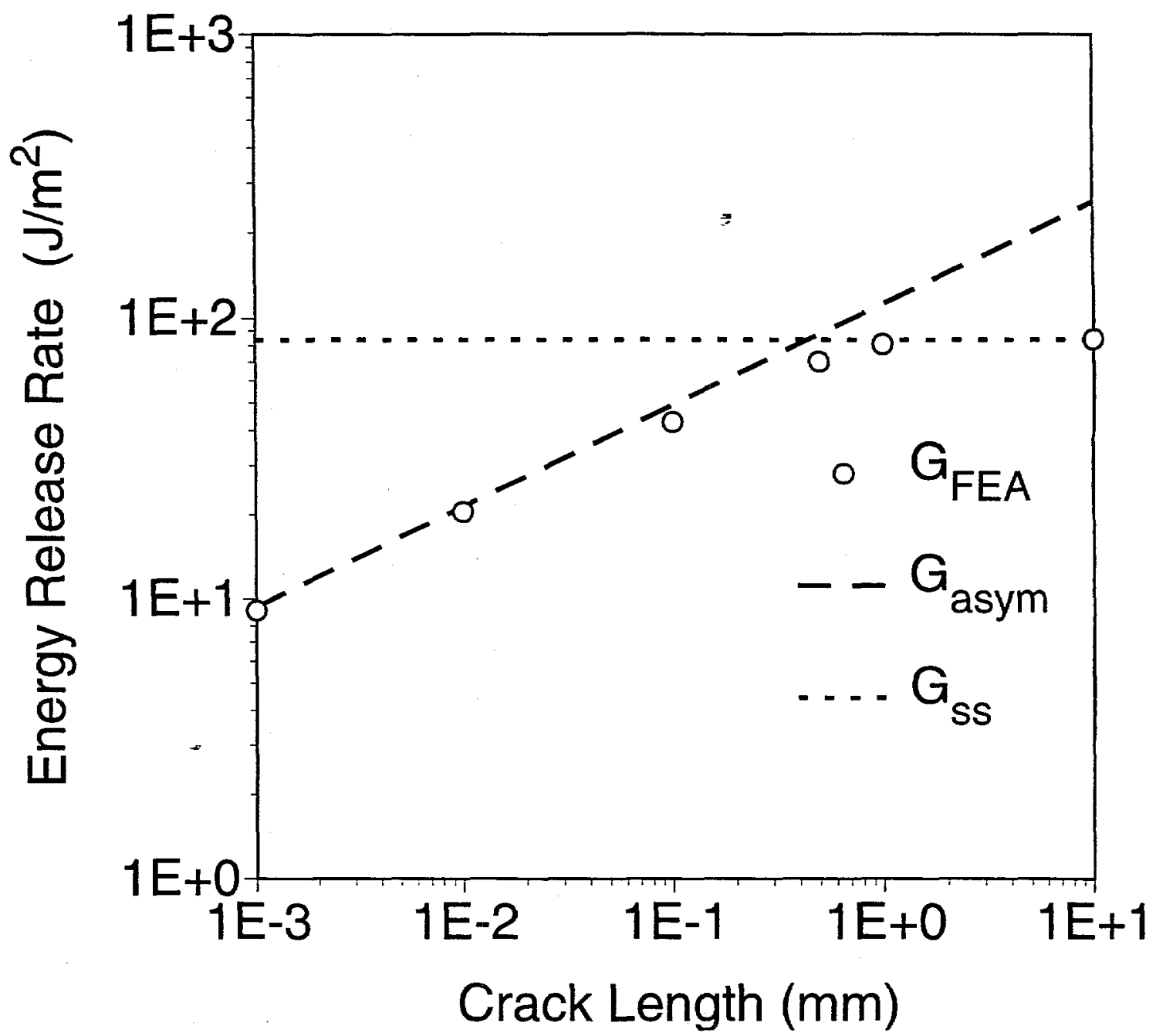

Figure 18. Comparison of finite element and asymptotic solutions for energy release rate $(\bar{\sigma}=30.7 \mathrm{MPa}) . \mathrm{G}_{\mathrm{FEA}}$ is the finite element solution; $\mathrm{G}_{\mathrm{asym}}$ is the small-scale cracking solution; and $\mathrm{G}_{\mathrm{ss}}$ is the long crack, steady-state solution. 


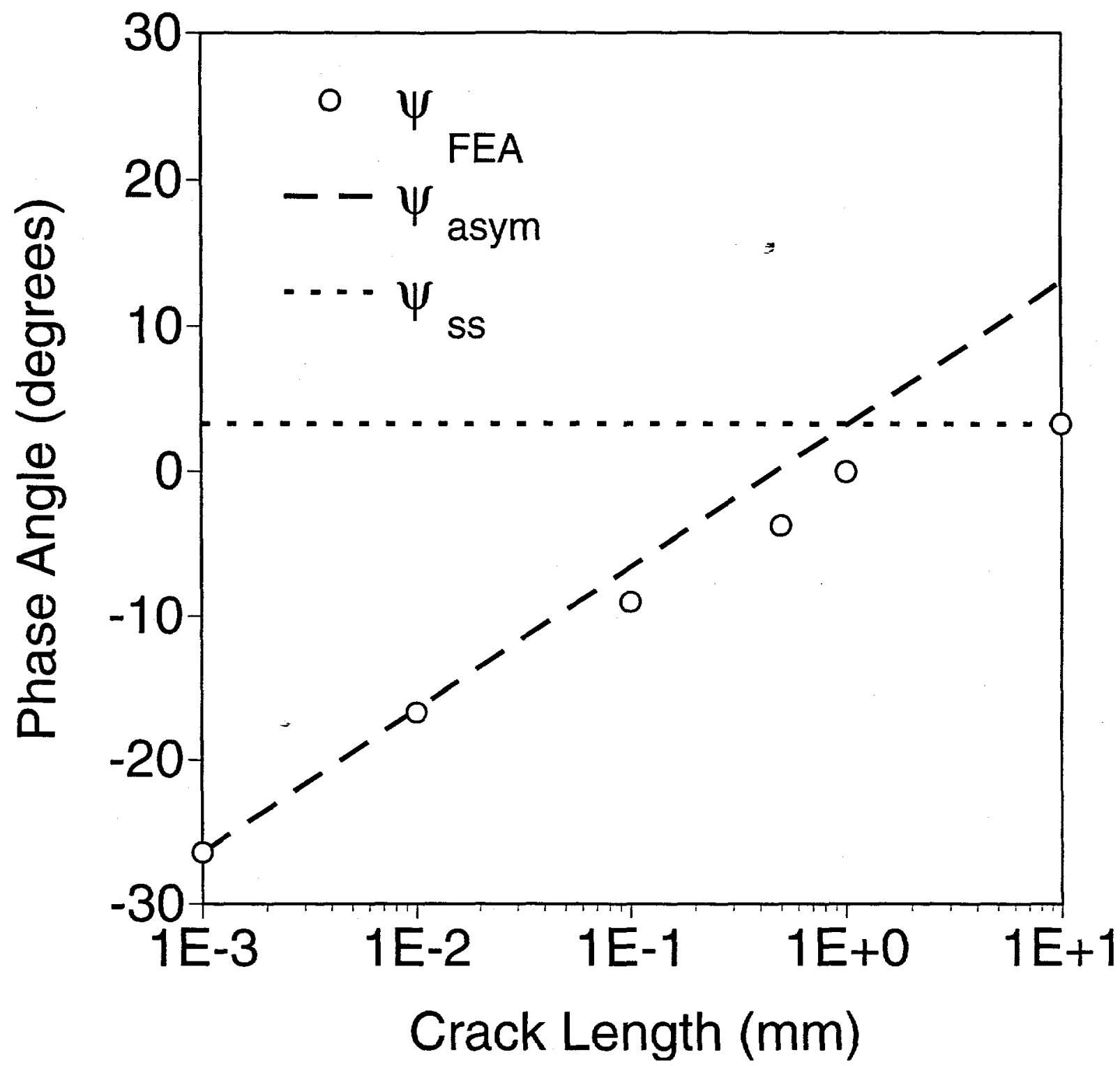

Figure 19. Comparison of finite element and asymptotic solutions for $\hat{\psi}_{r=0.01 \mathrm{~mm}}$. $\hat{\psi}_{F E A}$ is the finite element solution; $\hat{\psi}_{a s y m}$ is the small-scale cracking solution; and $\hat{\psi}_{s s}$ is the long crack, steady-state solution. 


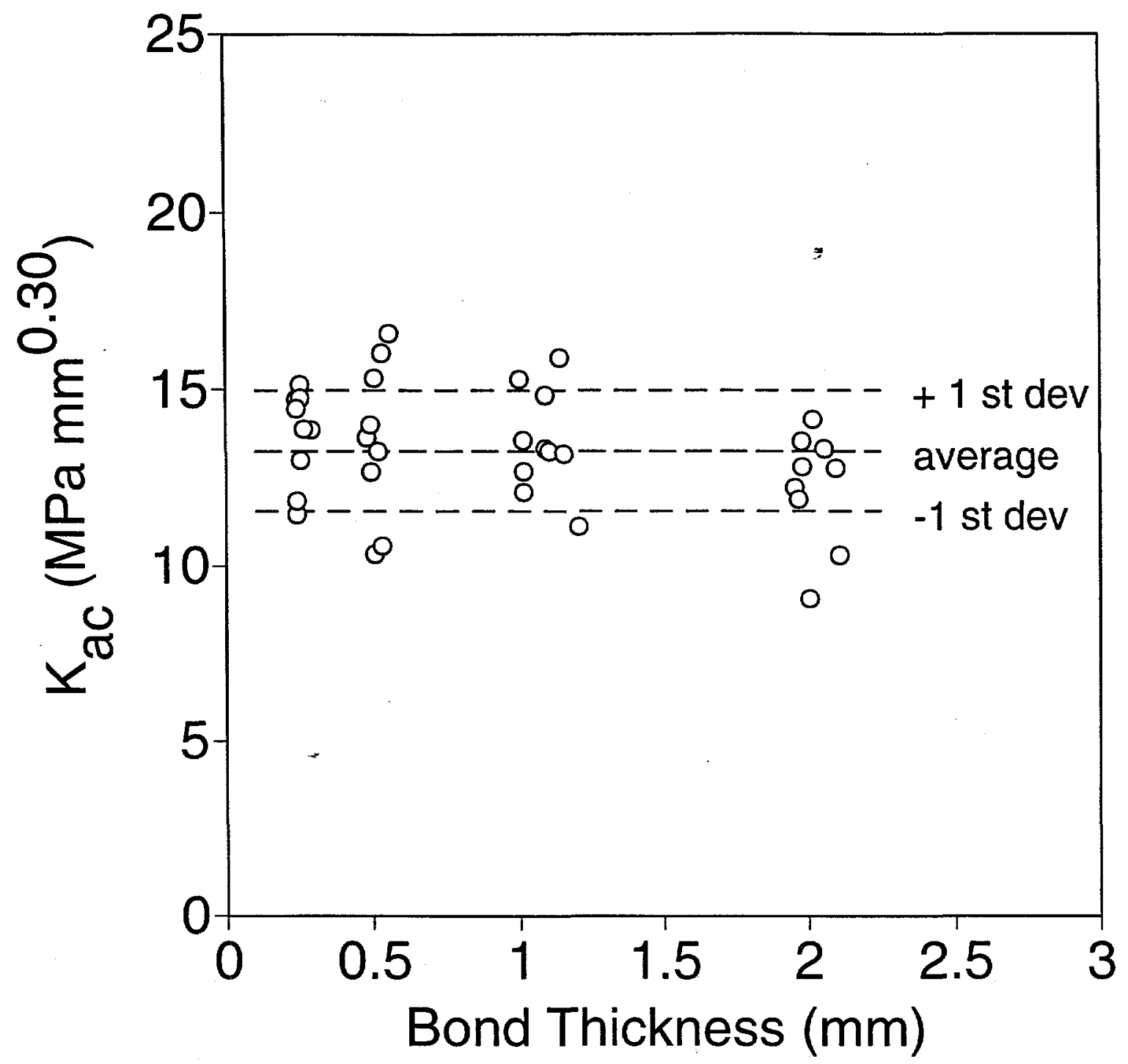

Figure 20. Interface-corner fracture toughness for joints with steel adherends (st dev denotes standard deviation). 


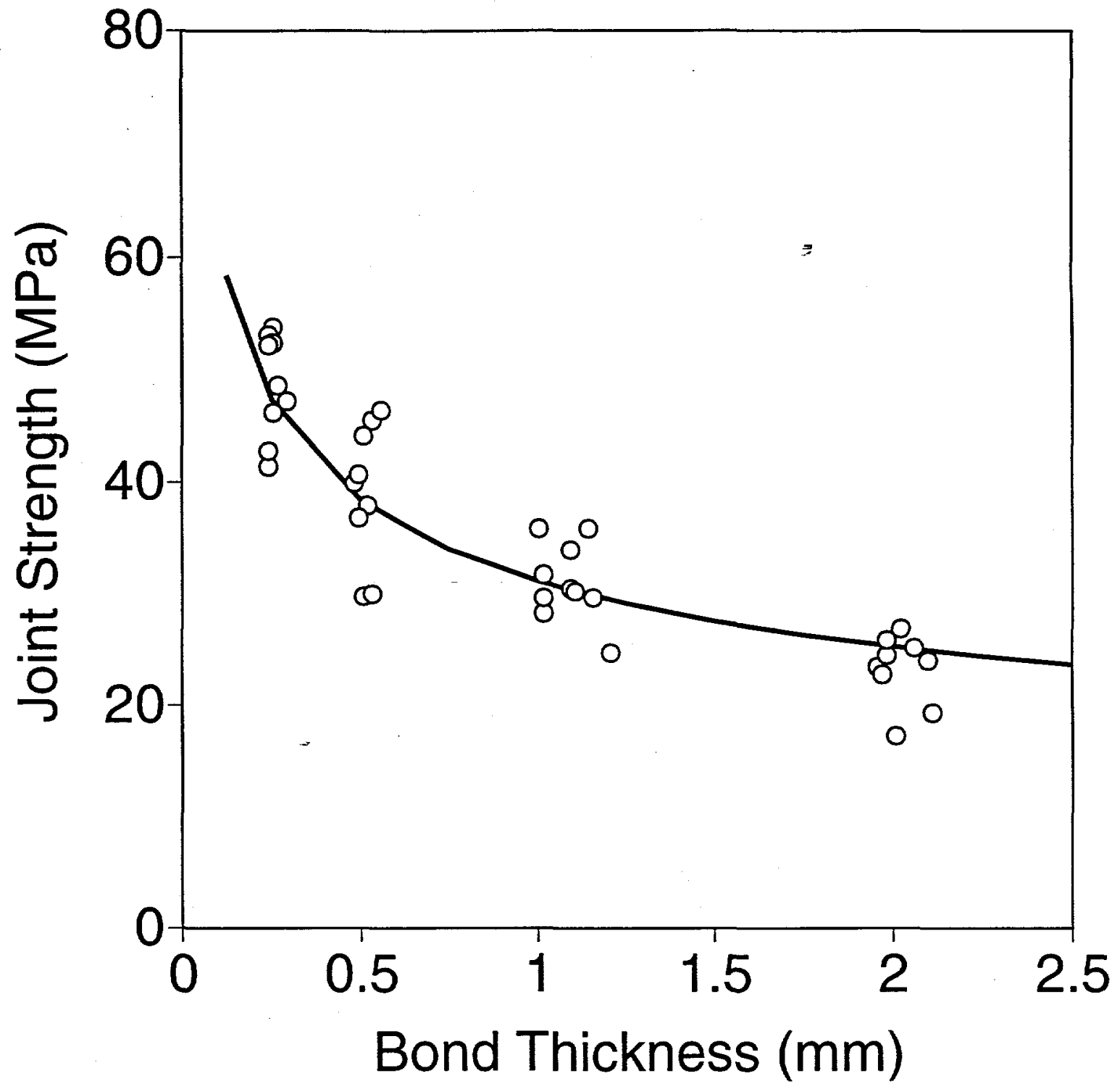

Figure 21. Measured butt joint strength vs. bond thickness for joints with steel adherends and prediction based upon an interface corner toughness of $\mathbf{1 3 . 3}$ MPa mm.3. 


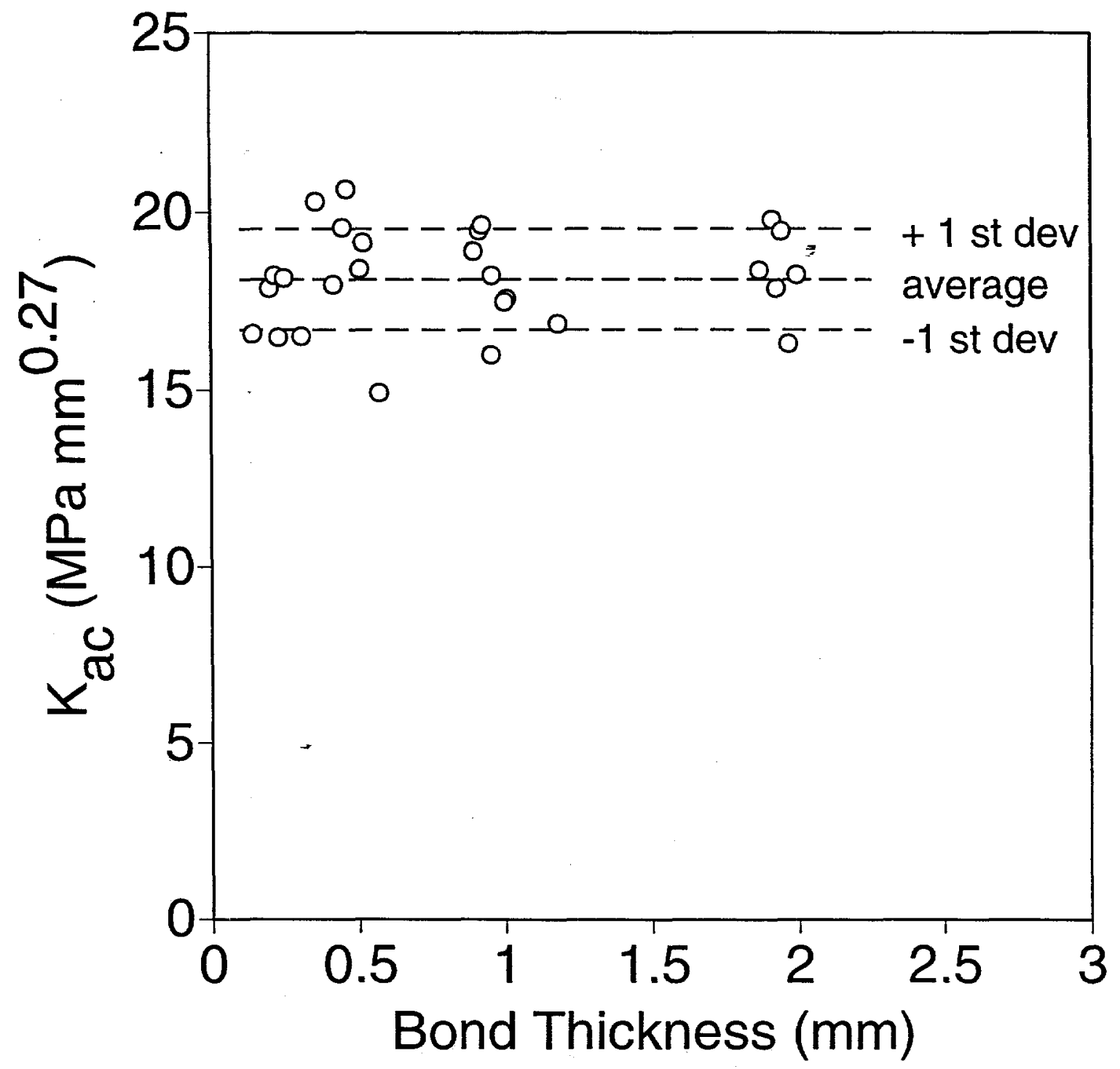

Figure 22. Interface corner fracture toughness for joints with aluminum adherends. 


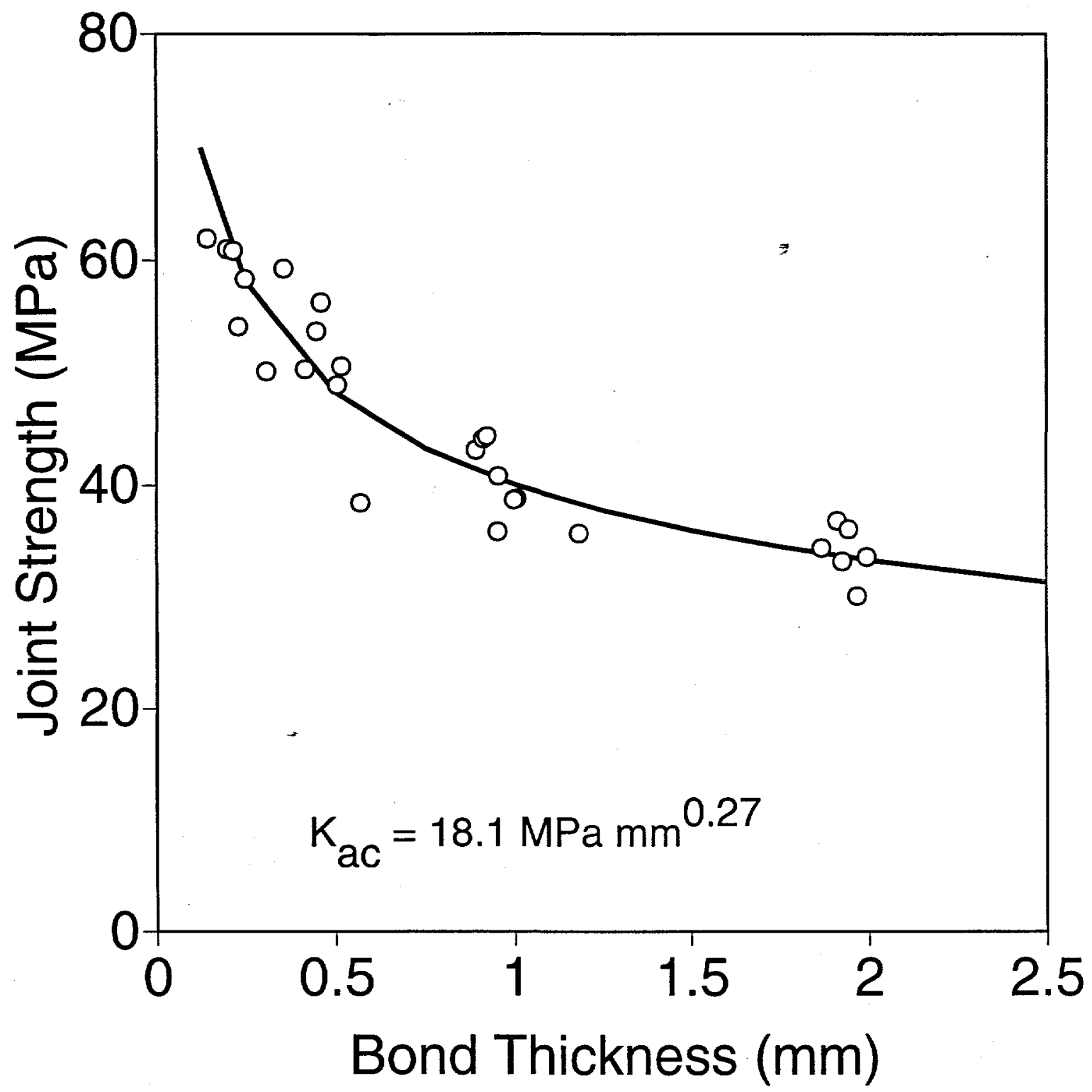

Figure 23. Measured butt joint strength vs. bond thickness for joints with aluminum adherends and prediction based upon an interface-corner toughness of 18.1 MPa mm ${ }^{0.27}$. 


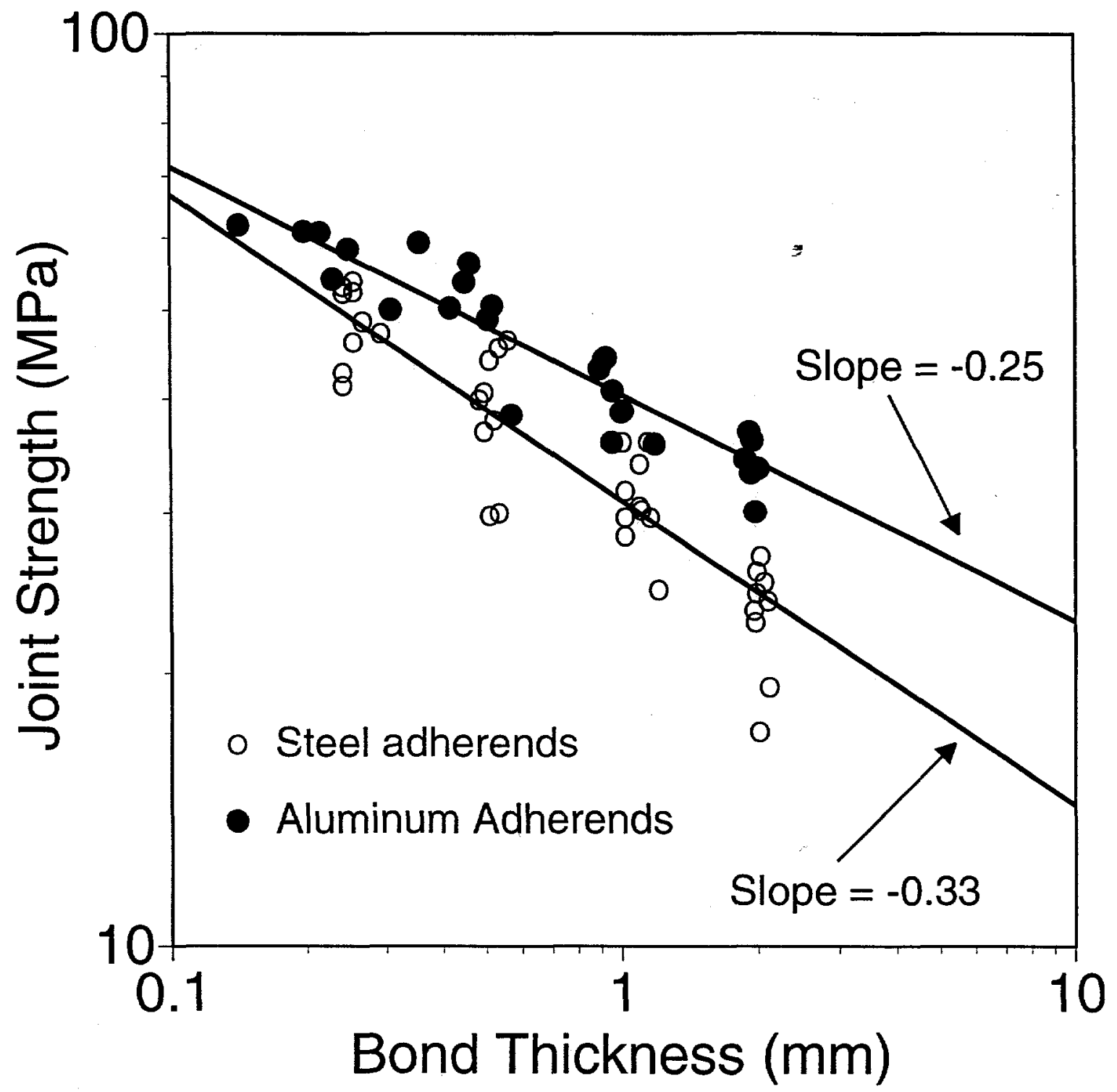

Figure 24. Butt joint strength vs. bond thickness for joints with either steel or aluminum adherends. 


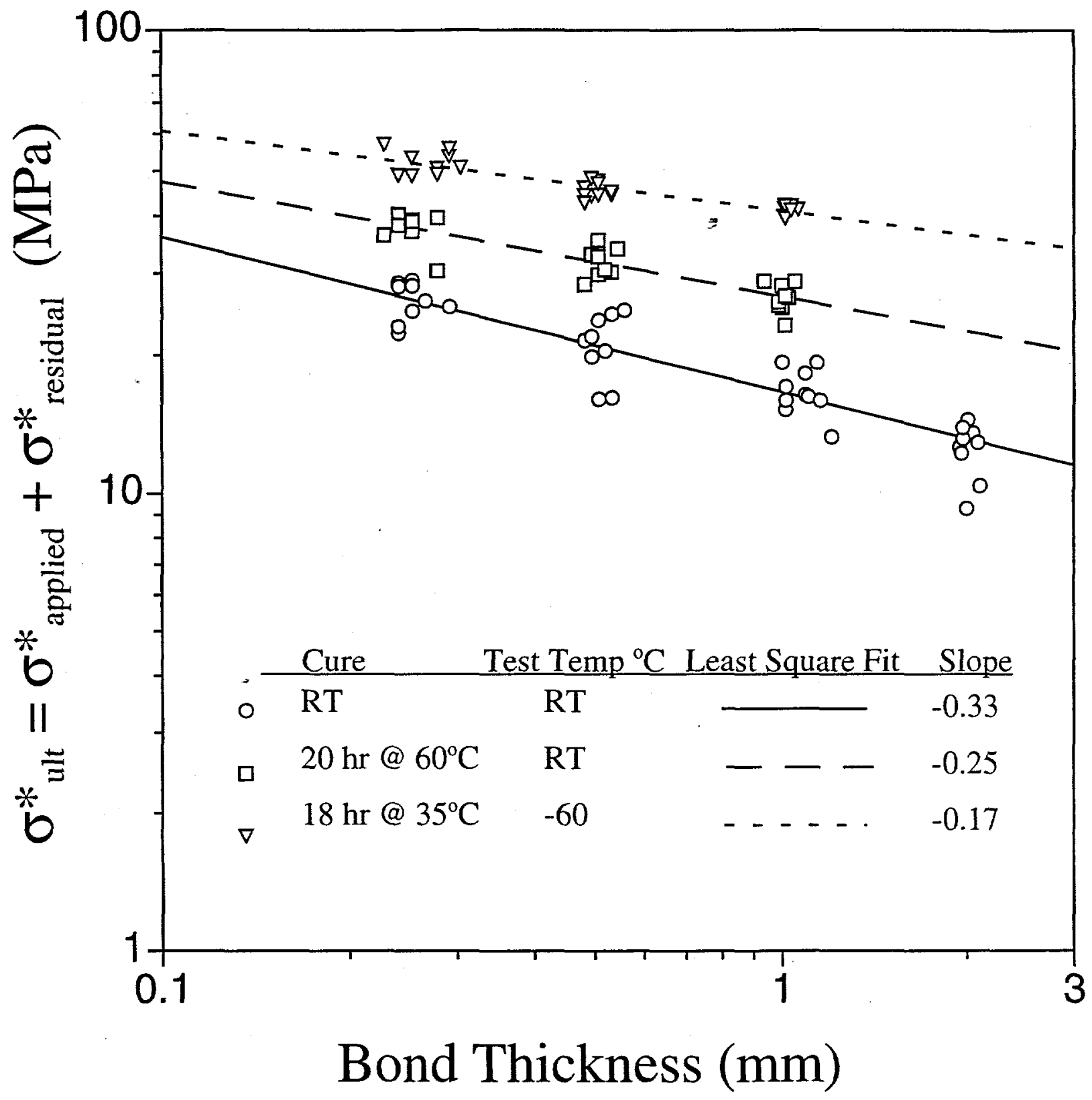

Figure 25. Butt joint strength vs. bond thickness. The characteristic failure stress includes both applied load and estimated residual stress. 


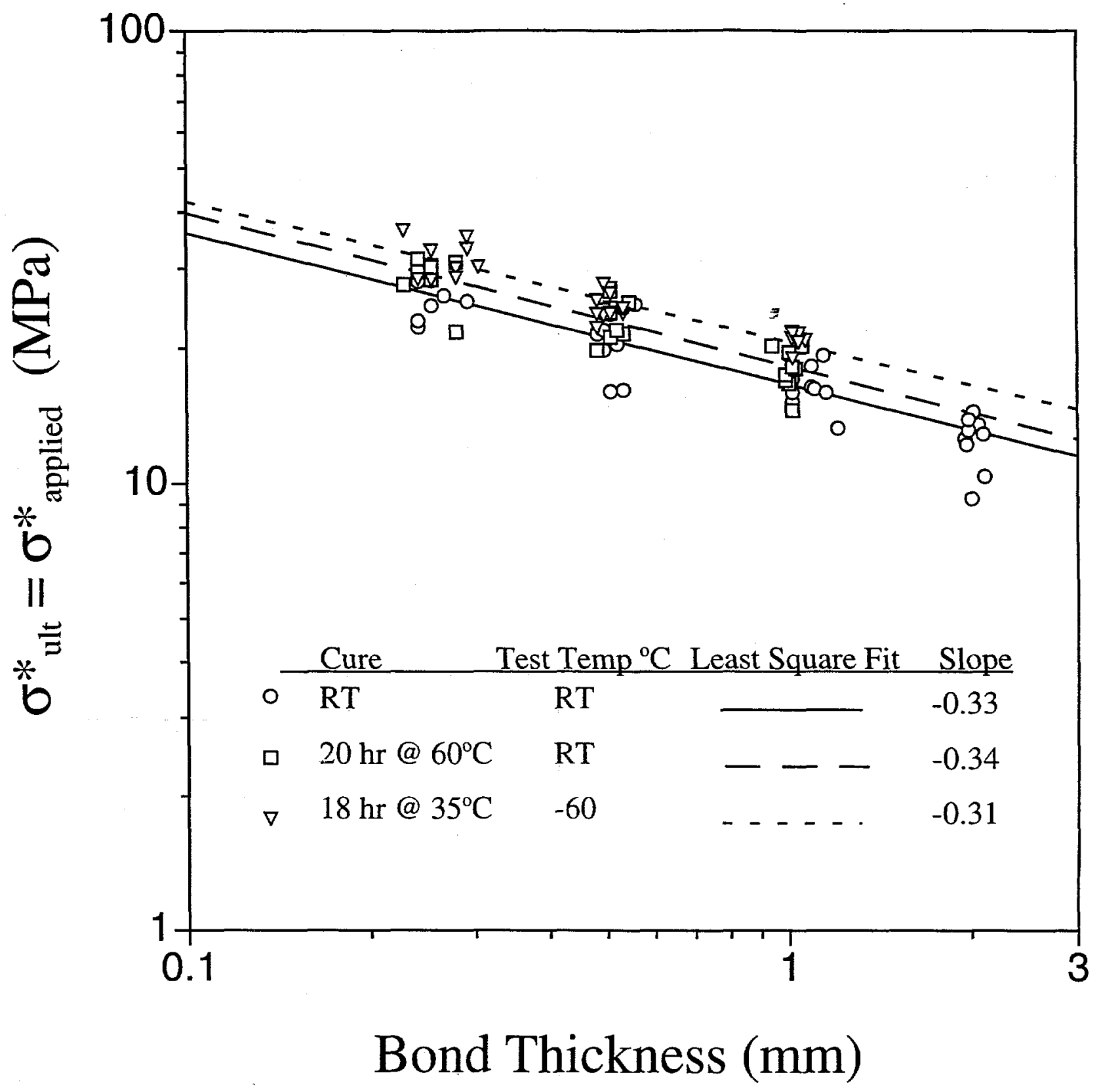

Figure 26. Butt joint strength vs. bond thickness. The characteristic failure stress includes only the applied load. 


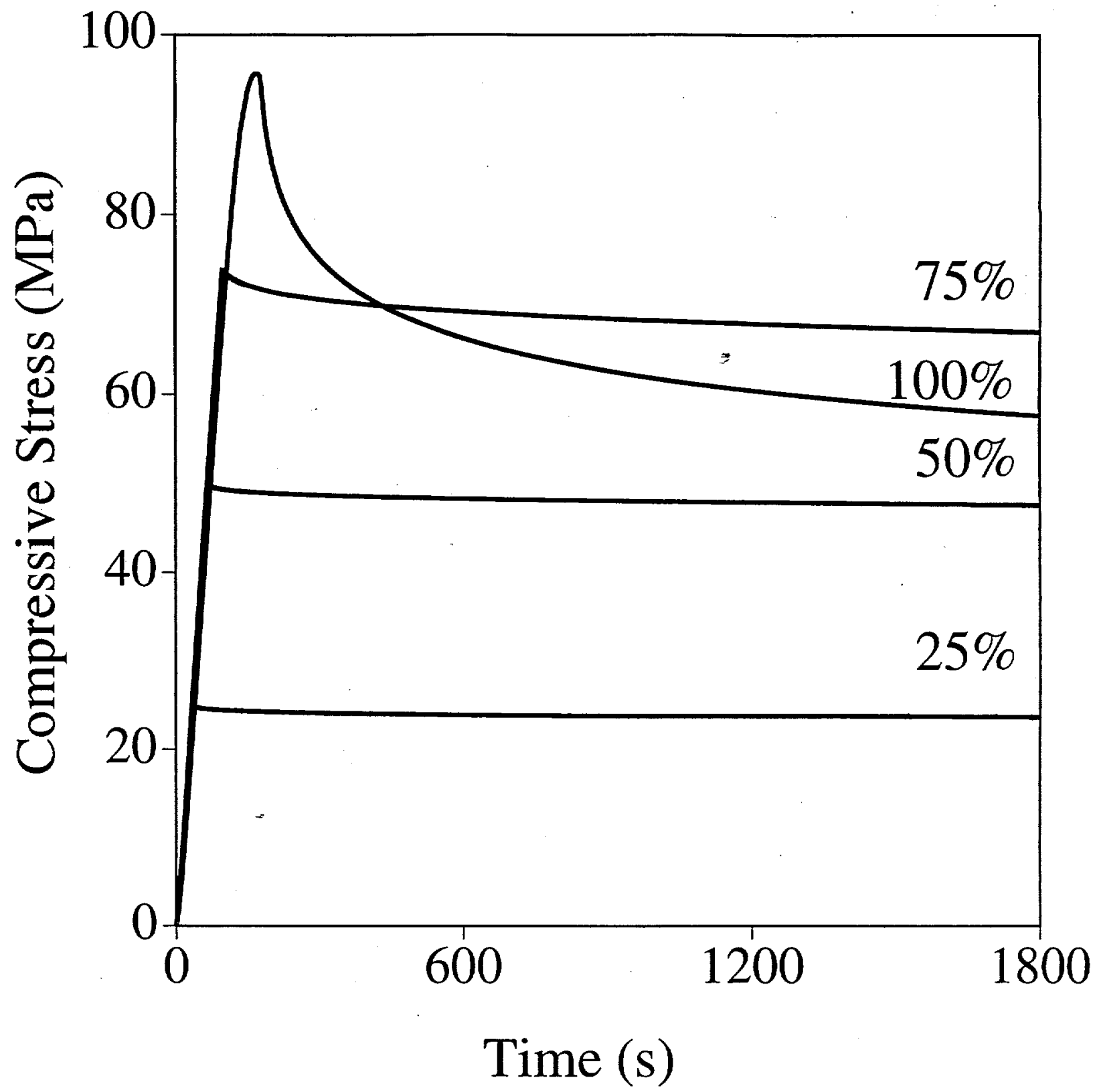

Figure 27. Room-temperature stress-relaxation data for an Epon 828/T403 adhesive cured $20 \mathrm{hrs}$ at $60^{\circ} \mathrm{C}$. Specimens are loaded to 25 percent, 50 percent, 75 percent, and 100 percent of yield at $0.0002 / s$ prior to fixing the displacement. 


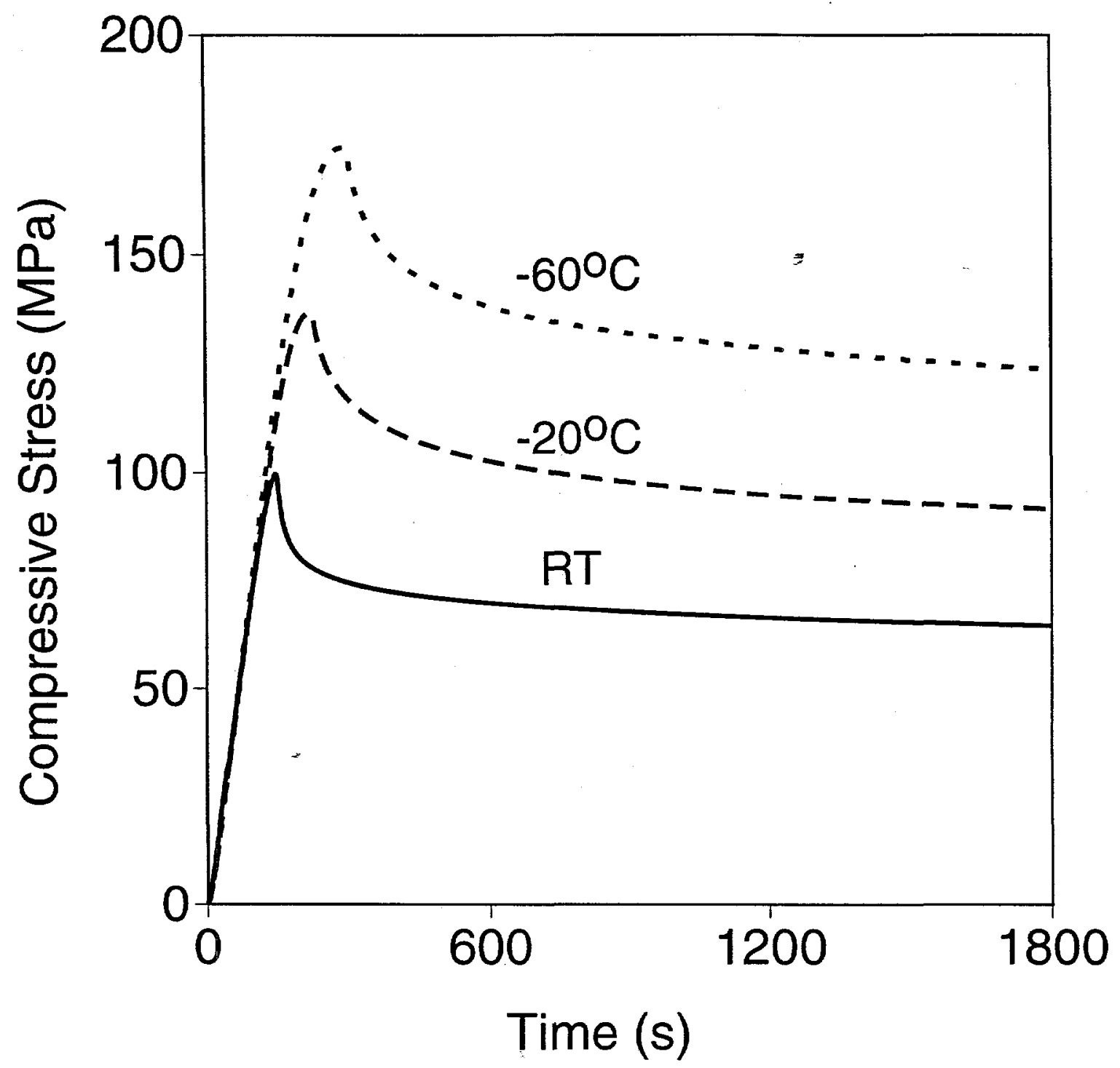

Figure 28. Stress-relaxation data for an Epon 828/T403 adhesive cured $18 \mathrm{hrs}$ at $35^{\circ} \mathrm{C}$ and tested at three temperatures. Each specimen is loaded to yield at $0.0002 / \mathrm{s}$ prior to fixing the displacement. 


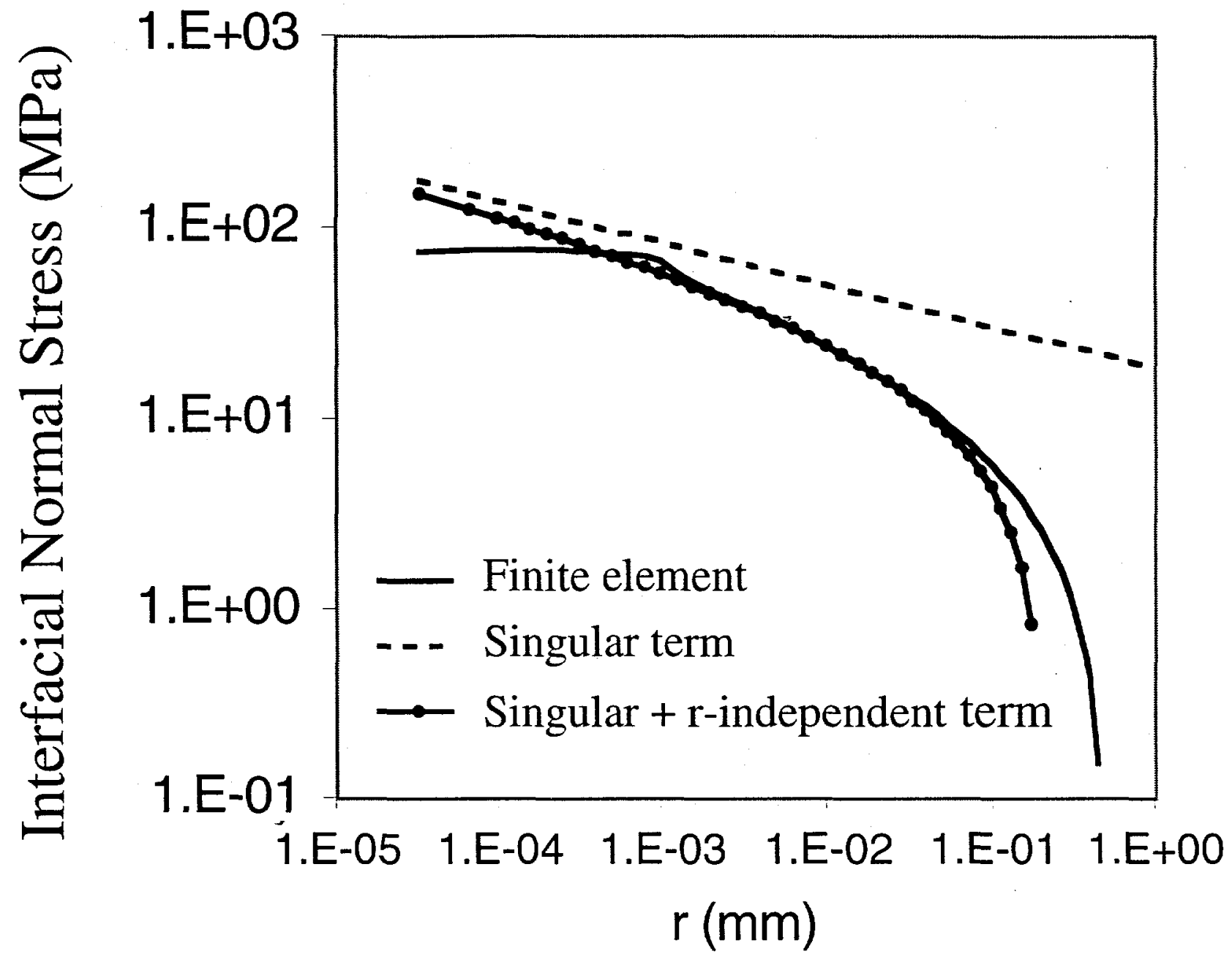

Figure 29. Comparison of linear-elastic finite element and asymptotic solutions for normal stress for a thin layer on a rigid substrate subjected to uniform cooling. 